\title{
INDIANS, ENVIRONMENT, AND IDENTITY ON THE BORDERS OF AMERICAN LITERATURE
}

\section{Lindsey Claire Smith}

A dissertation submitted to the faculty of the University of North Carolina at Chapel Hill in partial fulfillment of the requirements for the degree of Doctor of Philosophy in the Department of English.

Chapel Hill

2006

Approved by

Advisor: Gretchen Bataille Advisor: Trudier Harris Reader: Linda Wagner-Martin

Reader: Maria DeGuzman

Reader: Valerie Lambert 
(C) 2006

Lindsey Claire Smith

ALL RIGHTS RESERVED 


\section{ABSTRACT \\ Lindsey Claire Smith: \\ INDIANS, ENVIRONMENT, AND IDENTITY ON THE BORDERS OF AMERICAN LITERATURE \\ (Under the direction of Gretchen Bataille and Trudier Harris)}

This dissertation foregrounds boundary crossing among American Indians, African Americans, and Euramericans as a central feature of American literature. The authors discussed, including James Fenimore Cooper, William Faulkner, Toni Morrison, Alice Walker, and Leslie Marmon Silko, place this cross-cultural contact in nature, not only collapsing cultural and racial boundaries, but also complicating divisions between "wilderness" and "civilization." Responding to contemporary theoretical approaches to race, culture, and nationhood, this dissertation points toward the multiple perspectives and cultures that distinguish American literature as well as highlights the role of geography in these critical discourses, forging a connection between ecological theory and ethnic studies.

Whereas Euramerican writers demonstrate multi-racial coexistence on the frontier as idyllic yet fleeting due to national expansion, African American and Native writers reverse this model, identifying Black-Indian alliance as the source of resistance to colonization and environmental degradation. This study thereby probes the prominent roles that American Indians occupy in major American novels, not only as emblems of ecological acumen, but more important, as participants in cultural exchange that informs American identity. 
For Jerre Brokaw (Delaware)

1929-1999

dear friend and inspiration 


\section{ACKNOWLEDGMENTS}

I am very grateful to my parents, Dwight and Charlene Smith, and my brother, Benjamin Corbett Smith, for their love and support as I've made my way through graduate school and the dissertation stage. I would also like to thank my advisors and committee members, Gretchen Bataille, Trudier Harris, Linda Wagner-Martin, Valerie Lambert, and Maria

DeGuzman, for their advice and mentorship. Additionally, I am especially indebted to Sandra Hoeflich, Associate Dean of the Graduate School at UNC-Chapel Hill, and Penny Aldrich, supporter of the Sequoyah Fellowship for American Indian Students/Studies, who have made sure that I have been supported financially during my years as a graduate student. Thanks also to my smart and beautiful girlfriends: Jennifer, Sarah, Grace, Rose, Pam, Karen, Megan, Malinda, and Katherine. Let's continue to cheer each other on! Finally, thanks to my greatgrandmother, Eva Clayton, who taught at the Wynnewood School in Indian Territory. Can't wait to meet you someday. 
TABLE OF CONTENTS

Page

CHAPTER

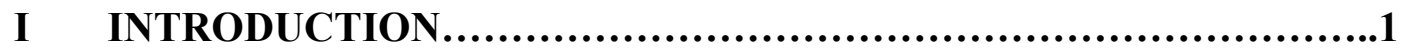

II CROSS-CULTURAL HYBRIDITY IN JAMES FENIMORE COOPER'S THE LAST OF THE MOHICANS............................9

III LEGACY OF "DOOM" ON THE CROSSROADS OF WILLIAM FAULKNER'S YOKNAPATAWPHA.......................50

IV INDIGENOUS "REMEMORY": CULTURAL HYBRIDITY AND THE NATURE OF RESISTANCE IN THE NOVELS OF TONI MORRISON...................................................97

V ALICE WALKER'S ECO-“WARRIORS”...............................140

VI THE EARTH REMAINS: PLACE AND PROPHECY IN LESLIE MARMON SILKO'S ALMANAC OF THE DEAD.....................188

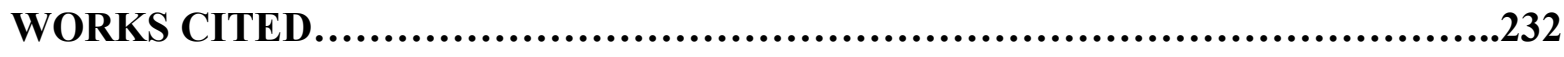




\section{CHAPTER I: INTRODUCTION}

Studies of race relations in American literature have long concentrated on slavery and the Jim Crow era, highlighting the polarization of blacks and whites as a defining force that drives our understanding of society. Such studies — though certainly relevant and applicable — do not provide a comprehensive picture of the history of interracial and crosscultural interaction in literature or in America. Since its earliest years, America has been distinguished by a diversity of American Indian peoples who have alternately struggled with and survived through their encounters with those of other backgrounds, especially those of African American and Euro-American descent, as well as those representing varied populations of the Americas. In order to achieve a more dynamic comprehension of race in American literature, it is necessary to recover and reexamine texts that complicate a polarization of black and white, and in so doing, unearth perceptions about American Indians that inform our notions of heritage, community, spirituality, and American identity.

Contemporary American writers such as Michael Dorris, Toni Morrison, Clarence Major, Alice Walker, and Leslie Marmon Silko have emphasized just such multi-dimensional portraits in their novels, often reflecting their senses of their own varied ethnic identities. While these contemporary authors clearly reflect a progression in the way race is represented in literature, from a limiting black-white binary to a more accurate, dynamic reality, it is important to note that the intersection of black, white, and red in American fiction precedes these writers. By examining earlier depictions of American Indians, African Americans, and 
whites in contact, readers may approach contemporary literature more critically and discover that some longstanding beliefs about race, especially inaccurate ideas about American Indians, persist.

The backdrop for these multi-racial encounters in American literature is the wilderness landscape and its associations with pre-lapserian innocence and quintessential American possibility. With James Fenimore Cooper's Last of the Mohicans (1826) as a starting point, one can identify a constant link in American fiction between human beings' relationships to nature and land and their relationships with those of other racial, ethnic, and cultural backgrounds. Significantly, from Last of the Mohicans to Alice Walker's Meridian (1976), nature's restorative potential is associated with American Indian legacies that hold healing power for communities. While white and African American authors illustrate this recuperative potential in a generally consistent manner over time, American Indian authors such as Leslie Marmon Silko present Natives' relationship to nature and to those of other racial backgrounds in radically different terms. For Silko, the healing power of the natural world coincides with a prophetic and literal reclamation of the land by its indigenous inhabitants.

This dissertation uncovers more fully this connection between cross-racial contact and environment and responds to contemporary theoretical approaches to race, culture, nationhood, and ecology. These approaches include Willliam L. Katz's and Jack D. Forbes's studies of black Indians, Gloria Anzaldua's and Homi K. Bhabha's writings about cultural hybridity, Philip Deloria's and Shari Huhndorf"s analyses of "playing Indian" traditions, and Lawrence Buell's and Donelle Dreese's ecocritial work. This study also affirms the prominent roles that American Indians occupy in major American novels, not only as 
emblems of ecological acumen, but more important, as participants in cultural exchange that informs American identity. Further, the project recognizes the significance of Native responses to American literary paradigms, responses that have often been overlooked in literary criticism.

One of the most significant challenges of a discourse that questions typical racial classifications and accounts for the impact of cultural hybridity is the difficulty of pinpointing better definitions for contested concepts such as "race" or "ethnicity." While "white" and "black" are commonly used to designate an individual's race according to color, these words, having long been the standard for racist social strictures, deny the realities of varied ethnicities among these populations. Terms such as "African American" or "Euroamerican" do a better job of emphasizing culture over color, perhaps accompanying a societal shift in the direction of cultural plurality, yet still they do little to signify the diversity represented by individuals of similar skin colors. Indeed, the political boundaries of Europe and Africa are ever-shifting, and many of the diverse populations who originated in those areas have long since migrated to other continents, making connections between geography and ethnicity, and ethnicity and color, tenuous. Further, these linguistic markers, which are employed broadly to mark individuals' identities, are problematized when those individuals use other methods or words to identify themselves. This discrepancy is particularly important for discourse concerning indigenous Americans.

As is widely known, a major linguistic mistake occurred when "in 1492, Columbus sailed the ocean blue." Thinking he had reached the West Indies, Columbus incorrectly called the individuals he encountered in the Americas "Indians." While the word "Indian" was thereafter used for centuries to refer to indigenous Americans, the term created an obvious 
linguistic challenge for distinguishing the differences between these Americans and residents of India. In recent decades, as compound words such as "African American," "Asian American," and "Mexican American" have entered the language, the term "Native American" has come into fashion, especially in academic circles, to refer to tribal populations. However, the term "Indian," or the variation "American Indian," remains the norm among many tribes. ${ }^{1}$ More importantly, American Indians use tribal names, such as Cherokee, Diné, Delaware, or Hopi, to refer to themselves and to classify members of various Indian nations. These signifiers indicate the ways in which discussing these groups solely as members of a Native American "race" denies the parameters that individuals in these populations use to identify themselves.

The difficulty of classifying American Indians racially is a subject of much heated debate, both within and outside of Native communities. Much of the trouble can be traced to the 1887 Dawes Allotment Act, which required members of tribes to register with the United States government and receive individual portions of land (Gibson 300). While this law's explicit purpose was to transform American Indians into farmers and free up large parcels of Indian land for public sale, another of its results was an imposed system of tribal membership based on "blood." To this day, many tribes, especially those that were forcibly relocated to Indian Territory (present-day Oklahoma), require members to trace their "Certified Degree of Indian Blood" to an ancestor who registered on the Dawes rolls (though a high number of Indians refused to register, tribal membership can only come from identifying a family member on one of these rolls). This focus on "blood" pervades perceptions, particularly non-

\footnotetext{
${ }^{1}$ Because I believe that members of these communities know best how to refer to themselves appropriately, I use the term "American Indian" in this dissertation. Since "African American" is widely used both in insider and outsider communities, I employ that term throughout.
} 
Indian perceptions, of American Indian authenticity, leading inquiring minds to constantly question American Indians, especially those who do not "look Indian" (whatever that means), about their blood quantum. Mention Native ancestry to any non-Indian, and his/her response will inevitably be: "How much?"

This fascination with "blood" makes sense in an American society where historically, whiteness and blackness have been the two racial categorizations that distinguish free from not-free. As is well documented, African Americans have been classified as "black" when any "drop" of black "blood" is present in their lineage. The very word "black" privileges color as the mark of race. When it comes to discussions of American Indians, scholars and others often attempt to follow this problematic model to classify members of these communities, but in this, they err. The current issues being debated all over Indian country reflect the shortcomings of this formulation. From casino gambling to hunting rights, from language retention to resource management, American Indians are constantly living out the complexities of living as sovereign nations (or, as the United States government prefers, “domestic dependent nations") within American borders. This national, political identity, grounded in specific tribal locations in the Americas, accompanies the cultural traditions and ancestral ties that inform Indian identity. These aspects of identity do not always coincide with fixed degrees of Indian "blood," as blonde-haired, green-eyed Cherokee-speaking Indians in Northeastern Oklahoma claim authenticity just as "full-blood" individuals living on reservations in New Mexico or Arizona do. In this way, evaluating American Indians as defined by color or "race" is ineffective.

Recognizing the error of such typical racial constructions with regard to American Indians begs the question: If usual definitions of race are insufficient for scholarship concerning 
Indians, why are they effective in relaying the stories of other groups? This project suggests that they may not be. From the works of Cooper and Faulkner, which portray diverse characters who adopt and reject traditions of various "races"; to the novels of Toni Morrison and Alice Walker, which display black-Indian hybridity as the key to psychological healing; to an innovative almanac by Leslie Marmon Silko, which emphasizes the transcultural and transnational reach of the Laguna Pueblo, many works of American literature complicate the language of "blood" and raise the possibility that such language is really a mask for cultural realities that are far more difficult to articulate.

As writers attempt to portray these realities, they tread into dangerous waters, where issues of cultural power and authority sometimes limit what is acceptable to readers and critics. Most American Indian scholars question Cooper's capacity to create believable American Indian characters, in part because of his European ancestry, and while Faulkner's stories are generally held in higher regard, they too are generally seen as inappropriate reference points for American Indian experiences in America. This evaluation is valid considering the rich array of writings by American Indians that, though often neglected by scholars in English departments, do more authoritatively recount American Indian cultures and more broadly enhance American Studies. Similarly, though the works of African American writers such as Morrison and Walker are not as often criticized for the ways in which they draw American Indian characters, few would turn to them as resources for American Indian studies, just as few would look to Silko's work to recount African American experiences. Is it appropriate to gauge a writer's ability to illustrate race based on the background that he or she represents? If not, how may readers determine who has the appropriate authority to write characters of certain racial backgrounds? If Cooper is misguided in his attempt to create Mohican 
characters, should Silko not attempt to draw African American characters? Who is best equipped to write characters who bridge these racial boundaries?

Though this dissertation does not definitively answer these questions, it locates environment as a starting point for tackling these issues concerning cultural or racial authority. Throughout each of the texts discussed, writers demonstrate varying levels of sophistication in creating a sense of place that corresponds to "authentic" culture. While Cooper is successful in illustrating wilderness as a locale where disparate cultures collide and at least partially transform one another, he is not as successful at drawing complex societies and settlements, both European and American Indian, in the Northeast (though it is questionable whether this was, or should have been, part of his authorial intent). Faulkner, who is renowned for his fictional representation of various populations present in Lafayette County, Mississippi, falters in his limited view of the future for African American and American Indian cultures, as he suggests that indigenous traditions, like the lush Yoknapatawpha forest, will inevitably be subsumed in a broader, mixed American culture. Morrison accurately identifies the shared experiences of African Americans and American Indians in her novels, locating tribal legacies in the South and illustrating the intermingled ancestries of both groups. However, few of her characters assert hybrid black Indian identity in the present; instead, her characters focus on the persistence in family or geographical names of American Indian legacies from the past. Walker herself claims black Indian identity, ascribing honor to her Cherokee ancestors, but her portrayal of this ancestry, as well as her depiction of black Indian characters, suffers in its lack of cultural specificity, or more specifically, grounding in a Cherokee place.

Finally, Leslie Marmon Silko, perhaps the author who is most successful in evoking cross- 
cultural hybridity, locates identity in particular cultural geographies, chiefly the Laguna Pueblo. Throughout her text, Silko locates culture in ecological areas that are infused with the enduring impact of ancestors, especially the impact of their spiritual sensibilities, for good or for ill. Silko illustrates heritage as a matter not of "blood" but of place; the earth remains, however altered, and so does indigenous identity, regardless of ineffectual beliefs about purity or authenticity. The key, then, to cultural or racial authority lies in maintaining connections to particular places, an effort with which her diverse characters have varying success.

Silko's presentation of identity as a matter of place illumines broader arenas in American literature where cultures come in contact, internationally, in warfare, or in the domestic sphere, for example. Importantly, though her own Laguna identity surely plays a role in her depiction of American Indian characters, it is her concentration on the specific landscapes that inform these Indian characters' experiences that lends her texts cultural authority. Similarly, the other authors in this study seem most successful in drawing characters of particular ethnic or racial orientations when they know the histories and cultures, based in specific places, that those characters represent. As the Americas, and the literatures that represent them, continue to be places where various peoples converge, discussions of culture must move beyond rigid classifications of color or "blood" and focus instead on the various traditions that influence these in-between places, or borderlands. 


\section{CHAPTER II: \\ CROSS-CULTURAL HYBRIDITY IN JAMES FENIMORE COOPER'S THE LAST OF THE MOHICANS}

During his time, James Fenimore Cooper achieved the height of literary fame for his creation of the Leatherstocking series as well as numerous other publications. In Cooper's mind, American writers were too often overshadowed by European literary models, and much of his aim in composing his uniquely American stories was to render a national intellectual tradition that would be somehow indigenous. Born in New Jersey in 1789, in an America newly independent from British control, Cooper found America's indigenous peoples themselves to be his source material for this indigenous tradition. These American Indian characters serve many purposes in Cooper's texts, from exemplifying the wilderness, to providing dramatic images of battle and adventure, to offering a non-Christian mystical flavor to an otherwise Anglo perspective. However, on a deeper level, and perhaps most importantly, Cooper's Indians play an integral role in various meditations on American possibility, specifically the human concerns that accompany European Americans' growing occupation of North America. These concerns include the sustainability of tribes' traditional livelihoods, the nature of colonial power, and the complexities of cultural and racial diversity. In this way, Cooper presents a human frontier in addition to a geographical one, a varied microcosm that reflects a uniquely American cross-cultural sensibility.

Cooper scholars have generally recognized The Last of the Mohicans (1826) and its American Indian characters as emblematic of the Vanishing American convention in American literature, whereby Natives must disappear in order for a young America to fulfill 
its destiny. In a popular sense, the novel has come to be viewed as an adventure story of our country's beginnings, an American counterpart to Sir Walter Scott's Waverley escapades set against the backdrop of a pristine yet unpredictable wilderness, the inhabitants of which eventually disappear. These understandings of the novel clearly refer to European models, from Scott to Rousseau, and even to Columbus. According to Stelio Cro, Columbus, convinced he had reached the golden age of mankind, "of primitive man in the state of nature or the noble savage, as he will be known in the eighteenth century" (386), provided a description of the American Indian that captured this myth of "noble" savagery: "These people are very peaceful and fearful, naked as I have said, with no weapons and without laws" (qtd. 394). As Cro further explains, the first historian of the "discovery," the Italian humanist Peter Martyr, continued this association of Indians with the Golden Age, articulating beliefs that the "New World" was unspoiled, with inhabitants ripe for the civilizing influences of Europeans who could themselves become closer to perfection through their affiliation with and mastery of what they perceived to be a human embodiment of nature; in short, the "new man" would be superior to the old one (396). As Cro elucidates, "the myth of the noble savage. . will gradually become the symbol of a new era, the era of individual freedom" (396). In this way, American Indians-or perceptions of them-are necessary for Europeans to formulate not only a vision of liberty, which is the foundation for their new society, but also a unique, innocent identity in a world that is far removed from Europe.

The Indians' role in defining America and differentiating it from the "Old World" perhaps explains the extreme popularity of Cooper's Leatherstocking series among nineteenthcentury readers who were eager to locate a unifying, recognizable history for their "new" 
country, which was enduring-violently-the growing pains of settlement and national expansion and was seeking to define its unique contribution to literature, art, and history amidst the shadow of Europe. Ironically, while Indians were chief referents for imagining Americanness, they were also the chief roadblocks to the nation's achievement of dominion over the North American continent, and as a result, the American experience came to be typified in literature by Native and European contact and confrontation-in other words, encounters at both cultural and geographical borders. As Shari Huhndorf, as well as Monika Kaup and Debra Rosenthal, eloquently explain, these encounters encompass a need for those of European origin to legitimize their presence in America. Huhndorf asserts ${ }^{1}$ :

These fundamental contradictions in American identity and history-the tension between the ideal of a free and democratic nation and the reality of racial hierarchies, the discrepancy between the myth of peaceful expansion and the history of bloody conquest-reemerge again and again in the cultural imagination. It is, perhaps, for this reason that European Americans have always been obsessed with stories of the nation's origins, repeatedly retelling and refiguring their collective past in selfjustifying ways. (11)

Indeed, as Amy Kaplan has shown, although Americans have often denied that their collective history is at least in part a history of imperialism, establishing American identity within the context of "settling the frontier" has always had profound moral implications for Americans.

The binary between the "old" individual and "new" and the moral complications of contact between these oppositions have thus permeated approaches to Cooper's text from the time of its publication to the present. In the latter half of the twentieth century, scholarship has more

\footnotetext{
${ }^{1}$ Huhndorf's landmark text Going Native (2001), akin to Philip Deloria's Playing Indian (1998), concentrates on the way in which, coinciding with the military conquest of Native America in the latter half of the nineteenth century and extending well into the twentieth century, European Americans have permanently appropriated Native culture in order to vitalize and enforce a unique national identity because of ambivalence about modernity. According to Huhndorf, "Going native ... expresses European America's anxiety about the conquest and serves in part to recast this terrible history by creating the illusion of white society's innocence. At the same time, these events also assert white dominance" (21).
} 
explicitly emphasized the moral failings of Europeans in their opposition to and domination of American Indians and has concentrated on the societal consequences of those failings. Examples of these critical approaches are numerous. Leslie Fiedler has posited, "This Europe and this America are ... no more facts of geography than Cooper's Indians and whites are facts of ethnography; the place-names stand for corruption and innocence, sophistication and naivete, aesthetics and morality” (191). Gaile McGregor offers, “. . .the Indian offered Cooper a versatile reference point for exploring the psychic social and particularly the moral dimension of the American's existential dilemma" (125). Robert Milder concludes: "the ... dominant mood is one of loss, not celebration. Partly this loss is the Indians,' but the more significant loss is that of the conquerors themselves, whose succession to the land is tainted by violence and guilt"” (408-9; italics mine). And Geoffrey Rans finds, "One of the great puzzles in any rigorous reading is how it could ever have stirred the patriotic sense, how the pride taken in the emergence of an American voice could have so completely obscured what that voice was saying" (4). These readings, while apt in the way in which they problematize conquest, or "settlement" of America, and point toward the social criticism in Cooper's novel, nevertheless maintain a focus on the psychological and ethical dispositions of Europeans and neglect this kind of complex study of American Indians. Yet this unbalanced characterization does not necessarily mirror an equivalent phenomenon in Cooper's novel. In fact, in several ways, The Last of the Mohicans actually offers a more dynamic-though often subtle-presentation of cross-cultural contact-and even reciprocity-than most critics have recognized.

Kaup and Rosenthal are among a small number of scholars who address the prominence of cultural and racial hybridity in American literature, specifically in Cooper's works. Drawing 
a comparison between Fiedler's classic American studies perspective and Terry Goldie's

postcolonial discussion of the phenomenon of "indigenization" in literature, Kaup and

Rosenthal offer the following analysis:

... both Fiedler's classic American Studies approach and Goldie's postcolonial critique of this position remain caught within a binary mode (white v. Indian), which cannot adequately recognize a third dynamic, the process of hybrid crossing. To view the imaginary kinship of whites with Natives merely in terms of appropriation is to overlook that the process of imaginary projection as native American is more than semiotic kidnapping to empower Euro-Americans (whom Goldie assumes remain essentially unchanged). (xiv)

In addition to arguing for greater attention to the mediation of boundaries and the crosscultural exchange evident in Cooper's text, Barbara Mann rightly points out that a continued exclusive emphasis on Cooper's ties to European sources neglects the extent of his knowledge of indigenous communities, including the Oneida community that had inhabited the land of his childhood, in the Northeast. Mann argues:

Too frequently, scholars assume that gift-wrapping "white guilt" for presentation to the nearest Native gets them off the critical hook, but they err. For some elusive reason, Euro-Americans seldom take the step of educating themselves concerning Native history and culture. ... If they cannot locate the Leather-Stocking core, it is because they are looking in all the wrong places: in Europe, John Locke and Sir Walter Scott instead of into the Fire at Onondaga, the mainland colonial slave codes, or the rift between colonial British and American policy on Indian miscegenation. Ironically, for all touted multiculturalism in academia today, there has been surprisingly little movement in the direction of assessing James Fenimore Cooper as an author ahead of his time in terms of cross-cultural application. (2-3)

In order to accurately assess Cooper's contribution to American literature, especially to recognize the relevance in the present day of the issues he raises in The Last of the Mohicans, a reading of the text with particular attention to the cultural hybridity he depicts is useful.

Cooper sets up the novel with several suggestions of the many cultural forces that have converged to create America-and the tension that convergence has instigated. The 
introduction evokes a sense of multiplicity among Indian people, referring to a diversity of tribes as well as of tribal languages and suggesting the possibility of intersections among American Indian and Asiatic cultures. Yet Cooper acknowledges among readers a simplistic and widespread fear of Indian "savages," which contributed to the popularity of narratives of captivity in the years following King Philip's War and later accompanied violent campaigns against American Indians. Rather than stoking this fear, Cooper seems to somewhat defuse it in the introduction, instead characterizing Indians' temperament as a bit more complicated:

Few men exhibit greater diversity, or, ... greater antithesis of character, than the native warrior of North America. In war, he is daring, boastful, cunning, ruthless, self-denying, and self-devoted; in peace, just, generous, hospitable, revengeful, superstitious, modest, and commonly chaste. These are qualities, it is true, which do not distinguish all alike; but they are so far the predominating traits of these remarkable people as to be characteristic. (v)

While this description is not altogether three-dimensional, it does attribute a degree of complexity to American Indians that challenges one-dimensional presuppositions that some readers may have espoused.

Interestingly, while Cooper avoids a stock introduction to his Indian characters, he also does not offer a categorically positive presentation of European Americans in the beginning of the novel, avoiding the kind of heroic portrayal that readers may expect. Instead, the colonists' dispositions border on irrational hysteria:

Numberless recent massacres were still vivid in their recollections; nor was there any ear in the provinces so deaf as not to have drunk in with avidity the narrative of some fearful tale of midnight murder, in which the natives of the forests were the principal and barbarous actors. As the credulous and excited traveler related the hazardous chances of the wilderness, the blood of the timid curdled with terror, and mothers cast anxious glances even at those children which slumbered within the security of the largest towns. In short, the magnifying influence of fear began to set at naught the calculations of reason, and to render those who should have remembered their manhood, the slaves of the basest of passions. (14) 
In this way, Cooper relays volatility in the setting of his narrative, which heightens a mood of suspended action and excitement, yet he also provides a basis for the human considerations that will accompany his adventure tale. As John McWilliams reveals, "For the casual nineteenth-century reader, Cooper plainly knew how to turn racial fear into a gripping read" (16). Amid unstable borders, the characters (and readers) are forced to confront those whom they perceive to be their opposition, and in the process they have the opportunity to be transformed.

Since most criticism of the Leatherstocking series has maintained as its framework a binary that depicts Europeans as having a culture and Indians as being in a state of nonculture, this criticism has ignored the possibility of an America that encompasses cultural influences of both groups. According to Fiedler, as an heir of Rousseau, Cooper depicts a "compelling vision of a society uncompromised by culture" (37). However, in several instances, Cooper offers scenes of Indian and white characters discussing their cultural origins in the American landscape and relating them to the broader discussion of the development of a nation. One example occurs early in the novel in a conversation between Bumppo and Chingachgook, in which they compare stories of how their people came to inhabit their current geographical space. Referencing the moral questions surrounding European entry into the area, Bumppo, speaking in a Native language, simply makes the origin stories parallel, asserting: "Your fathers came from the setting sun, crossed the big river, fought the people of the country, and took the land; and mine came from the red sky of the morning, over the salt lake, and did their work much after the fashion that had been set them by yours; then let God judge the matter between us, and friends spare their words!'” (34). 
However, Bumppo apparently finds that sparing words will not satisfy his curiosity, and he continues with an evaluation of his European ancestry, disparaging whites' tradition of depending upon print to convey their experiences yet venerating the Bumppos for their skill at shooting. He then inquires of Chingachgook's ancestors: “. . . every story has its two sides: so I ask you, Chingachgook, what passed, according to the traditions of the Red Men, when our fathers first met?" (35). Chingachgook, after relaying an emergence narrative of his people's journey across the plains to his current dwelling, tells, with some emotion, of the Mohicans' thriving culture at the time of contact with whites: “. . we were one people, and we were happy. The salt lake gave us its fish, the wood its deer, and the air its birds. We took wives who bore us children; we worshiped the Great Spirit; and we kept the Maquas beyond the sound of our songs of triumph!" (37). Finally, Chingachgook describes the effect of contact:

The Dutch landed, and gave my people the firewater; they drank until the heavens and the earth seemed to meet, and they foolishly thought they had found the Great Spirit. Then they parted with their land. Foot by foot, they were driven back from the shores, until I, that am a chief and a Sagamore, have never seen the sun shine but through the trees, and have never visited the graves of my fathers! $(37-8)$

In this exchange of ideas concerning the relative merits of their cultures, Bumppo and Chingachgook engage in a moral debate about the events surrounding the growth of the American nation-the same kind of debate that has endured to the present day. Importantly, each man is reminded both of the achievements that his ancestors have contributed to his present condition as well as the mistakes his people have made. Though the Dutch are chiefly to blame for displacing Chingachgook's community, Chingachgook seems to regret that his kin, who were previously able to ward off enemies, failed to stand their ground because of 
the influence of alcohol. Likewise, it is probable that Bumppo's "solemn feelings" (38) are due in part to his identification with the infiltrators. As a result, rather than representing a binary of "sophistication versus naivete," the two seem to exhibit mutual insight.

Not only does the two characters' conversation display a contemplative approach to multiple histories and the implications of the meeting of those histories in America, but this episode also conveys the way in which this meeting at the borders is linked to the processes of the natural environment. For the ancestral communities of both characters, thriving within the American landscape has involved control of ecological resources. When Chingachgook remembers the "happy days" of his people, his memories are specifically characterized by plentiful ecological resources and a capacity to keep enemies, "Maquas," from accessing those resources. Similarly, Bumppo's understanding of his genealogical identity corresponds to his ancestors' skill at hunting the creatures that inhabit that ecological space. Thus, each character's cultural ancestry is clear in how he relates to the natural world. Chingachgook's heritage is a tradition of synchronizing life, both spiritually and practically, to natural phenomena and waging war to maintain that existence; the Bumppo legacy involves confronting wilderness, whether for survival or for sport. The environmental dimension to this convergence of varied and conflicting cultural legacies is key to the novel's orientation as particularly American. As McGregor explains, "The brand of nature to be found in America, far from being inferior to the European style, was thus uniquely suited to the optimism of a new nation" (94). Rather than the sense of order ascribed to the Romantic natural scenes of Europe, America's landscape was far more complex and open to possibility, yet this possibility is not necessarily always unequivocally optimistic in Cooper's novel.

Cooper's characters locate their identities in specific environmental spaces, and when 
those spaces change or are transformed, a sense of loss often ensues. According to Donelle Dreese, ${ }^{2}$ this kind of "territorialization" occurs when individuals identify "a landscape or environment as intrinsic to their own conceptualizations of self" (3). Dreese further explains that "landscape or place is used metaphorically to represent sites of conflict or refuge when writers more closely examine borders and zones of human and ideological contact" (18). Dreese's ecological framework applies to Chingachgook's sense of dislocation as a result of his separation from the shores his people inhabited before the arrival of the Dutch. He is particularly saddened because he has never seen the sun as his ancestors did, and he has never visited the land where they are buried. In effect, he is removed from his "Native space." Similarly, he articulates his lack of hope for the future in ecological terms, of geographical dislocation: "Where are the blossoms of those summers! Fallen, one by one. So all of my family departed, each in his turn, to the land of spirits. I am on the hilltop, and must go down into the valley; and when Uncas follows in my footsteps, there will no longer be any of the blood of the Sagamores, for my boy is the last of the Mohicans" (38). And as Cooper depicts, more widespread dislocation of Indian people, the people of the Iroquois Confederacy in particular, has taken place in the time since the plot of this tale. Yet significantly, the rightful place of these peoples on these lands is evident in the geographical spaces named for them: "In a short time there will be no remains of these extraordinary people, in those regions in which they dwelt for centuries, but their names" (23).

Like Chingachgook, Bumppo also seeks to locate a sense of identity by connecting to the natural world, and when that world is altered, he too expresses ambivalence. One of the most

\footnotetext{
${ }^{2}$ Dreese discusses "reterritorialization" primarily as it applies to contemporary American Indian literatures, but her theories seem nonetheless pertinent to Cooper's portrayals of American Indians' connection to land and environment.
} 
poignant instances in which Bumppo conceptualizes his self in terms of ecological

phenomena occurs in his description of Glenn's Falls:

These rocks are full of cracks, and in some places they are softer than at othersome, and the water has worked out deep hollows for itself, until it has fallen back, aye, some hundred feet, breaking here and wearing there, until the falls have neither shape nor consistency. ... If you had daylight, it would be worth the trouble to step up on the height of this rock, and look at the perversity of the water. It falls by no rule at all; sometimes it leaps, sometimes it tumbles; there, it skips; here, it shoots; in one place 'tis white as snow, and in another 'tis green as grass; hereabouts, it pitches into deep hollows, that rumble and quake the 'arth; and thereaway, it ripples and sings like a brook, fashioning whirlpools and gulleys in the old stone, as if 'twas no harder than trodden clay. The whole design of the river seems disconcerted. First it runs smoothly, as if meaning to go down the descent as things were ordered; then it angles about and faces the shores; nor are there places wanting where it looks backward, as if unwilling to leave the wilderness, to mingle with the salt! ... After the water has been suffered to have its will, for a time, like a headstrong man, it is gathered together by the hand that made it, and a few rods below you may see it all, flowing on steadily toward the sea, as was foreordained from the first foundation of the 'arth! (63-4)

In this illustration, Bumppo captures the complex confrontation of peoples, their origins, and cultures that typifies the historical moment in which he finds himself. Just as the falls, which have been altered due to the ravages of time and the interference of human travelers, seem disconcerted, lacking rule, and at times hesitant to converge on their way to a vast sea, so too are various groups in America experiencing tension and violence in their encounters with one another on their way to a common plain.

Similar to Chingachgook's description of his existence before the arrival of the Dutch, Bumppo seems to remember a time when the falls were undivided and undisturbed. In this self-referential formulation, he likens the falls to a conflicted man, which clearly alludes to his own conflicted identity as one bound to his American Indian comrades yet also defined in part by his European origin. And also like Chingachgook, at the end of the novel, Bumppo is compelled by a tremendous sense of loss as a result of the fading presence of his people: his 
European traveling companions as well as his fellow dwellers of the woods. Importantly, his connection to a particular geographical space strongly compels him:

Deserted by all of his color, Hawk-eye returned to the spot where his own sympathies led him, with a force that no ideal bond of union could bestow. He was just in time to catch a parting look of the features of Uncas, whom the Delawares were already inclosing [sic] in his last vestments of skins. They paused to permit the longing and lingering gaze of the sturdy woodsman. ...(413)

For Bumppo, who as an individual encompasses a hybrid identity, the location of contact among varied peoples is the most appropriate place to continue to live out his existence.

In the same way that these locations of contact, or ecological spaces, correspond to Chingachgook's and Bumppo's senses of personal ancestry and identity, these zones also exhibit a synergy with the events in the novel that bind them and other characters together in a narrative of cross-cultural contact in early America. This linking of ecology and human originary action reflects David Mazel's understanding of environmentalism as a more complicated discipline than a philosophy that mirrors domestic Orientalism, or an approach to nature as "a self-evidently pure and 'good' resistance to an external and 'bad' force" (“American" 43). Drawing on the lessons of Said's framework, Mazel argues for an analysis of environment as "just one of many potential modes for exercising power, as a particular 'style,' both political and epistemological, 'for dominating, restructuring, and having authority' over the real territories and lives that the environment displaces and for which it is invoked as a representation" (43). In this reading, in Cooper's novel, the natural world is more than a passive abstraction to be confronted; instead, it is an agent that is present in human actions.

The environment's participatory role is evident perhaps most strikingly in scenes of violence and apparent degradation that heighten the plot's suspense. One such scene occurs 
when David Gamut's colt is killed before Bumppo, Chingachgook, and their fellow travelers become entangled in the many bloody battles that will typify their journey together. Though Gamut begs for the creature's life, Bumppo insists that circumstances necessitate the sacrifice of the innocent and instructs Uncas to bring a quick end to the foal:

'When men struggle for the single life God has given them,' said the scout sternly, 'even their own kind seem no more than the beasts of the wood.' ... the wounded foal, first rearing on its hinder legs, plunged forward to its knees. It was met by Chingachgook, whose knife passed across its throat quicker than thought. ... This deed of apparent cruelty, but of real necessity, fell upon the spirits of the travelers like a terrific warning of the peril in which they stood, heightened as it was by the calm though steady resolution of the actors in the scene. (54)

This scene parallels the indiscriminate destruction of a woman and her infant at the massacre after the surrender of Fort William Henry, where nature itself seems to encompass the devastation wrought by human conflict. Flowing with rivers of blood and dotted with the bodies of the dead, the landscape, after Indian allies of the French slaughter retreating English, captures the harsh but intrinsic essence of humanity. This human reality is marked by violence yet survival:

The fiercer element had cropped the verdure of the plain, which looked as though it were scathed by the consuming lightning. But, here and there, a dark green tuft rose in the midst of the desolation; the earliest fruits of a soil that had been fattened with human blood. The whole landscape, which seen by a favoring light, and in a genial temperature, had been found so lovely, appeared now like some pictured allegory of life, in which objects were arrayed in their harshest but truest colors, and without the relief of any shadowing. (213-4)

These scenes, and the environments that enact them, lay out the bare and sometimes ugly truth of human actions, especially within the context of contact across varied cultures. As Shirley Samuels has shown, "these killings conflate domestic and wild, suggesting the conflation of animals and humans throughout the novel" (87), and ultimately, "frontier transactions involving animals and humans produce a radically crossed or miscegenated 
identity, producing, in effect, a miscegenation between nature and culture" (89).

This conflation of features of the natural world with the processes of human cultures in contact is also highlighted at the end of the novel when almost all of the main characters don disguises of nature, including animalistic costumes, in order to rescue Alice and Cora from their Huron and Delaware captors. As Betty Becker-Theye points out, these humans in animal disguise, akin to the murdered infant who is represented by the helpless colt, are virtually the only animals present in the novel, making the human/environment bond all the more pointed in the transmission of the plot (48). This donning of elements of the natural world first occurs when Chingachgook, who is skilled at 'tak[ing] down natur' on scraps of paper" (270), makes a "natural fool” (271) of Duncan Heyward, using key symbols of nature to paint on him the disguise of a juggler, a healer who tags along with tribal allies of the Hurons, an identity far removed from his stature of leadership as a major in the English military. Through this disguise and his use of French, he is able to enter the company of the Hurons, whom he acknowledges have "an instinct nearly commensurate with his own reason" (272) and proceed to the location where Magua is holding Alice captive. Before entering the cave, at Bumppo's instruction, Heyward washes away the paint in order to approach Alice in a pale-faced state that Bumppo believes a white daughter of a colonel expects. However, in order for Heyward to remove her to safety, he must disguise Alice in the clothes of an Indian woman, thereby continuing to, in the Samuels's words, "trouble the presumed integrity" (99) of European identity in order to ensure survival.

Hawkeye, Gamut, and Uncas are also critical to this rescue scene, as their assumption of animal disguises further enables them and their friends to escape the Huron camp. After Uncas is captured, Hawkeye enters the camp disguised as a bear and attempts to signal his 
presence to Gamut by singing. Confused and a little afraid, Gamut exclaims to Heyward that Alice is expecting him, which spurs Heyward's enactment of his escape plan. Hawkeye enters the cave and frightens Magua, allowing Heyward to tie him up and escape with Alice. Still in the guise of a bear, Hawkeye goes to the hut where Gamut, still mentally shaken about the seemingly human nature of the bear, has covered his bald head with a "triangular beaver" (317). After Hawkeye reveals himself to Gamut, the two enter the hut where Uncas is imprisoned, and there, the three men swap dress: Uncas wearing the bear skin, Hawkeye wearing the clothes of Gamut, and Gamut wearing Hawkeye's hunting shirt in order to remain and impersonate Uncas. This almost comical exchange signifies a breakdown in categorizations which may be perceived to be rigid, including demarcations of race and nature versus society. As Mazel concludes, toward its end, the novel moves into a "fluidity of performance-suggesting that nature is not 'natural' at all but performative. . . . there looms also a sense of category crisis, of a breakdown in the very structures by means of which nature and culture have been demarcated in the first place" ("Performative" 108). This "category crisis," or instability of social, natural, and cultural boundaries, accompanies an instability in identity for many of the major characters, who without rigid boundaries, renegotiate their understandings of both their relations to one another and their own senses of self.

Although Jane Tompkins has argued that the process of trading disguises allows the major characters to safely maintain their own definite identities, shielding them from cross-cultural contact that has effects below the surface of appearance (38), other critics, including Samuels, rightly argue that these disguises are merely one reflection of the way in which the novel continually complicates rigid classifications of identity, emphasizing "collisions and 
confusions" (98). More extensive evidence of the way in which this meeting of ostensibly disparate cultures produces more enduring consequences occurs in the temperaments and behaviors of the characters themselves, especially the characters' relationships to one another. While Fiedler has made much of the "doubling" of opposite characters in the noveldark-skinned versus white, savage versus civilized, Christian versus pagan-most of the characters in fact display some kind of mediation or modification as a result of their experiences in the woods with representatives of other cultures, displaying what anthropologist Irving Hallowell calls "transculturalization." This is a phenomena whereby individuals "enter the web of social relations that constitute another society, and come under the influence of its customs, ideas, and values to a greater or lesser degree" (523). As a result of this transculturalization, many of the characters express traits that make them decidedly more rounded than most critics have acknowledged, and these characteristics make for fruitful, multi-faceted comparisons that move beyond binary match-ups.

While much has been written about the "savage nobility" of Cooper's American Indian characters, including Uncas and Chingachgook, most critics are content to understand Magua as simply savage. Whether they attribute this savage characterization to Cooper's failure to portray effective literary characters or to his supposed racism against American Indians, these critics fail to evaluate Magua within the context of cultural collision in Cooper's text, a context which places him squarely at the crossroads of various tribal and colonial alliances during a time of war. Relegating him to a stock, "bad Indian" camp, many fail to perceive the diverse influences and experiences that have made Magua the more interesting tragic villain that he is. Cleverly, Cooper draws Magua in a way that plays into the fears of nineteenthcentury white readers, yet he also projects readers' fears onto a character whose quest for 
revenge is largely due to the harmful actions of European settlers.

Magua's description of the history behind his arrival as a Mohawk warrior reveals the degree to which European infiltration has contributed to his present state. He explains to Cora:

Magua was born a chief and a warrior among the red Hurons of the lakes; he saw the suns of twenty summers make the snows of twenty winters run off in the streams, before he saw a paleface; and he was happy! Then his Canada fathers came into the woods and taught him to drink the firewater, and he became a rascal. The Hurons drove him from the graves of his fathers as they would chase the hunted buffalo. $\mathrm{He}$ ran down the shores of the lakes, and followed their outlet to the city of cannon. There he hunted and fished, till the people chased him again through the woods into the arms of his enemies. The chief, who was born a Huron, was at last a warrior among the Mohawks! (119-20)

This narrative, which Daniel Peck calls "the novel's most compelling elegaic vision of Indian dispossession" (9) is remarkably similar to Chingachgook's description of his own people's dispossession and his particular sadness at being separated from the graves of his ancestors. The similarity begs the question: Why do Magua and Chingachgook end up so remarkably different?

The answer seems to lie in Magua's "becoming a rascal," neglecting the values of his people and becoming subject to the influence of those who want to use him, especially French commanders allied with the Mohawks. The difference in the two characters' animalistic names reveals much about their natures; as Hawkeye explains, "what [an Indian] calls himself, he generally is" (67). According to Hawkeye, Chingachgook, whose indigenous name means "big serpent" in English, "understands the winding and turnings of human natur' [sic]" (67), which perhaps explains why, even though he has aided Heyward and Munro and developed a profound bond with Hawkeye, he has nonetheless endured as a valiant Mohican warrior even as the rest of his people have dwindled due to European 
encroachment. In contrast, Magua struggles with the Delaware language and refers to himself in French as "Le Renard Subtil," or "The Subtle Fox," the name given to him by his "Canadian fathers," a designation that emphasizes Europeans' approximation of him, an identity that he has internalized. In this way, Magua's betrayal of Heyward in the beginning of the novel, when he intends to lead him and the Munro daughters into a trap, as well as his insistence on exacting revenge on Munro by taking one of his pale-faced daughters as a wife, is right in line with this French colonial affiliation, as it mirrors Montcalm's violation of his terms of surrender with Munro, a surrender which features a slaughter of innocents while the English are in retreat to Fort Edward. Unlike Chingachgook, whose body is drawn clearly in "intermingled colors of white and black" (32), Magua's face reflects the degree to which his alliances have transformed him: "The colors of the war paint had blended in dark confusion about his fierce countenance" (20).

Importantly, Magua is thereby not the simple, inhuman "savage" that many readers, and some critics, expect him to be. What makes him so interesting is the degree to which he recognizes the corruption of the people with whom he has consorted. At the end of the novel, in his appeal to Tamenund for the return of his escaped prisoners, Magua portrays the white man as most cunning: "With his tongue, he stops the ears of the Indians; his heart teaches him to pay warriors to fight his battles; his cunning tells him how to get together the goods of the earth; and his arms inclose the land from the shores of the salt water to the islands of the great lake. His gluttony makes him sick. God gave him enough, and yet he wants all” (3567). Magua places the blame for his weakness for alcohol, through which he strayed from his people and for which Munro has publicly "whipped him like a dog" (120), squarely with colonial invaders: "Was it the fault of Le Renard that his head was not made of rock? Who 
gave him the firewater? Who made him a villain?" (120). Indeed, it may be Magua's refusal to see his own agency in his fate that is his tragic flaw, a complexity of character that makes him quite compelling. As Craig Rinne has revealed, this ambiguity has led Russell Means (Oglala Lakota) and Wes Studi (Cherokee), actors who portray Chingachgook and Magua in Michael Mann's film version of the novel, to develop an appreciation for the character: "Both actors view Magua as a complex, fully developed American Indian character. Studi says that .. 'he has reasons, ... it makes him feel better to act ruthless"' (7).

Like Magua, Cora exhibits a plurality of affiliation, but whereas Magua's personal weakness leads to villainy within this context of transculturalization, Cora's moral fortitude makes her the novel's heroine. As the child of Colonel Munro and a woman descended from Africans enslaved in the West Indies, Cora is portrayed as of mixed ancestry, an embodiment of her father's cross-racial union. Cora's diverse background distinguishes her from her purely Scottish sister Alice, and the two provide a commentary on femininity in an American space separate from the fineries of Europe, a commentary that also plays upon racial stereotypes. While Alice is timid and easily frightened into faints, Cora is passionate, independent, and brave, reminiscent of other heroines of popular nineteenth century fiction yet unique in her effectiveness in a wilderness setting outside of the domestic sphere. Her appearance is likewise unique: "The tresses of this lady were shining and black, like the plumage of the raven. Her complexion was not brown, but it rather appeared charged with the color of the rich blood, that seemed ready to burst its bounds. And yet there was neither coarseness nor want of shadowing in a countenance that was exquisitely regular and dignified, and surpassingly beautiful" (21). Cora's matchless attributes prepare her for the trials she endures, particularly as she protects her sister, suggesting that for Cooper, cross- 
racial affiliation is the key to the future of the Americas. As McWilliams explains, "To all characters who understand the forest, Cora seems a significant human being but Alice remains at best a tender blossom" (73).

Nina Baym has written extensively of the contrast between Alice and Cora, emphasizing the appropriateness of Alice's ineffectual behavior in a male-dominated white world, behavior which Baym believes ultimately saves her. She explains,

Alice's very tenderness and softness, her constant need to be tended, watched over, taken care of, finally save her, but Cora's very strength, her firmness, boldness, fortitude, and thoughtfulness have the opposite result. A woman's weakness is her strength in the white world, because it inspires men like Duncan, representative of European-American civilization, to fight for her. (77)

Baym is correct that Alice is the more appropriate match for Duncan in the white world, especially because, as Barbara Mann reminds us, under colonial law, Cora could have been enslaved in that world (51). However, Alice is not the only character for whom Heyward and others risk their lives; Cooper has gone to great lengths to craft an elaborate and dangerous cooperative escape plot, complete with costumes, for the survival of almost all of the main characters, and later in the novel, Uncas leads an entire Delaware nation, as well as Hawkeye, David, and Heyward, into war against Magua and the Hurons on Cora's behalf. More importantly, while Alice does not embody the strength of Cora, she is not quite the shrinking flower that many critics have perceived her to be, and she does exhibit insight and bravery at crucial moments. It is because of Alice that David Gamut, who becomes key to the later success of the escape plan, is included among the company, as Alice suspects that Cora's initial trust of Magua may be misplaced. Further, when Alice first sees the gallant Uncas, she recognizes that a fear of Indian savagery that has accompanied her genteel upbringing may have been unfounded, telling Heyward, "I could sleep in peace ... with such 
a fearless and generous looking youth for my sentinel. Surely, Duncan, those cruel murders, those terrific scenes of torture, of which we read and hear so much, are never acted in the presence of such as he!" (61). Alice correctly puts her trust not solely in Heyward, but also in Uncas, the most skilled warrior in the novel.

Additionally, Alice expresses her solidarity with her sister at times when Heyward is ready to give Cora up. When Cora faces the prospect of becoming Magua's wife in order to spare her and Heyward, Cora, who is too distraught to decide whether she can make the sacrifice, asks Heyward for his judgment, yet he shrinks from the task. It is instead Alice who makes the call: "looking like some beautiful emblem of the wounded delicacy of her sex, devoid of animation, and yet keenly conscious," Alice asserts, "No, no, no; better that we die as we have lived, together!" (129). Finally, Alice stalwartly stands up for her sister when Heyward first finds Alice in the cave and suggests leaving Cora behind because of her "obscured worth" as a mixed blood, which precludes his earlier "open admiration" of her (24). Withdrawing her hand from Duncan's and interrupting his case for an immediate departure, Alice quips "You knew not the merit of my sister" (308). Although Fiedler complains that immediately after this conflict, when Heyward proposes marriage, "she responds, not with the proud warmth of Cora, but trembles and almost faints as is 'common to her sex"' (206), Alice is in fact not shrinking from the prospect of marriage; instead, she is shrinking from the prospect of marriage to someone who may have earlier preferred her sister but who has just told her her sister is worthless! Ultimately, Alice is not in simplistic opposition to Cora; instead, like Cora, she exhibits perception and rises to new levels of endurance because of her journey through an ecological space she has never before faced, a zone of varied crosscultural contact that leaves her transformed to some degree. This transformation-not 
Duncan-is what truly leads to her escape. Like her encasement in Indian clothing, her survival is tied to a more resilient identity. As Samuels asserts, "The novel might be said to locate the future of national culture in the wrapping of Alice's body" (99).

Despite Alice's strides, she is not prepared to go head-to-head with Magua, which is exactly what Cora does. Perhaps because of her own diverse heritage, her "dark secret" that could potentially lead to her enslavement if exposed, Cora exhibits a complex interest in Magua. Upon first seeing him, she displays "an indescribable look of pity, admiration, and horror" (21). Though he represents to her a savage villainy that she has surely been warned against, Magua is nevertheless similar to her in his affiliation with a European power structure that degrades him. At first she defends Magua, scolding others who question his loyalty, demanding: "Should we distrust the man because his manners are not our manners, and that his skin is dark!" (24). Certainly her initial rush to defend the guide with whom she has no acquaintance stems chiefly from her sense of identification with him on some level.

Later, however, when Magua tries to take her as his wife, Cora is disgusted and shocked, as her upbringing as a "chaste female" would certainly preclude union to an indigenous American. Cora engages in a debate with Magua that captures the way in which rigid racial structures that she has been reared to uphold, boundaries which require her to pass as white, are threatened in the present setting. She naively questions the plausibility of Magua's request: "And what pleasure would Magua find in sharing his cabin with a wife he did not love; one who would be of a nation and color different from his own? It would be better to take the gold of Munro and buy the heart of some Huron maid with his gifts" (122). Yet Magua does not want a life mate; he wants revenge. Not only does he want Cora to experience physical hardship that mirrors the whipping he received at the direction of Munro, 
but also by taking Cora to live among the graves of his fathers, he wants Munro to experience the kind of dislocation from the space of his kin that he himself has experienced: "When the blows scorched the back of the Huron, he would know where to find a woman to feel the smart. The daughter of Munro would draw his water, hoe his corn, and cook his venison. The body of the grayhead would sleep among his cannon, but his heart would lie within reach of the knife of Le Subtil" (122-3). Without the forced security of firm racial boundaries, Magua emphasizes that European entrants into America are subject to the same kind of transformation that they impose upon the country's indigenous inhabitants. In the words of Mann, "Cora, the assimilationist, identifies with and defends European interests, which she has internalized as her own. Magua, the Indian nationalist, rejects and hates European interests as inimical to his being. Importantly, neither can acquit the defendant, Munro, no matter how much Cora might like to" (56).

When Cora fails to convince Magua to stop his pursuit of her, she appeals to a higher authority: the Tamenund, or chief, of the Delawares. Cora's respectful approach to the aged Tamenund-she kneels before him "with a species of holy reverence" (360)-impresses the patriarch enough for him to consider her appeal. However, Cora's pleas do not discount the central fact of the interests of his Delaware people and the impact of their dispossession that drives the Tamenund's judgment. When Cora tries to convince the chief of a white leader's past release of a young relation of his, perhaps an invented strategy, the Tamenund is unmoved and insists on her comprehension of the condition of his people. Like Magua, his thoughts are primarily with a past greatness, which he recollects in ecological terms: "It was but yesterday, ... that the children of the Lenape were masters of the world. The fishes of the salt lake, the birds, the beasts, and the Mengwee of the woods, owned them for Sagamores" 
(361). It seems that Cora recognizes the validity of the Tamenund's argument, as she at last bows her head and "struggle[s] with her chagrin" (361). Further, the Tamenund highlights the negative traits he has observed among the "palefaces," particularly their abhorrence of intermarriage, saying "The dogs and crows of their tribes ... would bark and caw before they would take a woman to their wigwams whose blood was not of the color of snow." (362). To this summation, Cora concedes simply "It is so" (362). As Rans explains,

The power and truth of Magua's words quite overcome for the time being our sense of his cruel intentions as the villain of the romance, especially as his narrative finds further and less compromised expression in Tamenund's ruminations. They override Cora's pleas and evoke in clouded poetic memory the history of Indian victimization at the hands of the white man ... Again it is given to Cora to concede the point-and it could not be more touching that she, of mixed blood, is the recipient of these particular words. (113)

In short, the Tamenund backs Magua up, and Cora has no further comment.

However, though Cora admits the validity of the case against her father, she does not give up her plea for the safety of her sister, directing the chief to listen to the strongest of her allies: Uncas, who is being held prisoner in the Delaware community. A masculine counterpart to Cora, Uncas, called "le cerf agile" or "The Nimble Deer," is the strongest, most positive man in the novel and is therefore predictably her suitor by the end of the narrative. Like Cora, he is described as remarkably beautiful, calm, and composed in the face of danger. Unlike Magua, the "nimble deer" has retained his synergy with the "attitudes and movements of nature" (61), and he speaks in the Delaware language, the language of his fathers. Though his captors decry his alliance with the "Yengeese" over the French, Uncas is finally spared death because of the discovery of his tortoise tattoo, the symbol of his revered lineage in the dwindling Mohican turtle clan, the proof of his status as a young chief and the source of hope for the Delaware people. As Uncas assumes his authority as sagamore, he 
unites the Delawares, regardless of English or French affiliation, and they submit to his judgment, allowing Heyward and Alice to go free and accepting Hawkeye as a legitimate ally. Yet in a heart-wrenching moment, he validates Magua's right to hold Cora captive in accordance with Delaware custom, and Cora bravely agrees to follow Magua, rejecting Hawkeye's offer of death for her preservation. Though Uncas accedes to this custom in allowing Magua to disappear into the trees, he immediately rallies his people, including his non-Delaware friends, to catch up to Magua and fight the Hurons to retrieve Cora. Overall, it seems that Uncas is about as Delaware, or more specifically, Mohican, as it gets in the novel.

Significantly, however, Uncas's rightful assumption of the leadership of the Delawares is not tied to isolation from outside influence. In fact, though Uncas is surely the most positive representative of American Indians in the novel, his long separation from his Delaware relations, who have entered into alliance with the French; as well as his comradeship with Bumppo; and his amenability to Heyward, Gamut, and Munro, have contributed to his ability to effectively lead his people in a space of increasing cultural complexity. Rather than simply his dark skin, it is this effectiveness in a pluralistic context that makes him the appropriate match for Cora, who herself is an image of strength amid adversity as well as an embodiment of racial plurality. It is for this reason that when Baym reads Uncas's intelligence, which Cooper portrays as surpassing that of others in his nation, as "unlike an Indian" (78) and therefore suitable for non-Indian Cora, it is hard to miss the Anglo bias that permeates most critical evaluations of the pairing. A better assessment attributes the union to the two characters' integrity.

While Uncas preserves the interests of his people while yet going to battle for Cora, Cora sacrifices herself for her sister and Heyward, retaining her commitment to the judgment of 
God, rejecting offers of martyrdom on her behalf. Cora's moral fortitude is most poignant when at the moment of her imminent death, she turns heavenward, asserting, "I am thine! Do with me as thou seest best!" (399), leading Magua to hesitate in his mortal intentions toward her. Conflicted, "The form of the Huron trembled in every fiber, and he raised his arm on high, but dropped it again with a bewildered air, like one who doubted" (399), and it is another Huron, not he, who kills Cora. Magua thereby displays his own humanity in his struggle to decide whether to end her life, apparently moved by her faith and bravery. As Milder observes, "without being timorously pious, Cora is the locus for the Christian idealism in The Last of the Mohicans" (427). In this way, Magua seems to internalize Cora's example on some level, highlighting the way in which the process of mutual exchange in the novel, through which characters are affected by one another's actions and motivations, is apparent.

This transculturalization is further emphasized at the end of the novel after Cora and Uncas have been killed and are memorialized in a funeral of sorts. Six Delaware girls, who resemble Cora in appearance "with their long, dark, flowing tresses falling loosely across their bosoms" (402), visibly reflecting the pervasiveness of her legacy, provide a positive assessment of Cora's and Uncas's relationship:

He was of a race that had once been lords on the shores of the salt lake, and his wishes had led him back to a people who dwelt about the graves of his fathers. Why should not such a predilection be encouraged! That she was of a blood purer and richer than the rest of her nation, any eye might have seen: that she was equal to the dangers and daring of a life in the woods, her conduct had proved; and now, they added, the "wise one of the earth" had transplanted her to a place where she would find congenial spirits, and might be forever happy. (406)

Indeed, the relationship endures as the stuff of legend, as for many years afterward, their union is incorporated into the oral traditions of the Delaware, who recant the story of Cora 
and Uncas during "long nights and tedious marches" (412) as well as in preparation for battle.

The novel's intermingling of red, white, and black in the venerated union of Cora and Uncas is thereby significant, as it seems to enact a positive evaluation of the potential for racial and cultural confluence that has always been a distinctive reality in America. As Peck discerns, "Cooper is dealing with the relations between the three main races then inhabiting North America, and testing the possibility of their being brought together. It is the sort of subject in which Cooper was characteristically interested, and the method he employs is equally characteristic" (13). As Rosenthal explains, this method of hybrid crossing, especially the intermingling of white and Native, is more broadly pervasive: "many early white authors ... presented [Natives] in terms of sexual relations with the colonists.... The importance of miscegenation to national literature seems to be a hemispheric theme in the Americas, for many Latin American novels also figure Indian-white mixing" (122-3). Therefore, in keeping with Huhndorf's ideas about "Going Native" as a means of locating American identity, it seems that the national literary sovereignty-and perhaps cultural sovereignty-that Cooper was so eager to assert is tied to his integration of black and white with Indian in his novel. However, as many critics have so importantly asked, if Cooper sees miscegenation as positive, perhaps the key to locating a unique American identity, why did he kill off both Cora and Uncas at the end of the book?

As Mann reminds us, Cooper's historical moment was one of pervasive fear of sexuality, much less interracial sexuality. She concludes, "Direct discussion of any touchy subject-race or sex, especially-was worse than a crime; it was a social blunder, so Cooper's contemporaries were accustomed to following a trail of deep-throated hints to the 
unspeakable point" (50). Clearly, by disallowing Cora's and Uncas's relationship, especially preventing a consummation of that relationship, Cooper is making a safe call for the sake of his nineteenth-century readers. Here is where the myth of Vanishing American comes into play for Cooper. As Rosenthal points out, "Disappearance becomes a narratological device, a deus ex machina for allowing authors to extricate themselves believably from controversial or difficult plots.... Readers at that time, familiar with the myth of the Vanishing American, readily accepted plots that dissolved interracial romance by having the Indian simply vanish" (135).

In addition to allowing Cooper's escape from a controversial conclusion, the deaths of Cora and Uncas spare the author the task of formulating a shared life for the two, as readers would likely find such a formulation unbelievable. How would Cora continue her Christian piety when she would likely be shunned by many Christians because of her interracial marriage and exposed African lineage? Would she be able to build a life with Uncas as well as continue her close association with her sister after Alice and Heyward have rejoined "civilized" society? As Milder explains, "the issue Cooper addresses is not the sexual anxiety raised by the prospect of miscegenation ... but the cultural anxiety surrounding the possible incorporation of the Indian and the Negro into American society" (427). Rather than simply Cooper's own fear of miscegenation, which Fiedler believes spurs the deaths of hero and heroine, readers' discomfort with cross-cultural exchange, as is apparent in American society even today, surely also played a prominent role in Cooper's creative decisions. As McWilliams asserts, "The Delaware maidens' song . . calls for an alternate vision of race and gender. . In 1757, in 1826, or in the 1990s, the maiden's song envisions a time that, if it ever existed, is both clearly past and not yet come again" (75). 
The fate of Cora is not Cooper's last word on the potential for cultural confluence in America, however; for subtler but nonetheless pervasive possibilities for exchange, we must turn to Hawkeye. Like Cora and other characters, Bumppo mediates among many groups in the novel, offering commentary on their various characteristics in the process. Further, Bumppo acts as a cultural interpreter of sorts, offering his evaluation, especially to the white characters, of "savage Mingos," Christianity, and the intricacies of hunting, and by the end of the novel, providing the Delawares a link to the white world. Because of this obvious role as mediator, or cultural interpreter, most readers have overlooked somewhat hidden yet nonetheless significant clues to Natty's more profound struggle, that of locating an identity within a world-and a rearing-that is culturally multiplicitous. Throughout, Bumppo seems hyper-concerned with estimating his own value according to sometimes disparate cultural criteria and comparing that estimation to the attributes of both Indian and white others. Bumppo's efforts of self-analysis are most evident in his relationships with other male characters, including Gamut, Heyward, Uncas, and Chingachgook.

Hawkeye's encounters with David Gamut reveal his conflicted feelings about the merits of Christianity, especially relative to the life in the woods that he has long been living. Hawkeye seems to prefer a pantheistic approach to spiritual belief, though when Gamut suggests that American Indians practice idolatry, he vigorously defends American Indian worship of the Great Spirit as similar to the Christian monotheism of Gamut. Bumppo's primary complaint with Christians is apparently their reliance on written commandments rather than on experiences of God in the processes of nature. Noticing Gamut's possession of a Bible, Bumppo insists:

there are men who read in books to convince themselves there is a God. . . If any 
such there be, and he will follow me from sun to sun, through the windings of the forest, he shall see enough to teach him that he is a fool, and that the greatest of his folly lies in striving to rise to the level of One he can never equal, be it in goodness, or be it in power. (138)

At this point, Gamut is uninterested in hearing an alternate view of religion, one that draws "faith from the lights of nature, eschewing all subtleties of doctrine," and he quickly quits the conversation, believing "neither profit nor credit was to be derived" (138).

Despite Bumppo's initially negative evaluation of Gamut's beliefs, later, before the two enter battle to rescue Cora, and David requests that Bumppo forgive his foes should he be killed, Bumppo provides qualified validation of Christianity. Wistfully, perhaps in recognition of his own Moravian roots, Bumppo is clearly moved: "There is a principle in that, ... different from the law of the woods; and yet it is fair and noble to reflect upon. ... It is what I would wish to practice myself, as one without a cross of blood, though it is not always easy to deal with an Indian as you would with a fellow Christian” (325). Bumppo internalizes the Christian example set by Gamut, though he believes that such a lifestyle is not quite possible in the world he inhabits. However, like Bumppo, by the end of the novel, Gamut exhibits modification on some level, compromising his rigid rejection of nonChristian spiritual practices. As the Delaware girls sing of Cora's virtues, in part her Christian virtues, in a Delaware language as well as in a Delaware spiritual tradition, Gamut is also affected: "David was not reluctant to lend his ears to the tones of voices so sweet; and long ere the chant was ended, his gaze announced that his soul was enthralled" (407). Bumppo's and Gamut's relationship thereby highlights the crossing of boundaries in the novel in addition to exemplifying the conflicted nature of Bumppo's self-understanding. Similarly, Hawkeye's interactions with Heyward also indicate a need for the scout to 
explain himself on many levels. Early in their acquaintance, Bumppo seeks to emphasize Heyward's unfitness for a life in the woods as well as Heyward's role in European infiltration, which has instigated the hardships that the Delawares are facing. Initially, the tension between the two characters is clear, as Bumppo asserts: "I call him liar that says cowardly blood runs in the veins of a Delaware. You have driven their tribes from the seashore, and would now believe what their enemies say, that you may sleep at night upon an easy pillow" (58). Heyward is unimpressed by Bumppo's admonition: "Heyward, perceiving that the stubborn adherence of the scout to the cause of his friends the Delawares or Mohicans, for they were branches of the same numerous people, was likely to prolong a useless discussion, changed the subject" (58).

However, as their journey through the forest proceeds, the two men are drawn closer together through their efforts to insure the safety of the Munro sisters. Bumppo, who has earlier exhibited a fondness for Alice upon their first meeting, responding to her with "a look of open pleasure" (45), gives Heyward his blessing before the major goes in Indian disguise to rescue-and propose-to her in the cave. Again, Bumppo apparently feels a need to assert his European lineage yet also justify his diversion from European cultural practices while suggesting to Heyward that he exhibit the same kind of modification: "may Providence bless your undertaking, which is altogether for good; and remember that to outwit the knaves it is lawful to practice things that may not be naturally the gift of a white skin" (272). Therefore, like Gamut, Heyward relaxes his resistance to cultural mediation in part through his relationship to Bumppo, and Bumppo continues to promulgate his belief in his own racial purity while explaining behavior that is supposedly contradictory to it.

Heyward's alteration of his opposition to American Indians takes place largely through his 
relationship with Uncas, a relationship that seems to provoke the jealousy of Bumppo.

Bumppo often attempts to instruct Uncas in the finer points of combat, even though Uncas

clearly does not need much assistance in this area. In one instance, Bumppo's criticism of

Uncas leads Heyward to intervene in defense of the young Mohican, inspiring mutual respect among the two:

"I cannot permit you to accuse Uncas of want of judgment or of skill," said Duncan. "He saved my life in the coolest and readiest manner, and he has made a friend who never will require to be reminded of the debt he owes." Uncas partly raised his body, and offered his hand to the grasp of Heyward. During this act of friendship, the two young men exchanged looks of intelligence which caused

Duncan to forget the character and condition of his wild associate. (85)

While this moment is pivotal for Heyward, it provokes the envy of Hawkeye, who then begins to recount many times that he and Uncas have saved each other's lives, an exercise of attempted one-upmanship.

Uncas's positive disposition toward Heyward stems in part from his frustration with Bumppo's continual criticism, which the scout so obviously exercises in order to foreground his own skills as a hunter and warrior. While Uncas shows no outright disrespect to his avuncular companion, after Bumppo refers to Uncas's battle skills as "like that of a curious woman" (141), Heyward senses the young one's vexation: "Heyward thought the manner of the young Mohican was disdainful, if not a little fierce, and that he suppressed passions that were ready to explode, as much in compliment to the listeners, as from the deference he usually paid to his white associate" (141). Uncas's usual deference to Bumppo extends beyond a desire to honor a friend of his father; this deference seems to proceed from a sense of pity. For example, during their execution of their costume-swapping escape plan, Bumppo acknowledges Uncas's superior faculties in assuming the guise of a bear. Uncas declines to 
corroborate Bumppo's evaluation, however: "Whatever might have been the private opinion of Uncas of their respective abilities in this particular, his grave countenance manifested no opinion of his own superiority" (323). Throughout scenes such as this, Uncas proves himself to be a humble budding leader, but he also appears to occupy a need to appease Bumppo, as if he understands that the scout possesses a fair amount of insecurity about his role in the surviving community of Mohicans.

Bumppo's insecurity is due in part to his removal from the father-son bond that Uncas and Chingachgook share. Though the shared respect among the three characters is apparent, there is still a Mohican identity that unites father and son, a strong identification that is difficult for Bumppo to adopt, despite his Mohican-fashioned livelihood. Observing Uncas and Chingachgook together, Bumppo's feeling of separation from them is clear: "It appeared to him as though the foresters had some secret means of intelligence, which had escaped the vigilance of his own faculties" (231). This separation is also evident in the way in which the two Mohicans' relaxation from a façade of warrior strength only takes place apart from

\section{Bumppo:}

Casting off, at once, the grave and austere demeanor of an Indian chief, Chingachgook commenced speaking to his son in the soft and playful tones of affection. Uncas gladly met the familiar air of his father; and before the hard breathing of the scout announced that he slept, a complete change was effected in the manner of his two associates.... The eyes of the father followed the plastic and ingenious movements of the son with open delight, and he never failed to smile in reply to the other's contagious but low laughter. While under the influence of these gentle and natural feelings, no trace of ferocity was to be seen in the softened features of the Sagamore. (236-7)

Chingachgook's deepest kinship is with his son, and this affiliation supersedes the relationship of the Mohicans to Bumppo. At last, while Bumppo has stayed far distant from European civilization, despite his Native sensibilities, he remains conspicuously "The 
Deerslayer" and not an approximation of "The Nimble Deer."

As Samuels articulates, the conflict suggested by this name differentiation signals the novel's "instabilities," which "point to the violent struggle ... to locate personhood" (88). Accordingly, Bumppo's constant comparison to Heyward and Gamut in one instant and the Mohicans in another is a reflection of his continual efforts to locate an identity in a space of mediated borders. Bumppo's mannerisms, which also vary according to his purposes, demonstrate this pluralistic identity. In one instance, during a debate with Uncas and Chingachgook about whether to journey by land or water, Heyward observes that Bumppo "affect[s] the cold and artificial manner which characterizes all classes of Anglo-Americans, when unexcited" (235). Yet moments later, when he seems to be losing the argument, Bumppo "suddenly assume[s] the manner of an Indian, and adopt[s] all the arts of native eloquence" (236), which finally leads the others to act according to his conviction. Similarly, Bumppo's insistence on flaunting the "purity" of his whiteness amid his pronouncements about the "true" nature of Indians, including the dastardly dispositions of the Iroquois, further imply the scout's persistent attempts to delineate an identity as Anglo at times and as Delaware at others. A close reading of the text reveals the "gleam of resentment" (216) on the face of Chingachgook when Bumppo, during his rail against the French and pledge of revenge, hypocritically pins such vengeful tendencies on Natives while again asserting his European ancestry: "Revenge is an Indian feeling, and all who know me know that there is no cross in my veins" (216). As Becker-Theye observes, "When closely examined, the contrast between evil Iroquois and good Delawares is mainly a rhetorical prejudice of Hawkeye.... Although it is true that the word savage is applied at least 53 times to the Iroquois and only twice to the Delaware, it is Natty Bumppo, not Cooper, who is most fond 
of the term" (55).

Bumppo's obsession with proving his white legitimacy while also demonstrating hunting and battle skills that are commensurate with the Mohicans are crucial to understanding his characterization; indeed, unlike Cora's determined resolve, Bumppo's disposition seems to be the most conflicted in the novel. Critics have provided many explanations for this conflicted portrayal, the most popular being that Bumppo finds himself to be morally superior to and therefore severed from European society yet not quite savage enoughthrough blood or culture - to be Indian. Despite the reams of critical attention devoted to Cooper's Leatherstocking novels over the years, including articles focusing on Cora's racial ancestry, few have discovered subtle hints that provide a possible cause of Bumppo's role as a sometimes reluctant cultural mediator: his own multiracial heritage.

Barbara Mann suggests the possibility of Bumppo's multiracial ancestry because of the historical realities, specifically many accurate references to the tribal societies of the Iroquois Confederacy, which pervade Cooper's works, particularly The Last of the Mohicans. Correctly disapproving of academics' longstanding ignorance of and carelessness about American Indian cultures, Mann argues that a concentration on Cooper's European sources has precluded necessary attention to his sources in indigenous America, which make many parts of the novel, such as Cooper's portrayal of intertribal conflicts and Native leadership systems, in addition to his characterization of Magua as well as Bumppo, much more significant in the development of a uniquely American literature. Rejecting the views of Tompkins and Slotkin, who depict the novel as simply a call for the regeneration of white culture by an ineffectual and unsophisticated adventure writer, Mann draws upon these overlooked but compelling considerations in her conclusion that "For my part, I believe 
Cooper knew exactly what he was doing" (56).

Mann's evidence for Hawkeye's part-Indian ancestry is chiefly based in Cooper's consultation of the writings of the eighteenth-century missionary to the Woodland Indians of the Northeast, John Heckewelder. According to Mann, "Antebellum readers, itching to scandalize their own prurience, . . . knew the code. . . . the very mention of 'Moravians'especially of any still out in the bush-screamed 'naughty sex' to American readers.... Moravian missionaries were known to marry Indians and recognize their cross-blooded offspring" (50). Additionally, Mann explains that the Mohican group of the Delawares, after being forced to give up their mid-Atlantic homelands, were pushed into the areas of the nations of the Iroquois Confederacy, their traditional enemies. One group of these Mohican/Delawares, known as "Moravian" Delaware, mistakenly thinking that Moravian missionaries were offering the adoption and full protection of white society in addition to Christianity, returned to the mid-Atlantic with the missionaries and unsuccessfully attempted to secede from the Iroquois Confederacy (55). Bumppo's division from the white world and affiliation with Uncas and Chingachgook may thereby have roots in the historical amalgamation of peoples in the Northeast.

Although Mann's call for greater awareness of the historical sources that illumine Cooper's portrayal of American Indians is wholly appropriate, one can probe her assessment further by unveiling the clues to Bumppo's heritage that are observable in the text itself. Most obviously, Bumppo's tiresome reminders of his white purity suggest that he is protesting too much. Further, Cooper's description of Bumppo's appearance contradict the character's evaluation of himself as of the same background as Gamut and Heyward. The novel's epigraph is crucial to this portrayal: "Mislike me not for my complexion, The 
shadowed livery of the burnished sun." While some may conclude that this line refers to Cooper's American Indians, it is instead most analogous to Bumppo's appearance. In comparing Bumppo to Chingachgook, Cooper writes: "While one of these loiterers showed the red skin and wild accouterments of a native of the woods, the other exhibited, through the mask of his rude and nearly savage equipments, the brighter though sunburnt and long-faded complexion of one who might claim descent from a European parentage" (32, italics mine). Notably, Cooper avoids calling Bumppo "white"; instead, the scout looks like one who may claim descent from Europeans. Such a formulation leaves room for Indians among Bumppo's ancestors.

Reading Bumppo this way, as an Indian-white cross-blood, makes his behavior at various points in the novel, including his efforts to establish legitimacy among a duality of peoples, more logical. In particular, his decision not to go for Alice, as well as his regretful headshaking after Heyward departs to propose to her, are solidly based in colonial law as well as the taboos of American society. In this way, rather than viewing Bumppo as a "moral hermaphrodite of the wilderness" (2), according to Balzac's formulation, it is more accurate to understand the character as outlawed from cultivating a relationship with a white woman like Alice as well as hesitant to pursue an Indian or African American woman because of his desire not to blow his cover as a "purely white" man. As Mann reminds us, "A self-hater, as any Indian Natty must be, would eschew marriage with an Indian while avoiding sexual relations with white women-a lynching offense for a slave or an Indian at the time. An Indian Hawk-eye lived and died alone simply because the risks of romance outweighed the benefits" (53).

Bumppo's responses to the events at the end of the novel also resonate anew in light of his 
portrayal as a "cross-blood." When the Delaware girls sing of the promise of Cora's and Uncas's union, the scout again shakes his head, "like one who knew the error of their simple creed" (407). Likewise, when Munro instructs Bumppo to communicate to the Delaware girls his belief that "the times shall not be distant when we may assemble around this throne without the distinction of sex, or rank, or color," Bumppo replies, "To tell them this would be to tell them that the snows come not in the winter, or that the sun shines fiercest when the trees are stripped of their leaves" (411). Although Tompkins and Fiedler conclude that Bumppo's responses indicate his horror of miscegenation, in fact they highlight his all-toopersonal understanding of the implications of this miscegenation for one such as himself. For Bumppo, the creed itself is not the error; it is the simplicity of that creed that is problematic. Since they are dead, Cora and Uncas, and more importantly, their progeny, no longer have to face the prospect of rearing multiracial progeny in a world apart from the transcultural zone they have inhabited over the course of the novel. Bumppo has indeed struggled with this multiraciality himself, and like Cora, he has gone to great lengths to prevent it from being exposed.

Finally, however, standing beside Chingachgook at the grave of Uncas, Bumppo seems to modify his attempts to distance himself from Indian blood lineage and finally approaches acceptance of both aspects of his identity. As Chingachgook decries his solitary existence without Uncas, Bumppo reassures him. "Gazing with a yearning look at the rigid features of his friend, with something like his own self-command, but whose philosophy could endure no longer," Bumppo implores:

No, Sagamore, not alone. The gifts of our colors may be different, but God has so placed us as to journey in the same path. I have no kind, and I may also say, like you, no people. He was your son, and a redskin by nature; and it may be that your blood 
was nearer-but if I ever forget the lad who has so often fought at my side in war, and slept at my side in peace, may He who made us all, whatever may be our color or our gifts, forget me! The boy has left us for a time; but, Sagamore, you are not alone. (414)

More than a pledge of friendship, this passage is Bumppo's revelation that though Chingachgook, as a full-blood, possesses "blood" that is "nearer" to Uncas's, he himself also at least partially embodies a shared Indian heritage. As the only "mixed-blood" around, he has "no kind," but Bumppo nevertheless finally owns up to his closer connection to the Mohicans. Thus, the process of transculturalization that has led other characters to change, however modestly, their rigid conceptions of their racial or cultural identities within a narrative that forces hybridity or "collision," has also impelled Bumppo to re-characterize his own identity.

Cooper's Leatherstocking novels will never be the authority on American Indians of the eighteenth century or their contact with other peoples in the formative years of the United States. For accuracy and relevancy in understanding the experiences of America's indigenous peoples during earlier centuries, it is imperative that students and scholars turn their attention to the early writings of American Indians themselves², such as Samson Occum, William Apess, John Rollin Ridge, Sarah Winnemucca, Charles Alexander Eastman, and Elias Boudinot, in addition to the works of figures such as Heckewelder. However, if The Last of the Mohicans is removed from the American literary "canon" (however it is formulated) and by all accounts it currently has been removed - scholars risk excising American Indians from the literary imagination of early America, especially because although there are many significant biographical and non-fictional American Indian writings that pre-date the

\footnotetext{
${ }^{2}$ Timothy B. Powell's Ruthless Democracy: A Multicultural Interpretation of the American Renaissance (2000) endeavors to reconfigure the American Renaissance, including "canonical" writers, within a multicultural context.
} 
twentieth century, there are few corresponding works of fiction.

A troubling tendency among scholars who neglect Cooper on the basis of his apparent racism or poor approximation of American Indians is that rather than actually learning more about the American Indians his characters are based upon, including becoming better educated about individual tribes or reading more American Indian writings, many literary critics instead turn their attention exclusively to Realists such as Henry James or the Transcendentalists, who, with notable exceptions such as Twain, for the most part focus on the meditations and concerns of white Americans struggling to measure up to or differentiate themselves from their European legacies. Thus it easier to disguise one's own view of the non-essential place of American Indian characters as Cooper's estimation than to do the hard work of becoming more knowledgeable. The literary "greats" whose place is etched in the canon are of course crucial to thorough study of American literature, but they obviously do not tell the whole story of a nation built on the convergence of unique cultures, the story that is key to understanding our country, the story that Cooper incompletely but dramatically conveys.

Studying Cooper is thereby an important part of coming to terms with a conception of literature as a heterodox, as Arnold Krupat suggests, an exemplification of cultures in contact, of writers answering, contradicting, and responding to the impacts of cultural convergence. This understanding of literature delineates Cooper as a source for Faulkner, who also wrote within yet challenged the black-white binary that drove Southern society, as well as for later African American and American Indian writers, including Toni Morrison, Alice Walker, Thomas King, Michael Dorris, and Louise Erdrich, who often refer to and counteract the conventions of Cooper's literary American Indians in contact with an over- 
arching American synthesis. Overall, Cooper's controversial conclusions about integration, land and ecology, and human identity reinforce his place in American literature. 


\section{CHAPTER III: \\ LEGACY OF "DOOM" ON THE CROSSROADS OF WILLIAM FAULKNER'S YOKNAPATAWPHA}

Much like James Fenimore Cooper, William Faulkner sought to reflect a sensibility that was uniquely American — or indigenous - and evocative of a longstanding heritage outside of exclusively European models. At the urging of Sherwood Anderson, Faulkner turned to the Mississippi landscape for inspiration, drawing on what Anderson called his "postage stamp of native soil" to create the fictional Yoknapatawpha County. In several of his stories and novels, Faulkner links the environment with the Native component of the community he portrays, addressing the human considerations that accompany greater industrialization and modernization and suggesting that Mississippi benefited from an ancient, home-grown civilization. As a result, Faulkner envisions Yoknapatawpha as a microcosm of sorts, wherein the realities of a geographical frontier echo the processes of diverse cultures in contact, where the fate of society can be measured to a large degree by the evolution of American Indians in a rapidly changing world.

Mississippi's rich history, which fascinated Faulkner throughout his life, is permeated by the legacies of many tribes, including Natchez, Biloxi, Pascagoula, Choctaw, and Chickasaw. The historical sources for the transculturalization that Faulkner depicts, especially the contact between American Indians and African Americans, grow from U.S. policies related to westward expansion, including those reflecting the purposes of containment and relocation of Indian tribes. These policies increasingly came to bear on the Mississippi tribes, and as a 
result, white settlers and enslaved African Americans came in close contact with Indians already present in the state. This collision of cultures produced complex conflicts over land ownership, slaveholding practices, and ways of commerce. In particular, the Chickasaw tribe, which by 1830 was concentrated in northwest Alabama and northern Mississippi, where Faulkner would later reside, experienced the late eighteenth and early nineteenth centuries as an era of legal and cultural conflicts within the tribe as well as with the United States and Mississippi governments, culminating in the tribe's removal to southeast Oklahoma in the late 1830s.

The Chickasaws' turmoil in Mississippi began in part with a 1801 treaty with the U.S. government, which committed the tribe to allowing a wagon road to be constructed on the Natchez Trace, a footpath that extended to New Orleans and had long been used by the tribe for trading and hunting purposes (Gibson, 148-9). The road, which the Chickasaws pledged would be open at all times to all people of the U.S., became the most heavily traveled road in what was at the time the southwestern U.S. as well as a favorite route for important figures such as George Washington and Meriwether Lewis. With the opening of the Trace, many more settlers had greater access to the natural resources of the area as well as to a wealth of goods available from the port at New Orleans. Likewise, Christian missionaries had greater access to the Chickasaw people, whom they sought to convert. But newcomers to the region were not the only ones who profited; at least in the short term, many Chickasaws also found the situation to be advantageous. The tribe greatly benefited in monetary terms from the large influx of travelers who were in need of provisions as they made their arduous trips along the Trace. Yet coupled with the tribe's expanding wealth was greater access to the alcohol that whites often used as payment for goods, and this alcohol became a critical factor 
in the tribe's declining ability to resist outside pressure to cede its lands to the U.S. government.

Whites and their slaves rapidly infiltrated Mississippi, and their growing power and influence led to Mississippi's entrance into the United States in 1817. By 1829, the state government had voted to extend its laws over Indian lands, joining them into organized counties, and by 1830, all Indians were deemed citizens of Mississippi, forbidden to hold any tribal office (Debo, Still 4). In 1830, the Choctaws, traditional rivals to the Chickasaws, entered into the Treaty of Dancing Rabbit Creek, in which they gave up their lands in Mississippi in exchange for land in Indian Territory (presently eastern Oklahoma) (Debo, Rise 69). The treaty allowed for any Choctaw to remain in Mississippi and become a U.S. citizen with a land allotment, but in actuality, these remaining Choctaws never received individual allotments and were instead crowded onto small, remote land districts in east central Mississippi ${ }^{3}$ (Debo, Still 42). Seeking to avoid the kind of fraud of which the Choctaws found themselves victims, Chickasaw leaders struggled to resist mounting pressure from the United States and hold on to tribal lands for as long as possible. Yet the Chickasaws increasingly saw alcohol plaguing their people, squatters illegally infiltrating their lands, and criminals stealing from them without any prosecution by the Mississippi government. Sensing that their options were either to leave or be destroyed, the Chickasaws entered into removal negotiations.

In 1832, Chickasaw leaders signed the Treaty of Pontotoc, in which they surrendered all of their land in Mississippi, a mass that totaled about 6,422,400 acres (Gibson 179). After searching in Missouri, Arkansas, Indian Territory, and Texas for land comparable to the land

\footnotetext{
${ }^{3}$ The descendants of these Choctaws who resisted federal removal are now known as the "Mississippi Band" of Choctaws and are a federally recognized, sovereign tribe in east central Mississippi.
} 
they were giving up in Mississippi and thereby suitable for the tribe's relocation, the Chickasaws concluded that there was no such suitable land available to them. As the years went by, there was less and less land available for relocation in these western lands, and finally the Chickasaws reluctantly accepted relocation to land within the Choctaw allotment in Indian Territory. In 1837, this agreement was solidified in the Treaty of Doaksville, and the Chickasaws began their removal period, their own "Trail of Tears." From that time until 1850, approximately 4,914 Chickasaw families and their 1,156 slaves made the difficult journey across Arkansas and into the Choctaw area, eventually regaining a vital tribal and cultural unity outside of Mississippi.

The Chickasaw experience in Mississippi may on the surface seem distant from Faulkner's own experience growing up in the northern part of the state almost a century later. However, even after the passage of many years, Faulkner was intrigued from a young age by the legacies of Mississippi’s American Indians. Faulkner's seventh grade teacher, Ella Wright, specialized in Mississippi history and taught about the Indians' role in the history of Oxford (Blotner 136-7), a role that is observable in the Chickasaw mounds remaining in the area and the Chickasaw names for its landmarks, such as the Yocona River, ${ }^{4}$ which is the source for the name of Faulkner's fictional county (73). Additionally, the land on which Faulkner's Oxford home, Rowan Oak, rests was ceded by a Chickasaw named E-Ah-Nah-Yea (651). Indeed, from the time he was young, Faulkner perceived Indian legacies as identifiable in geographical sites.

Faulkner's exposure to American Indian legacies was further reinforced in his friendships

\footnotetext{
${ }^{4}$ Arthur Kinney notes that although the word "Yoknapatawpha" frequently is defined as "water runs slow through flat land," according to a 1915 Choctaw dictionary, the word can be more literally translated as "plowed or cultivated land, or district," which is appropriate considering Faulkner's attention to the implications of Indians' adoption of farming.
} 
as a young adult. Faulkner often visited his dear friend Phil Stone and his brother Jack in Panola County, part of the Mississippi Delta. Faulkner was fascinated with Indian lore and grew to love the area for its dense forests, which seemed to him to represent Indian culture. He was particularly enthralled by the story of Jack's sickly infancy, when Indians helped to get him well enough to hunt by feeding him "bear gravy" (234-5). Another of Faulkner's friends, Dot Wilcox, was a Cherokee from McAlester, Oklahoma, who sold some of her land allotment and moved to Mississippi to become a beautician (235-8). Faulkner particularly took an interest in Dot's heritage, telling her, "I could write a book about your life" (qtd. 293).

Faulkner intended to create just such a "Golden Book" of Yoknapatawpha, which would outline the county's origins in American Indian societies. As Patricia Galloway notes, it is likely that Faulkner's formulation of the county's roots was based in the scholarship of John R. Swanton and his correspondent Calvin S. Brown, who had ties to the University of Mississippi during Faulkner's brief tenure there (11). The idea came about in 1945 when Malcolm Cowley proposed a Viking Portable Library volume to collect some of Faulkner's work and get it into print again (Blotner 1187). Faulkner planned to collect several Indian stories that he had already written and to include some new ones, ultimately tracing the history of Jefferson, the town based on Oxford in his works, back through the history of the Indians who lived there originally (1187).

Faulkner's idea never came to fruition in the form he originally conceived it, but the referents for his Golden Book idea nevertheless survive in stories about Mississippi's earliest inhabitants, which appear in parts of novels as well as in short stories published in journals and serials. In these works, "Lo!” (1934), “A Mountain Victory” (1932), “A Courtship" 
(1948), "Red Leaves" (1930), “A Justice" (1931), Go Down, Moses (1942), the appendix to The Sound and the Fury (1946), and Requiem for a Nun (1951), Faulkner reveals Indians' importance to his conceptions of his Mississippi world and its history. While his depictions of Indians cannot be understood as historically accurate, Faulkner creates Indian characters who are nonetheless a bit more complicated than transparent Noble Savages. As Robert Woods Sayre notes, "a significant amount of 'Noble Savage' and romantic literature was produced by writers with considerable knowledge of Indians, gained at first as well as second hand" (35). Thus, in light of the writer's fascination with the Choctaws and Chickasaws of his area, Faulkner's Indian stories can be read neither as completely made-up fantasies nor as historically accurate representatives of Mississippi history.

Faulkner's inspiration seems to lie in grounding his own place in a troubled Mississippi history and establishing himself as a unique part of a distinctly American literary tradition. In this way, simply dismissing the Indians of Yoknapatawpha as Noble Savages that fit a familiar pattern of justifying and romanticizing settlement of the American frontier does not quite render a complete understanding of how Indian people function in the fictional world Faulkner creates, or more importantly, how they function in his own authorial identity. After all, the modernization of Mississippi society, which coincided with the decimation of wilderness areas and the removal of most local tribes to Oklahoma, is a reality that Faulkner displays as mostly negative in his fiction, and despite his missteps in describing those tribes, his focus on the intersections of various peoples in a specific geographical space goes to the heart of an American experience that exceeds typical categorizations of Orient versus Occident. Ultimately, Faulkner's stories illuminate a broader reality in American literature, that of diverse cultures in contact on the American frontier, a theme in which boundaries 
among races, as well as between nature and civilization, become blurred.

Many critics, including Galloway, take issue with Faulkner's Indians because they are not modeled on actual people that Faulkner knew:

... his Indians are constructions, stage properties, not modified portraits of real individuals or individual types whom he knew personally and cared for, as was the case with many of his white and black characters. In Faulkner's Mississippi there were very few identifiable Indians, and his approach to portraying them was an amalgam of received stereotypes and modernist orientalism. (13)

Galloway overlooks Faulkner's relationships not only with Dot Halter, but also with people such as the man who worked with his father, on whom the character Boon Hogganbeck is based; and the storytelling blacksmith on his grandfather's farm, on whom Sam Fathers is based (Dabney 23). However, Galloway is correct in pinpointing Faulkner's detachment from Indian communities, despite his very basic knowledge of their histories in Mississippi.

Still, one wonders if it is possible to create any fictional characters who are not constructions, and further, if it can be taken for granted that Faulkner somehow genuinely comprehended the experiences of African Americans, even those whom he cared for, such as Callie Barr, and that therefore he drew them in a way that did not reflect stereotypes.

Thadious Davis, for one, in Faulkner's 'Negro' (1983), focuses her critical attention to Faulkner's construction of the Negro as a "central imaginative force" in his fiction (2), in which his "southern world is divided into two parts, one white and the other black" (4). Equally important is Galloway's use of the word "identifiable" to specify the kinds of Indians that may be considered "real." Why is it compulsory for Indian characters to express a kind of authenticity that is not demanded of characters of other backgrounds? Are Indians only "real" if they are recognized as such by white people? Is Sam Fathers any less a "real" Indian than Joe Christmas is a "real" African American? These questions bring to light the way in 
which scholars may internalize the very conventions that they dispute as well as indicate the degree to which historical racial categorizations continue to permeate the psyches of American readers even in a multicultural and ever more politically correct world.

Because of the complexity of evaluating Indian characters in the works of such white authors as Faulkner, Gene Moore has stressed, "In their mixture of the exotic, the grotesque, and the all too human, Faulkner's 'Indians' remain a troubling presence in his work" (Introduction 3). Philip Deloria's discussion of the Noble Savage convention in Playing Indian (1998) goes to the crux of this complexity and highlights the role that Indians play in American identity, beyond immediate questions surrounding conquest of the frontier and exoticism of the "Other." To this end, Deloria invokes D.H. Lawrence's writings about American identity, in which Lawrence names Indian people as the "very heart of American ambivalence" (3) yet in Deloria's eyes "struggl[es] to articulate something more" (4).

Deloria brings this need for further articulation to fruition by invoking a parallel to studies of blackness. Deloria argues for inclusion of American Indians in literary conversations about race that focus on black-white binaries, such as Davis's characterization of Faulkner's "Negro" or Toni Morrison's delineation of American Africanism in Playing in the Dark (1992). Deloria writes:

Blackness, in a range of cultural guises, has been an essential precondition for American whiteness, and it has taken material shape in literature, minstrel shows, class and gender relations, political struggles, and spatial geographies. ... the figure of the 'Indian' holds an equally critical position in American culture. (5)

Robert Dale Parker highlights this connection between Indianness and American culture in Faulkner's works: “Faulkner's Indian stories, therefore, shore up his and his readers'whatever their race — sense of whiteness, and more particularly, of white masculinity" (89). 
Yet importantly, Parker's and Davis's studies of Faulkner's fiction attend either to Indianness or blackness and not to the convergence of the two. Davis's most recent text, Games of Property (2003), for instance, is a revealing study of the intersections of race, law, and sexuality in Go Down, Moses, but her text only briefly mentions Chickasaws' "vexed relation to land and to slaves in Mississippi" (35) as part of her analysis of ownership and property. The task of probing Faulkner's depictions of race must thereby now become three-pronged. As Moore elucidates, “Faulkner's Native Americans reveal their potential as a disruptive third force that can serve to mediate or complicate the conventional racial alternatives of black or white" (Introduction 5).

Thus, though Faulkner mixes the imaginary with the factual to create a Lafayette County epic, mirroring Said's description of Western moldings of the Orient or Other into a mastery of human history (2-3), he also complicates racial polarization through themes of miscegenation and cross-cultural exchange. The author thereby demonstrates Deloria's connection of Indianness to whiteness and blackness and points toward a plurality—or hybridity—that problematizes accepted binaries of Occident/Orient, or white/black. As in analysis of Cooper's fiction, the work of Monica Kaup and Debra Rosenthal, which calls for greater recognition of the realities of hybrid crossing in American literature, sheds light on the need for a fresh approach to the complexities of racial convergence, which may specifically apply to the convergence of African Americans, American Indians, and Euroamericans, in Faulkner's stories. As Kaup and Rosenthal remind us, describing whites' connection to Indians as mere appropriation neglects the process of cultural exchange (xiv), the kind that typifies the unstable borders of Faulkner's literature as well as of his times. Significantly, the implications of these unstable borders are clear in the state of the 
environment, specifically in the manipulation of the land, which binds Native and soil together in Faulkner's postage stamp.

The process of cultural exchange that unites American Indian, African American, and Euroamerican in the Yoknapatawpha landscape is spurred by the historical basis of the participation of each of these groups, in varying capacities, in a common economy, which in turn accompanies the deterioration, or "deciduation," of wilderness areas and the Indian people who inhabit them. As Don Doyle states, Mississippi Indians, especially mixed-blood Chickasaws such as the Colberts, were quite successful commercially and adapted well to the cotton trade, expressing a proclivity for the acquisition of capital:

Very rapidly the hunting and gathering economy of the Chickasaws gave way to an agricultural economy of corn and cotton. ... As trade with the white world increased, the Indians shed their breechcloths, leather garments, leggings and moccasins for calico dresses, shirts, shoes, and hats, and a variety of adornments of European finery, much of it imported to the Mississippi frontier along the Natchez Trace. ("Mississippi” 151)

Arrell Gibson cites the Natchez Trace as the source for considerable tribal enterprises: "[Chickasaws] operated ferries on the rivers, and kept the public inns (called stands) which provided lodging, food, refreshment, and entertainment for travelers" (149). Drawing on John Hathorn's study of population groups in Lafayette County, Doyle also describes the way in which this economy drew black, white, and red together in the area: "By 1840 the newly-formed county had drawn nearly 3,700 white people; . . There were another 2,800 black slaves in the county by this time -44 percent of the over 6,500 total population. . . Almost overnight, a former wilderness of Indian hunting grounds had been turned into a plantation economy based on slave labor" (157). It is clear that Mississippi's Indians hardly remained isolated in an Edenic setting. 
Daniel Usner highlights the reciprocal interaction that accompanied the entry of newcomers into Indian communities: "many of these newcomers, who are usually cast by historians in a one-dimensional shove against Indians, relied on economic exchange with Indians or on other economic activities resembling Indian livelihood" (298). Not only did whites and Indians adapt to one another's livelihoods, but also African Americans, most of whom were enslaved but some of whom were employed in Indian commerce or construction facilities, acquired a facility with Indian languages in addition to English (306). Daniel Littlefield further explains this cultural transfer: "By the time of removal, some families of blacks had been among the Chickasaws for generations. They knew no other language or culture. They had learned the Indian mode of agriculture and had adopted the Indians' diet, medicine, and dress" (Chickasaw 24). As pressure to further "settle" Mississippi increased, Thomas Jefferson developed an effective scheme for acquiring Chickasaw land, which involved extending large amounts of credit to the tribe, drawing it into debt, and taking land cessions from it as payment, ultimately shrinking the Chickasaws' geographical base and culminating in their removal to Oklahoma (Usner 301). Thus, though Noel Polk believes that the Faulknerian Indian's undoing was that "he could not adapt to the white man's world" (Rev. 391), the Chickasaws' success at capitalism, for which they were deemed one of the "Five Civilized Tribes," was largely responsible for their vigorous efforts to resist removal and for the state of Mississippi's eagerness to send them packing.

Indians', whites', and African Americans' adoptions of each other's ways, and in particular, the mixing of these diverse peoples in northern Mississippi, are key to Faulkner's characterization of the history of Yoknapatawpha, a history that is traced through ecology. As Arthur Kinney argues, "Faulkner is concerned not only with slavery but with slavery's 
legacy of miscegenation. ... The very word 'mulatto' mirrors the antebellum association of slaves with animals, for it has a shared etymology with "mule"” ("Introduction" 12). While much critical attention has been paid to Faulkner's concentration on the affiliation and amalgamation of American Indians with African Americans, it is also important to consider his portrayal of white participation in this mixture and the role that this participation plays in determining the fates of the county's original inhabitants. One character who displays the influences of both European and Indian cultures is Frances Weddel, who is based to some extent on Greenwood LeFlore, the notable Choctaw chief. R. Halliburton has written extensively of LeFlore's acculturation with white society, remarking on his occupations as planter, slave owner, Union loyalist, and admirer of Napoleon and Josephine Bonaparte, who possessed a large plantation estate and manor house (named "Malmaison" after a chateau on the Seine where Josephine lived) (59). Two stories that feature Weddel, "Lo!” and “A Mountain Victory," seem to draw directly from LeFlore's experiences, though Weddel is Chickasaw in the former and Choctaw in the latter.

In "Lo!," Faulkner's only story that alludes explicitly to the political dimensions of whites' infiltration into American Indian spaces, environmental and cultural instability accompany "settlement" of the frontier. "Lo!," which was likely inspired by a trip that LeFlore once made to Washington for a conference with Andrew Jackson, has its basis in history, and is dotted with humor and wit, drawing upon the conventions of the popular fiction of Faulkner's day. Galloway points toward the significance of the "Mr. Lo" standard in writings at the turn of the century. These writings, which deal with the complex issues surrounding Indian wars, Removal, and containment (26-8), ${ }^{5}$ recollect the opening verses of Alexander

\footnotetext{
5 Parker correctly emphasizes the importance of Choctaws' and Chickasaws' own writings about Removal, including contemporary Choctaw authors Jim Barnes and Louis Owens and Chickasaw writer Linda Hogan, as
} 
Pope's Essay on Man: “Lo! The poor Indian, whose untutor'd mind / Sees God in clouds, or hears him in the wind" (qtd. 25). According to Galloway, "Lo!" can be read as a variation of the frontier tall tale, and "can be seen as a heavily ironic and explicit response to a particular formulation of the notion, popular in Faulkner's youth, that Indians were doomed to pass from the earth" (24-5). Importantly, Faulkner's depiction of Indians' confrontation of the U.S. government poses a course of history that deviates from accepted views of the inevitability of Indians' disappearance; it suggests that things could have turned out differently. As Moore notes, 'Perhaps 'Lo!' can also be understood as an extreme instance of Faulkner's technique of artistic reversal" ("Chronological” 65).

In the story, the meeting of the U.S. President and Weddel illustrates Kaup's and Rosenthal's discussion of a cultural exchange beyond appropriation because it presents Indians' challenge to the President's authority. This challenge is demonstrated chiefly in their peaceful invasion, for all practical purposes, of the White House and the geographical space that is the seat of U.S. power, which is in effect a reversal of East-to-West removal. The confrontation — and fluidity—of the borders between Indian and white are evident in ecological images, which mix what is natural and what is man-made. The encampments outside signify Indians' existence in a natural sphere outside of the pristine White House, but the window which draws the President's worried gaze away from his elegant French hand mirror and directly toward the falling snow outside indicates that nature will infiltrate that seat of "civilization." While the President represents the height of white male masculinity and dominance, he here appears almost exclusively in the interior of home, and the mixture of "Mongol" and civilization in his opponent is much the source of his anxiety as the sanctity response to Pope in his poem "Lo! The Poor Indian's Hope" (87). 
of his White House is disturbed. Significantly, though many have likened Faulkner's Indians to the childlike savages of Rousseau's imagining, it is the President who becomes insecure and childlike in this story, and the effeminacy that all but guarantees the Indians' disappearance in the Noble Savage model is ironically what allows them the upper hand - at least temporarily—in Faulkner's world.

Evidence of this reversal is present as the President peers ever-so-slightly out his door, where a bone, still containing flesh and the marks of human teeth, lies upon the carpet's rich pile. Looking to his own visage in his mirror, the President discerns not an infamous colonial warrior, but instead a confused child, an image which contrasts sharply with the notorious Indian "Face. . . a little Mongol; secret, decorous, impenetrable, and grave" (5), that he has been dreaming about for three weeks and that confronts him just outside his door. Indeed, Weddel and his companions are formidable figures for the President, seeming, in their frock coats and beaver hats, to come out of Pickwickian England, and at the same time appearing marked by nature, shunning boots, appearing in "dark, naked feet" (6). Similar to the transculturalization that the Indians display, the President embodies a whiteness that, although as invasive as the snow that falls on the tent-shaped mounds outside, is threatened despite its resoluteness. Confused by his legal status as father rather than enemy of the tribes, and destabilized by the Indians' invasion of the domestic realm of the White House, with which he is "ubiquitous and one" (7), the President cannot remain lord of his domestic scene. His status is clearly disrupted not only as he adopts a disguise in his own home, pulling his hat over his face, donning a large cloak, and tiptoeing barefoot in order to escape by the back stairs, but also as Weddel enters his bedroom in "dingy lace" and offers to him what appears to be a costume of "gold braid — frogs, epaulets, sash and sword—held loosely together by a 
bright green cloth" (11-12). Ultimately, this famous Indian fighter is rendered baffled and somewhat helpless through nonviolent dress-up.

Parker provides an apt discussion of the gender and sexual dimensions of the border collapse that takes place between Weddel and the President, also commenting on its connection to racial amalgamation. Highlighting the importance of Weddel's "soft" appearance, which includes "café-au-lait colored jowls" (15) and a full, red mouth, he argues:

Weddel gets everything he wants from Jackson, usurping the whites' leader in his own house, the figurative home of the nation. ... Jackson is afraid of but attracted to Weddel's French effeminacy. . . Jackson's problem with Weddel is not simply that he is effeminate, but that his effeminacy is café-au-lait. His mixed blood and genderbending suggest illicit sexuality and boundary breaking. A story about removal, racial conflict, and illicit sexuality has everything to do with boundaries, for Weddel will not keep to his supposed place. (92-3)

As Parker explains, a nineteenth-century obsession with justifying and owning the collective history of American conquest is not at work here; as Faulkner himself said, "I think the ghost of that ravishment lingers in the land, that the land is inimical to the white man because of the unjust way in which it was taken" (Gwynn and Blotner 43). In the words of Elmo Howell, “in dramatizing the Indians' tragedy, [Faulkner] did not fall into the kind of easy generalization that was common in the nineteenth century. His Indians owe nothing to Rousseau and the concept of the Noble Savage" (256).

A further basis for more careful analysis of Faulkner's Indians is their clever, almost trickster-like behavior throughout "Lo!." Behind Weddel's feminine appearance, the President observes something "willful, shrewd, unpredictable, and despotic" (15), indicating that this figure of considerable stature will not be easily controlled. Further, when the President inquires of the Chickasaw leader's correct name, unsure whether he should refer to him as "Weddel" or "Vidal" in the document exonerating his nephew of murder, Weddel 
resists: "Weddel or Vidal. What does it matter by what name the White Chief calls us? We are but Indians: remembered yesterday and forgotten tomorrow" (16). Exhibiting his knowledge of the transparency of white gestures toward Indians, Weddel disallows the President's naming him, reflecting the significance of naming in American Indian communities. Likewise, at the beginning of the story, when Weddel and his companion are discussing tactics for relating to the U.S. government, Weddel reveals his savvy: "You don't understand white people. They are like children: you have to handle them careful because you never know what they are going to do next. ... we'll have to try to act like these people believe that Indians ought to act" (6-7).

Finally, and perhaps most importantly, Weddel uses these tactics to achieve his true aim in his visit to Washington: to secure a government-to-government agreement, which maintains tribal sovereignty and retains free access to the ford for the tribe. Knowing that the ceremony to proclaim the nephew's innocence has been a ruse, invented in language taken from Petrarch's sonnets, at the end of the story, Weddel sends a letter to Washington that uses the threat of another Indian occupation of Washington to get what he has really wanted all along. Exasperated, the President makes another proclamation that assigns the ford to the Indians in perpetuity in exchange for their agreement to remain in Mississippi, which, after all, is the homeland they wish to protect, Weddel's companion having said of Washington: "I wouldn't have this town if they gave it to me" (6). Thus, Weddel exhibits considerable skills as a formidable opponent to his white "father," thwarting a white man's attempt to create a tollgate across a river that truly can be owned by no one.

Despite the story of Indian success in "Lo!," at the end of the story, the President attempts to re-secure a boundary between the U.S. and American Indians, which promises to allay his 
discomfort with the hybrid crossing that has occurred during the Indians' visit and seems to suggest the coming of actual events that led to most Chickasaws' and Choctaws' removals from Mississippi. In this way, Faulkner's "artistic reversal" does not discount the fact of Indian dispossession that cannot be ignored in his stories or in American history. However, even in light of this outcome, the borders between the two peoples have still retained fluidity, as "official" agreements and treaties have been disregarded over and over throughout the history of U.S.-tribal relations. In the words of Parker, “. . the irony is that the whites who so insisted that Indians establish boundaries would then ignore every agreement about boundaries that they forced on Indians" (93). Ultimately, "Lo!" asserts the political confrontations and cultural reciprocity that have distinguished the confluence of peoples in America, offering a portrait of fluid boundaries that is an alternative to rigid conventions of the nineteenth-century Romantic tradition.

Like "Lo!," "A Mountain Victory" portrays a meeting of white, red, and black in a wilderness episode that takes on cultural as well as political and social dimensions. Saucier's occupation as an officer in the Confederate army (despite Greenwood Leflore's allegiance to the Union cause) suggests the Southern tribes' overwhelming commitments to the Confederacy. As Gibson observes, “Some writers account for the Southern tribes' alliance with the Confederacy by pointing to blood ties. For example, in the case of the Chickasaws, most mixed bloods were related to Southern white families" (259). Angie Debo describes the same phenomenon among Choctaws: "There were many reasons why they should have felt that their fortunes lay with the South. Their laws supported slavery, and a few of them were large slave owners" (80). Indian stories should therefore not be read in isolation from the rest of the Faulkner canon, as the actions of Weddel and Ikkemotubbe (later "Doom") share a 
kinship with Faulkner's other legendary, power-wielding characters, such as Sutpen. This similarity is evident in Weddel's musings about Confederate defeat and its implications for his invented conception of his homestead, which resembles Sutpen's Hundred:

"Contalmaison. Our lives are summed up in sounds and made significant. That's why we must do so much to invent meanings for the sounds—-so damned much. .. It's nice to be whipped — quiet to be whipped. To be whipped and to lie under a broken roof, thinking of home" (42). Weddel's imaginings about defeat and its implications for the concept of home are bound to the zone of contact that is the setting for the story. Within and without Vatch's cabin, genders, races, and political allegiances collide, exhibiting the hybrid crossing that distinguishes much American literature.

While ostensibly the foremost point of contention between Weddel and Vatch is their opposing Civil War sympathies, in fact it is Weddel's multiplicitous heritage that is most troubling to Vatch, who refers to him as "You damn nigra" (7). Weddel comments on the irony of this antagonism: "So it's my face and not my cloak. ... And you fought four years to free us" (7). Importantly, though Weddel lives much like a white planter, he also claims, to some extent, African American identity by using the word "us." Not only is there irony in the conflict between Weddel and Vatch, but also the relationship between Jubal and Weddel highlights a cross-racial companionship that is unlikely between a Confederate major and an enslaved individual. Jubal, Weddel's "boy," exhibits disdain for "mountain trash" (7), a belief that Weddel belongs to him instead of the reverse, and a loyalty to Weddel's mother and to Contalmaison that, in light of Confederate defeat, has become moot. In a gesture of paternalism toward what he calls "an oppressed race burdened with freedom" (42), Weddel does not inform Jubal of the death of the mistress of Contalmaison, and the two characters 
display homosocial bonding that mirrors the relationship between Queequeg and Ishmael in Moby Dick. Their affiliation is evident as Weddel shares the beaver pelt lining of his coat with Jubal and in the face of danger, refuses to leave his friend, who has become too drunk to travel, with the hostile mountaineers. In the loft of a barn outside the cabin, Weddel and Jubal lie side by side in bed, and from this vantage point, Weddel rejects female companionship, which the mountain daughter has offered by sending her younger brother as messenger of her intentions. Throughout the story, Faulkner thus problematizes accepted distinctions and behaviors among artificially separate peoples, prompting readers to wonder: Is Vatch truly an abolitionist? Is Weddel, for all practical purposes, white, black, or Indian? How could Weddel fight in Jackson's army, considering Jackson's orchestration of Indian Removal? Are Weddel and Jubal master and servant or something more? In this isolated geographical space, some diverse characters come in contact and seek unexpected affiliation with one another while others display hostility that is not completely logical. This process of hybrid crossing illumines the limits of black-white binaries in approaching stories such as this.

By the end of "A Mountain Victory," the sense of instability that has characterized the tale comes to a head, as, in much the same way as "Lo!," white characters feel compelled to reinstate their separation from black and red. Though the young boy expresses hope for a brighter future that could result from marriage between Weddel and the abolitionist's daughter, he nonetheless seems to have been compelled to lead Jubal and Weddel into a trap, where, in the rugged landscape of rhododendrons and pines, Jubal, "like a cornered animal" (46), and Weddel meet their violent ends. Importantly, the reason the white Unionists kill the two seems to be a fear of miscegenation, and in particular, an inability to come to grips with 
the mixed heritage, outside of black-white polarity, that Weddel embodies. As Kinney explains,

... it appeared the abolitionist's daughter was attracted to Weddel despite his mixed ancestry and might leave with him. The reason the abolitionists kill the Confederate, then, is fear of miscegenation: a Confederate attitude, not the Unionist one to which they lay claim. ... Through the other other, Faulkner encodes the depravity of the white man and here of the Unionist sympathizer. . . In Faulkner, I would suggest, meaning resides not just in the white protagonist or the other, the African American, but also in the relatively untapped other other-the Indian. (“Faulkner's, 202)

Again, Faulkner seems to offer an "artistic reversal" here, a potential for an alternative history for race relations framed by the wilderness and enacted by characters who are likened to elements of nature. However, as Jubal and Weddel face choices as to which path they will take toward home, Faulkner imposes a realistic end for them. In this way, as does Cooper's novel, Faulkner's story rejects the inevitability of oppression and dispossession, instead portraying these historical realities as ensuing from whites' deliberate actions.

Faulkner's portrayal of the close association of Jubal and Weddel echoes the longstanding relationship between American Indians and African Americans that exists in American society to this day. According to Usner, "The influx of Afro-American slaves into the territory affected the economic life of Indians as deeply and equivocally as did white migration. ... Whether as slaves or as runaways, blacks ... contributed to the formation of multiracial families and even of scattered communities across the South" (309-10). As many critics, including Dabney have noted, Faulkner presents this cultural amalgamation in most of his Indian stories at least in part as a means of safely offering perspective on whites' wrongful perpetration of slavery. Critics should not discount the fact that Faulkner also used Indians to comment on Indians, particularly the results for their own communities of their 
participation in slaveholding as well as industrialization, yet these results are nonetheless tied to the fates of other Mississippi populations, particularly African Americans.

In his rendering of Indians acquiring slaves, operating and inhabiting steamboats, and eventually driving the highways in Cadillacs, Faulkner expresses Americans' ambiguous imaginings of Indians, blending expectations of Indian primitiveness with the realities of Indians' investments in "progress" and their lack of isolation from the broader tapestry of peoples that frame American society. Deloria thus pinpoints this ambivalence about Indians and modernization: "Symbolic systems surrounding Indians (nature, violence, primitivism, authenticity, indigeneity) and automobiles (speed, technological advance, independence, identity, progress) continue to evoke powerful points of both intersection and divergence" (Indians 141-2). He argues further, “... imagined Indians had to be protected from the contamination of the modern. That separation has driven expectations-even as it has proved impossible to sustain" (166). According to Parker, Faulkner's slaveholding Indians are also invested with traits that reflect anxieties associated with the collapse of rigid distinctions between white/male (power) and Other/female (powerless), as they are "relatively benign slave owners most of the time, yet occasionally ... murderous and cannibal” (83) and “... less dangerous, because feminized and effeminate, and at the same time more dangerous for the exact same reasons" (83).

The complexity with which Faulkner portrays modernization of Indians is apparent in his tracing of the evolution of Ikkemotubbe, a Chickasaw leader who achieves status as "The Man," into "du homme" or "Doom," a Europeanized despot. A prominent feature of the development of this character is the sense of nostalgia that accompanies stories about

\footnotetext{
${ }^{6}$ R. Halliburton Jr. writes that Greenwood Leflore changed his name from "Le Fleur" to "Leflore" and was called "as ambitious as Lucifer" during his rise to prominence among Choctaws (58).
} 
Ikkemotubbe's early days, "the old days," when "he was the best of them" (636). In "A Courtship," Ikkemotubbe is a young man, and his contact in the Mississippi wilderness with David Hogganbeck, a young white man, is idyllic, much like Cooper's portrayal of Chingachgook and Bumppo at the beginning of The Last of the Mohicans. The story, which is apparently part of an oral tradition told within the Chickasaw community as well as in collective Mississippi lore, describes the "old days" when Issetibbeha was chief, before Ikkemotubbe was Doom. At the time of the action, Jackson has imposed a boundary between the Chickasaws and the U.S., although as the narrator reveals, this boundary is somewhat artificial: "Issetibbeha and General Jackson met and burned sticks and signed a paper, and now a line ran through the woods, although you could not see it" (634). Issetibbeha has clearly begun the process of adopting white ways, as the Chickasaw area is now known as "The Plantation," and the boundary runs "straight as a bee's flight among the woods, with the Plantation on one side of it, where Issetibbeha was the Man, and America on the other side, where General Jackson was the Man" (634). Additionally, there are early signs of the infiltration of European finery, including the silver wine pitcher into which Herman Basket's sister shells peas and the harmonica that Log-in-the-Creek plays. Yet despite this acknowledgement of growing acculturation, this story suggests a time of relative harmony before Indians' adoption of large-scale slavery, when interaction and exchange between Indian and white seems to be mostly promising.

Reciprocity among whites and Indians is present as the steamboat, which the narrator likens to a racehorse, occasionally comes to the Chickasaw community for trading. During these visits, Captain Studenmare appears atop the vessel chewing tobacco, a staple of Indian culture, while Hogganbeck plays the fiddle and an enslaved African American boy operates 
the wheel. Though the trading is fervent throughout the day, Hogganbeck is most interested in dancing with the Indians and seems to consider remaining in their community permanently, neglecting to assist Studenmare and enslaved African Americans in their efforts to start the steamboat on its return trip to Natchez. Soon Hogganbeck becomes interested in Herman Basket's sister, to whom Ikkemotubbe is also attracted. The central focus of the story is thereby a wilderness trial between the two men, which has been settled on after much discussion of what is a fair and honorable test, and its purpose is to determine the rightful suitor for Herman Basket's sister.

The location in nature of the contest is appropriate considering its freedom from rigid distinctions of culture, which allows the development of a bond between the two men. As Otis Wheeler observes, "In Faulkner's treatment, the wilderness has two roles, apparently discrete, but eventually harmonized in a pattern that transcends human experience. First, it is the teacher of moral and spiritual truth; second, it is the victim of the Anglo-Saxon's rapacity" (127-8). Following Wheeler's first purpose, the wilderness here indicates the truth of universal friendship and brotherhood. Like in the other stories, the relationship between Ikkemotubbe and Callicoat exhibits a homosocial closeness with sexual overtones. Nature itself is somewhat feminine, and the impetus for the contest is the desire for a woman's affection. Accordingly, rather than a portrayal of naiveté versus sophistication, this friendship is one of more mutual insight, a shoring up of masculinity in the face of a threatening femininity. Like Jubal and Weddel, Callicoat and Ikkemotubbe share a bed, and during their foot race, they draw out each other's virility, listening to each other repeatedly "coming" and "falling." Finally, in an episode that has received much critical attention, the two enter a 
cave, with which vaginal association is unavoidable, ${ }^{7}$ and struggle to save each other from its crushing weight, with Hogganbeck finally inserting a pole into the opening and Ikkemotubbe pulling Hogganbeck to safety by grabbing him "by the meat" (650). Once the trial is over, the two discover that Herman Basket's sister has meanwhile married Log-in-the-Creek, and thereby the episode in nature has saved them from a domestic life. The rejection unites the two, and they share words of wisdom from wise men of their respective traditions, leading Hogganbeck to conclude, "Perhaps there is just one wisdom for all men, no matter who speaks it" (652).

Again, Faulkner seems here to be offering a portrait of mutual insight that is an alternative to the idea of Indians as destined to be conquered or whites as naturally the purveyors of conquest. However, as in his other stories, Faulkner hints at the reality that would sully this vision. At the end of the story, since Studenmare has taken enslaved laborers with him in his return to Natchez, the Indians, or the "People," must for the first time contribute to the functioning of the steamboat, a symbol of growing industrialization, by building the fire that will operate it. While in the beginning of the story, Hogganbeck was occupied solely with his fiddle as he approached land, by the end, as the People fuel the steamboat, he simply pulls the "crying rope" from time to time, aptly ringing out coming degradation. Significantly though, the steamboat passes the last bend and can no longer be heard in the area at all, indicating that the tribe, "in the old days," retains its cultural autonomy despite its appropriation of some European cultural ways. Nevertheless, Ikkemotubbe is soon on his way to New Orleans, from whence he will return with a new white friend, Chevalier Soeur Blonde de Vitry, whom no one in the tribe will love as much as Hogganbeck, and will begin

\footnotetext{
${ }^{7}$ In Playing Indian, Deloria discusses the pervasiveness of feminine images of the American landscape, which heighten its sense of availability and echoes a colonial belief in American Indian women's availability (53).
} 
his ascent to power as Doom. In a familiar pattern, Faulkner suggests a possibility for cultural exchange that is a glimmer of an alternative fate for the inhabitants of Yoknapatawpha, yet he also presents the forces that derail that potential. Chief among those forces is the imminence of a greater proliferation of slavery among Indian tribes, which will accompany greater commodification of the wilderness and emphasize the ambivalent results of "progress" in Yoknapatawpha.

"Red Leaves" portrays the tribe's greater investment in slavery after the return of Ikkemotubbe, an investment which transforms Chickasaw life as well as the relationships among Indians, whites, and African Americans. Like "Lo!," "Red Leaves" has some basis in local lore to which Faulkner was exposed in Oxford. According to Beverly Young Langford, the character Issetibbeha is similar to the actual Chief Tobba-tubby, who owned slaves, was buried with a treasure, and supposedly attempted to have a slave buried with him (22-3). Though the events of the story should not be taken as historically accurate, Faulkner seems to be figuring an American history here that is indigenous, bound to an intersection of peoples in a natural landscape, determined by crucial wrongs—enacted by whites and Indians- - that led to the degradation of that space. In this way, Yoknapatawphan history is not an account of romantic conquest of the frontier but is in effect a requiem for a by-gone era.

Some of the Indians of "Red Leaves" acknowledge the passing of better days for the tribe because of its adoption of slavery, yet these individuals' comments are not heeded by others in their community. Three Basket, ancestor of Sam Fathers, who wears an enameled snuffbox in his ear and emphasizes his rapport with those elders in the tribe who remember the old ways, speaks to his companion about the wrongs of slavery: "I do not like slavery. It is not the good way. In the old days, there was the good way. But not now" (6). Faulkner infuses 
the discussion between the two with dark humor; the characters criticize slavery because it forces them to find work for slaves to do and creates a value for black bodies that prevents Indians from being able to cannibalize them. Many critics have interrogated the reference to cannibalism in this story because of its devaluation of African American lives as well as its suggestion of barbarism among Mississippi Indians, a barbarism that is not based in historical fact. While both of these points of criticism are valid, it is also important to keep in mind Faulkner's subversive artistic tendencies. In "A Courtship," the narrator refers to the ridiculousness of whites' belief in Indian cannibalism: “As if any man, no matter how hungry, would risk eating the flesh of a coward or thief in this country where even in winter there is always something to be found to eat; - this land for which, as Issetibbeha used to say ... the Great Spirit has done more and man less than for any land he ever heard of" (634-5). Likewise, in "Lo!," Faulkner hints at white misconceptions of Indians in Weddel's statement, "we'll have to try to act like these people believe that Indians ought to act" (6-7). As a result, though Faulkner's humor is offensive, it is nonetheless drawing on the expectations of white readers and emphasizes the contrast between old days and the present system in which African Americans are wrongly transformed into commodities. As Berry concludes, "They are not like horses and dogs" (6).

In response to the central problem the tribe faces, that of determining how to accommodate the influx of enslaved African Americans into their community, Faulkner presents criticism of slavery that indicts not only whites, who introduce the concept to Indians, but also Indians, who follow their lead. Mimicry of the whites' slave-based plantation system comes after a suggestion by one of the Chickasaws: "Raise more Negroes by clearing more land, then sell them. We will clear the land and plant it with food and raise Negroes, and sell them to the 
white men for money" (54). Significantly, the tribe's decision is described as historically inevitable; an elder discusses the folly of adopting a plantation economy, but he is largely ignored. As he sits on the deck of the steamboat, a symbol of this coming plantation system that contrasts with the work of two nearby women who dress a fowl and shell corn, an elder recollects the old days:

This world is going to the dogs. ... it is being ruined by white men. We got along for years, before the white men foisted their Negroes upon us. In the old days the old men sat in the shade and ate stewed deer's meat and corn and smoked tobacco and talked of honor and grave affairs; now what do we do? Even the old wear themselves into the grave taking care of those who like sweating. (56)

The old man then speaks of the enslaved man who is attempting to flee burial with the justdeceased Issetibbeha. He recalls what happened the last time he saw this scenario, when Doom's servant likewise tried to escape live burial after Doom's death. The old man asserts that the former escape attempt lasted three weeks, which Basket and Berry dispute. When he begins to tell of his memories of that event, the old man's listeners simply leave him, showing their disregard of the oral tradition that is central to tribal custom.

The Indians' neglect of the old man points toward evolution in the tribe's hierarchy. This shift has come about after some tribal members have become affiliated with wealthy Europeans in New Orleans. A new configuration of dynasty in the tribe, signified in the red high-heeled slippers of Issetibbeha, “The Man,” resembles a European-style monarchy. While Doom has long since passed away by the time of this story, his influence nonetheless pervades the actions of later chiefs, Issetibbeha and his son Moketubbe. Doom's story, recounted in the narrative, consists of a journey to New Orleans, where he meets the Chevalier Soeur Blonde de Vitry. Though Doom is not the rightful heir to the tribal leadership, he passes as chief, and de Vitry names him “du homme," which evolves into 
Doom. With de Vitry as his companion in New Orleans revelry, Doom impregnates a young "daughter of a fairly well-to-do family of West Indians" (7) (apparently a coded reference to an African American). When the woman comes to the Plantation, Doom has risen to the office of Chief, presumably by poisoning his uncle. Later, Doom's son Issetibbeha carries out a journey that is similar to his father's; he travels to Paris, where an aging de Vitry introduces him in "certain circles" (54) and presents him with gifts such as the red slippers, which do not fit him because he usually is barefoot. Though it is not explicit in the text, Issetibbeha's son Moketubbe, who is eager to wear the red shoes himself, probably murders his own father in order to assume the position as Man, as Issetibbeha has expressed fears that Moketubbe "might think of doing anything" (54) to get the shoes.

Moketubbe's fervor for the red slippers exemplifies Doom's and his successors' zeal for European finery and white mannerisms. In much the same way that U.S. officials acquired land from Indians by offering such objects, de Vitry borrows money from Issetibbeha in exchange for trinkets - the slippers, a gilt bed, and a pair of girandoles — and a white man teaches the Chickasaw leader how to use snuff. As Moore articulates, "For Faulkner's Indians, caste and class are defined almost exclusively in terms of non-native materials" (“"European"” 263). Following a now familiar pattern, these objects allude to feminization of Indians that complements the effeminacy of the French patrons who influence them. By the time de Vitry befriends Issetibbeha, the Parisian is an old man "in a toupee and a corset and a careful toothless old face fixed in a grimace quizzical and profoundly tragic" (54). Moketubbe, in his high heels, exhibits a parallel effeminacy. As Parker notes, "The Indian men of 'Red Leaves' do not fit the stereotypes of masculinity. Faulkner imagines them as feminized or neutered" (90). This emasculation is the result of a preoccupation with 
European domesticity and its material trappings, which young Ikkemotubbe and Hogganbeck are able to avoid in "A Courtship." Though as Parker argues, it is ridiculous to expect any culture, Indian culture included, to not change over time (94), by the time of "Red Leaves," however, fancy ornaments are almost comically out of place in the Plantation. The steamboat, or de facto Plantation manor, is beginning to deteriorate, as mold takes over the wood, and it houses caged foxes and gamecocks, a far cry from the big game of tribal hunts. Issetibehha's gilt bed and girandoles are suspended with deer thongs, and Issetibbeha's wife prefers a quilt pallet on the floor to her husband's bed.

The way in which Indians become out of step with a vital lifestyle that is attuned to the environment, or a life that is "natural," differs in some respects with the way that African Americans, particularly the individual enslaved by Issetibbeha, appear. While in flight, the man keeps to the woods, experiencing a solitary wilderness trial. Sent away from the drumming that other African Americans are secretly participating in down at the creek, the native of Cameroon becomes totally acclimated to nature, removing his dungarees and covering himself entirely with mud. Observing two "soft-looking" (62) Indians traveling through the woods, he notices their carefully rolled trousers, straw hats and shirttails, and coming face to face with another Indian, he similarly appears vigorous compared to them: "the Negro gaunt, lean, hard, tireless and desperate; the Indian thick, soft-looking, the apparent embodiment of the ultimate and the supreme reluctance and inertia" (62). This compulsion for survival culminates in the man's incident with a snake, which strikes him several times. "Ole, grandfather," he says to the creature, “'It's that I do not wish to die,' in a quiet tone, of slow and low amaze, as though. . . he had not known the depth and extent of his desire" (62). At the end of his trial, facing his imminent death, taller than all the gathered 
Indians, the man returns to his ancestral tradition, singing "something in his own language, his face lifted to the rising sun" (64). The enslaved African American as emblematic of a human drive for survival reflects Davis's description: "By virtue of his enslavement and separation from his African homeland, the Negro is a dramatic representation of human struggle for survival.... His African heritage also makes him particularly attractive as an exotic primitive offering a vicarious escape from mundane concerns" (22). Indeed, it is the man's "wild" nature that seems to allow his endurance for so long. Thinking of his first days in America, when he spoke only his native language, he remembers eating a rat that was easy to catch because of its civilized association with man, civilization that seems to be the seed of the Indians' doom.

Though it is tempting to characterize Faulkner's African Americans as simply portraits of cultural endurance, it is important to recognize the ways in which "deciduation" has also occurred among them, chiefly because of their enslavement. In the Chickasaw Plantation, the two rows of slave quarters contain remnants of "homemade toys mute in the dust," "fetishshaped objects made of wood and rags and feathers," and "bones and broken gourd dishes," and Basket and Berry see "no sign of life" in the area (6). When the two Indians find the blacks gathered in the central cabin, where they house "cryptic ornaments and ceremonial records," they appear to be "like a single octopus. They were like the roots of a huge tree uncovered, the earth broken momentarily upon the writhen, thick, fetid tangle of its lightless and outraged life" (6). These images indicate the ways in which, muted and broken as a result of dehumanizing oppression, African Americans have unified and adapted to their conditions, displaying practices that are akin to Indian traditions but may also be rooted in the cultures of Africa. Accordingly, for better or worse, in the same way that the escapee 
carries both an amulet containing half of a mother-of-pearl that Issetibbeha brought from Paris as well as the skull of a cottonmouth he had killed and eaten himself, African Americans exhibit hybrid crossing, a phenomenon that is key to their American legacies.

Faulkner himself commented on this concept of adaptability in African Americans' experiences in remarks that were prompted a young black girl that he saw wearing a tartan dress. He said:

Once the Negroes used to have these parties where you could hear the drumming all night long in the distance. They called them 'picnics.'. . . The younger Negroes now are ashamed of all that. It's the same in the churches. They used to have trombones and banjos at the services. ... Now they have to imitate the white folks services. The Negro has been adaptable. He could even survive as a slave. The Indian couldn't. We'll soon see how adaptable the white is. (Blotner 1961)

Faulkner's comments suggest his view of history as a story of red, white, and black.

Embedded in his characterization of the fates of various populations is his belief in his own authority to evaluate the authenticity of indigenous American and African cultures. Interestingly, he laments that Indians have not been adaptable, yet it is their very pursuit of European values and commodities that leads to their demise in many of his stories. Faulkner speaks further of this demise in his explanation of the title of "Red Leaves," which he says refers to Indians: "It was the deciduation of Nature which no one could stop that had suffocated, smothered, destroyed the Negro" (663-4). Here it seems that Faulkner's historical vision is limited. What would he make of the current flourish of many Southern tribes, especially Chickasaws and Oklahoma and Mississippi Choctaws, post-removal? How would he account for enduring African American church traditions, which are mainstays of African American culture?

An analysis of the burial ritual that takes place in the story sheds light on a more precise 
understanding of Faulkner's characterization of the confluence of a European economy with American Indian and African American cultural traditions. The purpose of the slave's burial with the Man is to ensure that the deceased has his helper with him when he enters the afterlife. As Moore notes, this ritual seems to suggest that Indians have become dependent on African Americans and can no longer fend for themselves, as did Weddel in "Lo!" or Ikkemotubbe in “A Courtship.” As Doom's successors continue his legacy, they become less effective and lack self-determination. Moketubbe, for instance, is described as so inert that he is obese and "dropsical" (54). Moore continues, "Most of the tension and mystery of 'Red Leaves' depends on the contrast between the energy of the slave and the inertia of his captors: between the decadent and demoralized Indians who fall victim to the lure of European trinkets, and the noble slave who demonstrates the capacity of his people to suffer and endure" (“"European"” 267). According to this reading, it is not exactly adaptability that is the measure of an outnumbered or oppressed group's endurance. Instead, it is the result of that adaptability or culture crossing, the degree to which individuals seek power over others to the neglect of their own cultural values. As Bruce G. Johnson asserts, Faulkner's cultural "hybridization does not eradicate the power differentials between cultural groups" (112). Though African Americans, whites, and Indians have all met and engaged in cultural exchange in the Mississippi wilderness, African Americans have retained cultural traditions in ways such as secret drumming or language retention and displayed "natural" behavior despite their forced participation in American Indian and white plantation economies. Indians, on the other hand, have turned away from the warnings of their elders and the virtues of the old days, which Faulkner portrays as harmonious with the processes of nature, in a morally repugnant embrace of slavery and despotic behavior. This shift echoes the actions of 
Faulknerian villains such as Sutpen. No wonder Moketubbe is damned by doomed spirits.

Despots such as Moketubbe and his kin are not Faulkner's last word on the Indian people of Yoknapatawpha or their engagement with African Americans and whites, however. One of the most positive characters in all of Faulkner' fiction is Sam Fathers, counselor to Ike McCaslin and black-Indian hybrid of sorts. Faulkner introduces Fathers in "A Justice," a story of his paternity, which is linked to the actions of Doom. "A Justice," which is narrated by Quentin Compson, a prototype for the Ike McCaslin of later stories, is based in Sam's memory and on oral traditions that he retained from his people. Faulkner apparently based Fathers on a carpenter who worked at Greenfield Farm, the writer's venture into rural living, and over the course of several stories, the character becomes a sort of moral compass for the actions of whites who come to control the woods in greater and greater numbers.

Sam's racial and cultural lineage is complicated, as he espouses multiple ancestry. Although he lives with African Americans, he retains an identity separate from those in his community, despite the ways others characterize him: "the Negroes called him a blue-gumcalled him a Negro. But he wasn't a Negro" (183). The difference in Sam's physical features suggests his retention of an identity separate from the black-white divide that pervades his community:

He talked like a nigger - that is, he said his words like niggers do, but he didn't say the same words - and his hair was nigger hair. But his skin wasn't quite the color of a light nigger and his nose and his mouth and chin were not nigger nose and mouth and chin. And his shape was not like the shape of a nigger when he gets old. He was straight in the back, not tall, a little broad, and his face was still all the time, like he might be somewhere else all the while he was working or when people, even white people, talked to him, or while he talked to me. (184)

Likewise, members of different groups impose differing names, or verbal signifiers of his identity, upon him. He states, "These niggers ... They call me Uncle Blue-Gum. And the 
white folks, they call me Sam Fathers" (185). When Sam Fathers explains to Quentin that his real name, given to him by Doom, is "Had-Two-Fathers," Quentin replies "That's not a name. That's not anything" (185). Fathers then asserts, "It was my name once. Listen" (185), and then he proceeds to tell Quentin of the origins of his Indian identity.

Father's assertion of his Indian name contrasts with the evolution of Ikkemotubbe's name, which accompanies his transformation into a despot. First, Ikkemotubbe renames himself David Callicoat, after the white owner of the steamboat, before going to New Orleans, and after being christened "du homme" there by de Vitry, Doom kills the rightful heirs of the "Man" title. When Crawfish-ford (Sam's Father) ${ }^{8}$ and a black resident of the community become locked in a dispute over the affections of the black man's wife, at Doom's urging, they engage their "cocks" (again, the double entendre is hard to miss) in a contest. When that does not resolve the issue, and a baby (Sam) is born with a yellow color, Doom decrees "Any man is entitled to have his melon patch protected from these wild bucks of the woods" (203). After naming the baby "Had-Two-Fathers," he settles the matter by constructing a fence around the black man's cabin. Finally, the woman gives birth to a black baby.

The ecological dimensions of this action highlight the contrast between the legacies of Doom and of Fathers. Doom urges the People to cut down trees to make way for the steamboat's entry into the Plantation, seeking to make the space a slave-based system like white-owned plantations, and he enforces boundaries between Indians and blacks, which is emblematized in the construction of the fence as well as his lazing on the steamboat's deck with young black boys fanning him. Sam, however, despite his birth in Doom's era, seems to retain something of the older ways of the Chickasaws, reflected in his using tobacco with a

\footnotetext{
${ }^{8}$ In "The Old People," in Go Down, Moses, Doom is named as Sam's Father, a significant development because of Doom's sale of Sam's family into slavery.
} 
homemade pipe made of creek clay and a reed stem. Importantly, his endurance is facilitated through his affiliation with the African American community, which contrasts sharply with the actions of Indian slave-holding characters. Faulkner thereby ties Fathers's power to his hybrid crossing but also to his retention of more important virtues of Indian culture, including Chickasaw language, and his rejection of the activities of Indian despots.

The boundary crossing that Sam embodies is more thoroughly explored in Go Down, Moses, Faulkner's “mature statement about responsibility" (Wagner-Martin 7). In this novel, Faulkner interlinks the histories of varied peoples in Yoknapatawpha and illumines the fluidity — and faultlines — of their convergence in his Golden Book. On some level, each story in the text probes the central realities of history and inheritance and their connection to the land, subverting a white-washed, linear model of conquest. The text formulates a history of sorts in its intertwining of the McCaslin and Beauchamp families with the legacies of American Indians and more specifically, tribal values concerning land and environment. Ultimately, a dubious "progress" comes to Yoknapatawpha, prompting evaluations of the cultural shifts and transmutations that have led to it. In the words of Judith Wittenberg, "Go Down, Moses offers either direct or subtle evidence of a skeptical view of a commodified approach either to land or the methods of production" (61).

The mixing of overtly separate peoples is key to Faulkner's presentation of the impact of history on the actions and attitudes of those in the present. This mixing is established immediately in the text with "Was," which lays out the reason, Lucius Quintus Carothers McCaslin's incest with his own daughter, for the intimate McCaslin-Beauchamp connection and the fundamental wrong that later leads Ike McCaslin to renounce his inheritance. "The Fire and the Hearth" describes in detail the results of this miscegenation between the two 
families, portraying Lucas Beauchamp as a vigorous survivor of hardship akin to the runaway slave in "Red Leaves," but also naming him as the rightful, though unrecognized, family patriarch. Significantly, Lucas's status as head of the family rests on his relationship to the land, which is dotted with Indian mounds that he believes quake and throw gold coins at him. $\mathrm{He}$

had been born on this land, twenty-five years before the Edmonds who now owned it. He had worked on it ever since he got big enough to hold a plow straight; he had hunted over every foot of it during his childhood and youth and his manhood too, up to the time when he stopped hunting, not because he could no longer walk a day's or a night's hunt, but because he felt that the pursuit of rabbits and 'possums for meat was no longer commensurate with his status as not only the oldest man but the oldest living person on the Edmonds plantation, the oldest McCaslin descendant even though in the world's eye he descended not from McCaslins but from McCaslin slaves. .. (36)

Demoralizing experiences nonetheless pervade Lucas's endurance as McCaslin heir, chiefly Edmonds's betrayal of him. Zack and Lucas, like Jubal and Weddel and Ikkemotubbe and David, have lived almost as brothers, sharing a bed and a table, yet in adulthood, Zack has slept with Mollie, Lucas's wife. After a confrontation in which Lucas almost kills him, Zack perceives:

He's more like old Carothers than all the rest of us put together, including old Carothers. He is both heir and prototype simultaneously of all the geography and climate and biology which sired old Carothers and all the rest of us and our kind, myriad, countless, faceless, even nameless now except himself who fathered himself, intact and complete, contemptuous, as old Carothers must have been, of all blood black white yellow or red, including his own. (118)

In this description, Lucas, who embodies cross-racial exchange, espouses fury not only at Carothers's unjust bondage of African Americans, but also possesses a zeal for mastery of land and its economic potential. Still, injustice and zeal seem to drive Lucas's vigor, making him a formidable force, ironically not unlike Carothers himself. Accordingly, "Lucas 
remained" (105). In this way, the land's doomed inheritance is everyone's, not only Ike McCaslin's.

In "The Bear," Ike also recognizes that Carothers's legacy of wrongdoing is connected to the fates of multiple peoples and is rooted in his commodification of land. In section four of the story, Ike describes Carothers's manipulation of land for a corrupt purpose:

tamed and ordered or believed he had tamed and ordered it for the reason that the human beings he held in bondage and in the power of life and death had removed the forest from it and in their sweat scratched the surface of it to a depth of perhaps fourteen inches in order to grow something out of it which had not been there before and which could be translated back into the money he who believed he had bought it had had to pay to get it and hold it and a reasonable profit to: and for which reason old Carothers McCaslin, knowing better, could raise his children, his descendants and heirs, to believe the land was his to hold and bequeath. (254)

Faulkner portrays this corrupt colonial behavior as directly tied to Doom's degradation: “it was never old Ikkemotubbe's to sell to Grandfather for bequeathment and repudiation. . . . on the instant when Ikkemotubbe discovered, realized, that he could sell it for money, on that instant it ceased ever to have been his forever, father to father, and the man who bought it bought nothing" (256-7). This commodification of people and land is the source of Ike's decision to relinquish his inheritance, as "This whole land, the whole South, is cursed, and all of us who derive from it" (278). Faulkner later said that this sale of land by Indians to white people was the source of a "ghost of that ravishment [that] lingers in the land" (Gwynn and Blotner 43).

Despite the text's dark view of humanity and its dwelling place, Faulkner does offer a glimmer of hope in the person of Sam Fathers, who has the ability to show a younger generation, in the person of Ike, an alternative to the examples of history's venerated yet corrupt heroes. As in "A Justice," the source of Sam's wisdom lies in his mixed heritage, 
which instills in him a venerable spirit. Faulkner describes him as "of a people who had learned humility through suffering and learned pride through the endurance which survived the suffering, and on the other side ... of a people ... who now existed there in the solitary brotherhood of an old and childless Negro's alien blood and the wild and invincible spirit of an old bear" (295). Importantly, Fathers does not portend a brighter future or a more just world; he is clearly facing death, a truth that is parallel to the story's valorization of the hunt. As Philip Weinstein argues, "Sam represents in small ... an incoherent fusion of achieved independence and inalterable despoliation" (56). However, in light of Southern defeat (for Confederates as well as for enslaved African Americans and dispossessed American Indians), Sam's initiation of Ike into the virtuous, natural, "old" ways of the hunt, suggests the possibility of free will — a freedom to choose, even in the face of inevitable death, truth which Faulkner likens to God and which "covers all things which touch the heart" (260). Perhaps the most apt description of Fathers's impact comes in Ike's simple phrase "Sam Fathers set me free" (300). Marked by Sam in "The Old People" with the blood of the first deer he kills, Ike is capable of renouncing the horrible actions of his white ancestors against African Americans that he reads of in the ledgers, and is able to instruct Cass in the ethics of his decision.

The truth that Fathers instructs to Ike is bound to nature and demonstrated in the hunt, which, as in other stories, blurs the barriers of gender as well as of race. As is the case with David and Ikkemotubbe in "A Courtship," Ike's achievement of masculinity in "The Bear" ensues from his rejection of domesticity, which in later years is evident in his refusal to procreate with his wife, and his understanding of the woods as "his mistress and his wife" (326). As Weinstein articulates, the wilderness is an "escape from women ... integral to the 
gender politics of a culture committed to male honor" (136). Yet as Weinstein also recognizes, domesticity cannot be completely abandoned; Ash, one of two black people on the trip, fulfills a domestic function in his role as cook. Importantly, the hunting party, and the code of honor it espouses, is thereby distinctly white and male despite its apparent separation from cultural trappings. However, Weinstein continues, some participants, such as part-Cherokee Boon Hogganbeck and Sam Fathers, represent "the physical empowerment, the psychic centering, and the social impotence that accompany an exit from cultural convention" (138). In this way, Ike is affiliated more closely with Boon and Sam than with Major de Spain or General Compson, and without those two, the hunting ritual is largely meaningless for him, as is apparent later in "Delta Autumn." Unlike the others of the hunting party, Ike finds his identity by confronting Old Ben and not shooting, "embodying the desire to escape the codings of his cultural estate" (138), reflecting behavior that would be viewed by others as weak or womanly. Further, both Lion and Boon are described as "the woman" of their close relationship (220), and Bart Welling goes so far as to characterize the "he" bear as "in some ways also a she," displaying a nurturing presence for the orphaned Ike that evokes Faulkner's memories of Callie Barr (487).

In addition to compromising the strictures of race and gender, the hunt also blurs the lines between animal and human. As Faulkner writes, two men, Boon and Sam; and two beasts, Lion and Old Ben, share a kinship because of their "wild" blood, with a fading American Indian lineage living on not in Chickasaw tribal members but in wild animals of the wilderness. Importantly, because Boon's heritage is not of the same royal strain as Sam's, "only Sam and Old Ben and mongrel Lion were taintless and incorruptible" (191), and Boon defers to the authority of Lion, with whom he shares a bed. Only at age ten, when Ike sets 
aside his watch and compass, is he also free of the taint of "progress" and prepared to enter the hallowed wilderness, aware of his inheritance of the "big old bear with one trap-ruined foot" (193). These characters, unlike DeSpain and Compson, share a bond with animals chiefly because of their resistance of activities that commodify land and environment. ${ }^{9}$ This conservationist message, according to Lawrence Buell, reflects thinking that was becoming increasingly prevalent in the 1930s, accompanied by New Deal conservationist initiatives (11). But Buell goes on to assert that this environmental impulse is not unrelated to questions of culture, including "economic, social, and racial ramifications" (14). Ike's wilderness initiation, then, which leads him to renunciation of cultural wrongs, is the only hope for a reversal of the forces of degradation.

The fate of the wilderness - and its cultural associations - is apparent in "Delta Autumn," which portrays Ike's final hunting trip. From the events of this story, it is clear that Ike, who is now in old age, has failed to instruct later generations in his ethical principles or to affect change. This failure is evident in his own unstable behavior as well as in the behavior of later generations of McCaslins. According to Laura Claridge, "in his cessation of growth, or arrested development, Ike may be said to end up in a far worse state than that of the sinful past he so indicts" (248). By the time of Ike's final hunt, the woods are significantly reduced, shrunk by the infiltration of cars and trains and uninhabited by American Indians, who remain only in the names of the little towns. Faulkner's insistence that does and fawns, emblems of the motherly and regenerative force of the wilderness, should be protected goes ignored. And finally, Ike discovers that the commodification of black female bodies that was

\footnotetext{
${ }^{9}$ Interestingly, as Welling reveals, Faulkner himself purchased the woods where Callie introduced him to the outdoors, making him "the biggest landowner in Oxford," and he even considered parceling the woods into subdivisions (474-5).
} 
enacted by Carothers McCaslin so long ago is echoed in Roth's relationship and subsequent rejection of Tennie's Jim's granddaughter.

According to Bruce Johnson, this repeated cycle suggests Ike's failure to instruct: "Ike fails as a mentor to his cousin, Roth Edmonds. Roth escapes the responsibility to meet his black mistress and their bastard child at the campsite by coercing Ike into giving her an envelope with a "thick sheaf of banknotes"' (125). This action outrages Ike, who describes the curse that the commodification of land and culture has brought about:

This Delta. This land which man has deswamped and denuded and derivered in two generations so that white men can own plantations and commute every night to Memphis and black men own plantations and ride in jim crow cars to Chicago to live in millionaires' mansions on Lakeshore Drive, where white men rent farms and live like niggers and niggers crop on shares and live like animals, where cotton is planted and grows man-tall in the very cracks of the sidewalks, and usury and mortgage and bankruptcy and measureless wealth, Chinese and African and Aryan and Jew, all breed and spawn together until no man has time to say which one is which nor cares. . . . No wonder the ruined woods I used to know don't cry for retribution! He thought: The people who have destroyed it will accomplish its revenge. (364)

While many critics have interpreted Ike's comments as evidence of his racism and fear of miscegenation, that approach is not completely consistent with his portrayal in other stories. His comments emphasize not just a fear of race mixing, but a sense of loss, perhaps loss of authentic American culture, that he believes accompanies "progress" and the greater proliferation of a money economy. Importantly, while in Yoknapatawpha's earlier days, the mixture of white, black, and Indian was mostly positive, somehow the locus for a harmonious, indigenous existence, a later mixture that includes more religious and national diversity but lacks grounding in American Indian heritage emerges in a negative light. As a result, for Faulkner, as for Cooper, Indian heritage, which involves a synchronous relationship to the wilderness, is necessary for indigenous American identity; however, 
Faulkner's modernist rendering of "settlement" suggests greater fragmentation rather than a complete national narrative.

Faulkner's later writings, perhaps his final attempts to realize his "Golden Book" idea, emphasize this fragmentation, which originates in Indians' adoption of a plantation economy. His appendix to The Sound and the Fury, which he composed in the fall of 1945 when Malcolm Cowley was preparing The Portable Faulkner for the Viking Press, interjects American Indian legacies into the story in order to reveal its broader significance. In a letter to Robert N. Linscott, his editor at Viking Press, Faulkner asserted that he wished for the appendix to come first in the reprint of the novel, explaining, “... it is key to the whole book, and after reading it, the 4 sections as they stand now fall into clarity and place" (Blotner, 1208). Faulkner begins the appendix with an entry for Ikkemotubbe, whom he calls " $A$ dispossessed American king” (225), and details his parceling out of the wilderness in exchange for removal to Oklahoma. Even amid the tragedy of dispossession, however, Faulkner mentions the oil fortunes that Doom will likely discover in the West, further evidence of his transformation of land into profit-making commodity. Jason Lycurgus Compson, who acquires Ikkemotubbe's land by betting on horse races, christens the land Compson Domain, and develops it into a park rather than a forest, as Ikkemotubbe's descendants, and eventually all of their "wild blood," vanish (227).

Though Indians are completely absent from contemporary Yoknapatawpha in this formulation, the "ghost of the ravishment" of their land is nonetheless visited on the Compson children. Quentin III, Caddy, and Quentin ("The last"), are all described as either dying or doomed, and Jason IV enacts behavior that is clearly parallel to Doom's actions. Like Doom's parceling out of the People's land, Jason “chop[s] up the vast oncesplendid 
rooms into what he called apartments" (233). Additionally, he learns how to "class and grade cotton" (233), establishes his own business, and inhabits a rotten house akin to Doom's rotting steamboat shell. Following an established pattern in Faulkner's fiction, the only survivors of the novel are of course its African American characters. Like the escapee of "Red Leaves" and Lucas Beauchamp of Go Down, Moses, Dilsey simply “endured.” As in other stories, The Sound and the Fury thus presents intergenerational wrongs instigated by the dispossession as well as the degradation of Indians, and the endurance of African Americans is based in their morality and their unity. Unlike the Compsons, the Gibsons take care of others: Luster of Benjie and Frony of Dilsey. According to Davis, these characters reflect a "black centered experience" (72) that offers hope in the face of an otherwise nihilistic novel (108).

Requiem for a Nun, Faulkner's last novel, is his most overt integration of a narrative of Yoknapatawphan history, particularly "settlement," with a story of the moral failings of a contemporary era. The mixed-genre text parallels the birth of the town of Jefferson, signified in the securing of the jail and the construction of the courthouse, with the jailing of Nancy Mannigoe for the murder of Temple Drake's child. As Polk explains, the jail and courthouse represent "limitations on human freedom" (Faulkner's 24). Throughout the novel, Faulkner uses the word "doom" to describe the fate of the town, of which the courthouse is emblematic. Specifically, Faulkner's negative portrayal of the courthouse stems from its permanency, its stark, man-made difference from the wilderness that surrounds it: "its doom is its longevity; . . . the clock . . bursting in one swirling explosion out of the belfry ... had shattered the pristine air with the first loud ding-dong of time and doom" (41-2).

As in Faulkner's other stories, the remaining Indian residents of the county participate in 
the degradation of the wilderness, which instigates doom. Wearing "white man's denim and butternut and felt and straw" (42), the Chickasaws help the white infiltrators into their homeland search for the exorbitant lock which, when given up for lost, will be written onto the ledger of their account with the Bureau of Indian Affairs. While Indian leaders of past stories are consistently male, the "matriarch" of the tribe in this rendering is a woman, Mohataha, who, attired in a dress that Doom has given her, is "barefoot in a purple silk gown and a plumed hat, sitting in a gilt brocade empire chair in a wagon behind two mules, under a silver-handled Paris parasol held by a female slave child" (27). Mohataha's appearance as slave owner, looking like a "madam of a rich Natchez or New Orleans brothel" (186), mirrors Indian participation in transforming land and people into commodities. Faulkner identifies this activity as the source of America's doomed destiny:

the American earth, whirled faster and faster toward the plunging precipice of its destiny; That fast, that rapid: a commodity in the land now which until now had dealt first in Indians: then in acres and sections and boundaries:- an economy: Cotton: a king: omnipotent and omnipresent: a destiny of which (obvious now) the Plow and the axe had been merely the tools. . . (195)

This infiltration of cotton plunges Jefferson toward a "parasitic aristocracy" (195) that goes beyond the plantation economy of previous narratives and is borne out in the "countingrooms of merchants and bankers and the sanctums of lawyers, ... the county offices too: of sheriff and tax-collector and bailiff and turnkey and clerk" (195-6). Though Polk argues that the Indians' mistake is their "nominal and ineffective efforts to adapt to changing times" (Faulkner's 45), in their denim attire, under the authority of their queen, the Chickasaws have clearly bought into this aristocratic system.

Like Mohataha, Temple, a Mississippi debutante, is also part of a long line of Southern aristocrats, yet as is detailed in Sanctuary, she has also spent her share of time in a brothel. In 
order to have someone to talk to, who cares for her, who can manage her domestic needs, Temple must hire Nancy, an African American woman and former prostitute whom she calls a "nigger dope-fiend whore" (105). Significantly, displaying Faulkner's trademark artistic reversal, Nancy's murder of Temple's baby, the "doomed sacrifice," is ironically the source of Temple's only hope for redemption, as it prevents her from enacting her plan to abandon her family. Temple herself acknowledges that she was the one who destroyed her child when she "slipped out the back end of that train" (239) and began her episode with Popeye and ensuing experience in a Memphis brothel. Temple concludes that though at first, she believed it was necessary to forgive Nancy, she realizes that it is she who must ask for forgiveness, and she asks Nancy, whom Faulkner named as the "Nun" of the title (Gwynn and Blotner 196), for instruction. Nancy, who will be executed, explains to Temple that suffering, and simple belief in God, is necessary for salvation. The text ends with Temple's words about the necessity of God for forgiveness: "If there is none, I'm sunk. We all are. Doomed. Damned" (245).

The triangulation of Mohataha, Temple, and Nancy in Requiem for a Nun is a feminized version of the triangulation that produces characters such as Sam Fathers in Faulkner's other works. In their similar brothel-tainted histories, the three exhibit a crossing of the borders of red, white, and black that arguably encapsulates Yoknapatawphan — and American—history. As Mohataha adopts the trappings of an aristocratic system, placing her " $\mathrm{X}$ " on the paper that solidifies her people's removal to Oklahoma, she in effect borrows white identity and clinches the doomed legacy that will accompany the modern lives of Temple and Nancy. But though Temple is the only survivor, like Lucas and Dilsey, Nancy has the capacity to endure largely because of her suffering and her separation from the aristocratic legacy of the white 
and Indian characters. Perhaps because African Americans retain cultural signifiers that Faulkner views as authentic, such as the Carib-Spanish-French dialect of the people whom Sutpen enslaved, Nancy, despite her death, is saved. Unlike the inertia of Mohataha, Nancy exhibits the vigor of endurance, stating, "I can work" (239).

Though Faulkner's Golden Book project remains largely incomplete, the author's emphasis on formulating a history of his "postage stamp of native soil" pervades a significant number of his works, including stories that are often overlooked in the body of Faulkner criticism. This history reflects Faulkner's drive to situate his place in a uniquely American literature, and this unique Americanness is tied to crossing boundaries of race, gender and environment. Throughout Faulkner's tales of cultural conflict and confluence, the fate of American Indians is tied to the fate of the broader civilization. Whereas Romantic epics of the nineteenth century cultivate a national narrative that joins the success of a young American nation to the disappearance of Indians, Faulkner's works reflect a more modern sense of regret at the advancement of Western or white civilization that results in the dispossession of Indians and the enslavement of African Americans. This reversal accompanies a Southern rather than Northeastern setting for the stories, a locale that is haunted by a sense of defeat as well as nostalgia for a pre-industrial world.

Though analyzing the works of writers such as Faulkner and Cooper, who are characterized as some of American literature's canonical "greats," sheds light on questions of nation and culture among diverse peoples, including American Indians, the most important sources for the imaginings and perspectives of American Indians and African Americans comes directly out of their own rich literary traditions. Concerning American Indian literature, Littlefield and Parins assert, the late nineteenth and early twentieth centuries saw a 
literary flowering, which was characterized by the "ideas that the Indians were here first, that their treatment by the larger society was unjust, that they had contributed significantly to the making of modern America, and that they remained — and intended to remain —a part of the American scene" [xviii]. Examples of early twentieth-century American Indian literary figures whose writings are a fruitful basis for comparison to Faulkner's depictions of Indians include Mabel Washbourne Anderson (Cherokee), Muriel H. Wright (Choctaw), Rachel Caroline Eaton (Cherokee), Ora Eddleman Reed (Cherokee), and John Oskison (Cherokee) (xxii). African American literary figures have received more national recognition than these American Indian writers, however, and though their texts are not necessarily authorities on American Indian experiences, their literature transforms, confronts, and generally speaks with authority about the ideas of endurance and cultural survival that Faulkner raised in his stories. Perhaps no African American writer is more celebrated than Toni Morrison, who draws significantly upon Faulkner's literary conventions. Like Faulkner and Cooper, Morrison explores the textures of cross-racial contact, also grounding American identity in the experiences of American Indians. 


\title{
CHAPTER IV: \\ INDIGENOUS "REMEMORY": CULTURAL HYBRIDITY AND THE NATURE OF RESISTANCE IN THE NOVELS OF TONI MORRISON
}

\author{
Contemporary writers such as Nettie Jones, Clarence Major, Alice Walker, and Toni
}

Morrison depict the longstanding connection between African Americans and Native

Americans in American history and society, a connection that has recently attracted greater

scholarly attention. Historians William Loren Katz and Jack D. Forbes, who share much of

the credit for initiating scholarship concerning Afro-Natives, have rightly called for further

study of this important relationship, emphasizing the inaccuracy of a focus on a black-white

nexus in discussions of race in America. Forbes asserts:

The ancestry of many modern-day Americans, whether of "black" or "Indian" appearance, is often (or usually) quite complex indeed. It is sad that many such persons have been forced by racism into arbitrary categories which tend to render their ethnic heritage simple rather than complex. It is now one of the principal tasks of scholarship to replace the shallow one-dimensional images of non-whites with more accurate multi-dimensional portraits. (271)

Both Katz and Forbes have pointed toward contact between Africans and Natives of the Americas prior to the American colonial period, shared experiences of slavery at the hands of both Europeans and Natives, the development of unique black Indian communities on the American frontier, and cooperation in revolts against European control as evidence of cultural affinity, amalgamation, ${ }^{10}$ and shared senses of purpose among blacks and Indians,

\footnotetext{
${ }^{10}$ The Lumbee tribe of North Carolina is one Native American tribe that reflects the influence and integration of a range of cultures, including European and African American. The Lumbees' continued failure to attain federal recognition as a tribe reflects the way in which the United States has often refused to recognize the dynamic and unique nature of each Native American tribe. See Chapter Two, "We Ain't Got Feathers and Beads," of Fergus Bordewich's Killing the White Man's Indian: Reinventing Native Americans at the End of the Twentieth Century.
} 
the basis of a kinship that endures in modern times.

Recent studies of Afro-Native history and culture respond to Forbes's and Katz's call and further probe the implications of this field for an understanding of slavery in America. Jonathan Brennan's recent study of Indian-black experiences attributes the proliferation of African-Native communities to the colonial plantation system, which first exploited the labor of Native Americans and eventually relied upon the enslavement of both Africans and Natives (3). According to Brennan, many mixed communities resulted from these shared experiences of slavery (7), and in these communities, "distinctions between African and Native began to blur, especially as the term 'mulatto' was widely used to describe both African-European and African-Native American people” (7). Tiya Miles similarly emphasizes the largely unrecognized role of Natives in the institution of slavery, an oversight that she attributes to historians who have "painted slavery with a narrow brush" (138).

As Miles asserts, the enslavement of Natives, as well as Southern tribes' enslavement of Africans, indicate a variety of Native and black experiences that challenge popular historical assumptions, particularly classifications of "black" and "Indian" that disregard the potential for dual identity (146). Lindsay T. Baker's and Julie P. Baker's The WPA Oklahoma Slave Narratives provides portraits of African Americans who were enslaved by Southern Indians (or integrated into their bands, in the case of Seminoles). After their removal with the tribes to Indian Territory and the end of the Civil War, these individuals received tribal citizenship at the insistence of the U.S. government and were further acculturated into the tribes, speaking Native languages and employing Native cooking and medicinal practices (5). As Miles asserts, these individuals' espousal of Indian cultural practices can be understood in part as an act of resistance, one which privileges Indianness as its source rather than both 
Indianness and Blackness (155).

In addition to the black-Indian amalgamation that resulted from slavery, Brennan also highlights African-Native American populations known as Maroon communities, composed of Indians and runaway slaves, which often resisted European infiltration and rule in the South (8) and encapsulated the kind of inter-racial cooperation that some American writers have fictionalized. These Maroon communities are in a sense emblematic of a broader phenomenon of culture, one defined by active resistance as well as cultural hybridity, and may be understood as "in-between spaces" (2) which, according to Homi Bhabha, "initiate new signs of identity, and innovative sites of collaboration, and contestation, in the act of defining the idea of society itself" (2). Bhabha's characterization of maroon communities as a metaphor for "the force of the people of an Afro-American nation" (207) thereby emphasizes greater attention to points of cultural convergence as the loci for accurate studies of race in America.

Calls for greater recognition of multiracial heritages in scholarship, though certainly valid, contain potential pitfalls, including a tendency to view diversity as simply an effort to achieve representation of token "others" in various forums. In Bhabha's assessment, cultural diversity is "the representation of a radical rhetoric of the separation of totalized cultures that live unsullied by the intertextuality of their historical locations, safe in the Utopianism of a mythic memory of a unique collective identity" (49). Rather than cultural diversity, Bhabha argues for an "international culture, based not on the exoticism of multiculturalism or the diversity of cultures, but on the inscription and articulation of culture's hybridity. ... it is the 'inter'- the cutting edge of translation and negotiation, the inbetween space - that carries the burden of the meaning of culture" (56). Black Indians and black-Indian border crossings thus 
espouse a more accurate picture of American diversity, but more importantly, they assert cultural hybridity, which carries a number of implications for literary study.

Importantly, literary representations of cultural hybridity, particularly among Indians and blacks, must be studied critically in order to assess "the burden of the meaning of culture" that Bhabha challenges scholars to uncover. One such scholar of Afro-Native literature, Sharon Holland, personally resists the black-white dichotomy that denies her African, Native, and Irish ancestry. According to Holland, efforts to define tradition or authenticity in singular racial terms and subsequent efforts to apply such definitions to literature are problematic:

... to be African-American is really to be a conglomeration of selves and experiences, at once changeable and circumscribed by laws and regulations which attempt to control rather than speak to the difference that constructs, empowers and sustains communities. The efficacy and creation of literary canons can be described in very much the same way; establishing what is "real" and "American" runs parallel with attempts to master borders (both perceived and unperceived), to discipline people whose imaginations consistently resist and/or subvert attempts to establish recognizable hegemony, and to impose normalcy through notions of reality defined, for lack of a better word, as tradition. (334)

In Holland's view, rather than perceiving literature to be fixed, one should view it "as a process of both emancipation and sovereignty, as we are seeking the history and lives of a people whose experience crossed both the barriers of enslaved bodies and lands" (337). The words "emancipation" and "sovereignty" have particular resonance for black and Indian peoples, and the ways in which writers in these groups draw on both cultures reveal much about their associations of particular heritages with deliberate notions of freedom and selfdetermination, concepts that are central to a new narrative of multi-dimensional identity in America.

Toni Morrison's study of American Africanism aptly delineates white writers' imaginings of African Americans as characteristically not-free in literature, representations that, in their 
contrast with the liberated white characters in the texts, allow these writers to articulate narratives that center on freedom. Morrison argues, "It was this Africanism, deployed as rawness and savagery, that provided the staging ground and arena for the elaboration of the quintessential American identity” (44). Adding to Morrison's analysis, American Indians similarly take on the role of staging ground for genuine Americanness in the writings of James Fenimore Cooper and William Faulkner, but further, American Indians serve distinct purposes in writings by African Americans.

Miles concludes, based on the responses of interviewees in the WPA Oklahoma Slave Narratives, that appropriating a positive conception of Indianness allows those of African American ancestry to assert ethics of strength and resistance, at times denying the agency that blackness serves for those ethics. Morrison's novels, including Song of Solomon (1977), Beloved (1987), and Paradise (1998), contain examples of this association of Indianness with resistance as well as with an African American or Afro-Native history that is indigenous to America. Similarly, writers such as Okeh Tubbee, Leslie Marmon Silko, and Sherman Alexie portray blackness in order to highlight American Indians' struggles for civil rights as well as to illustrate living conditions on reservations or at sites of urban relocation. In this way, authors exhibit cultural hybridity not only in multiracial characters, but also in their associations of black or Indian ancestry with certain beliefs about American identity, specifically resistance to European efforts at domination. ${ }^{11}$

As in the writings of Cooper and Faulkner, the crossing of borders between blacks and

\footnotetext{
${ }^{11}$ Paul Pasqueretta names music, particularly blues, as the location for red-black convergence in writings by Toni Morrison and Sherman Alexie. See his article, "African-Native American Subjectivity and the Blues Voice in the Writings of Toni Morrison and Sherman Alexie," chapter 10 of Jonathan Brennan's When Brer Rabbit Meets Coyote: African-Native American Literature (2003).
} 
Indians in Morrison's novels is fundamentally tied to the American landscape, as questions of civilization and notions of savagery parallel images of nature in its varying degrees of wilderness. Conceptions of place, of heritage in America, thereby necessarily involve geography. As David Landis Barnhill asserts, "being in place is to assume that there is at least the possibility of living with the land and its processes" (5). For blacks and Indians, however, being in place in America is not consistently positive because of the history of violence enacted against them on the landscape. At the same time, nature, particularly agriculture, is key to the cultural legacy, especially the folklore, of these populations. As bell hooks contends, this mutual love for the "life-giving forces of nature" (52) is the source of common ground for Africans and Natives.

This ambiguity in approaches to nature is evident in Morrison's depictions of the natural world and its relationship to the characters in her novels, particularly American Indians, who are often key to African American legacies on the American landscape. According to Kathleen Wallace and Karla Armbruster:

In representing the subjugated standpoint of African Americans, Morrison is notable for exploring how the natural world has been used as an instrument of oppression but has simultaneously provided a source of sustenance and comfort. In doing so, she both challenges and ultimately enriches mainstream American environmental discourse, including the ecocritical discourse that has to some degree grown out of it. (213)

According to Gretchen Legler, this infusion of nature writing with realities of race, class, gender, and sexuality, is a radical form of resistance (73). As a result, Morrison's literary exploration of the natural world, wedded to history and culture and reflective of cultural hybridity, is a form of resistance.

As in Cooper's and Faulkner's examples, Morrison's novels feature symbiotic descriptions 
of humans and animals, which often indicate the social, psychological, or spiritual statuses of characters. Significantly, however, Morrison's animistic illustrations of characters differ from the above authors because they illuminate the degrees to which individuals experience freedom or bondage, primary realities in African American history. Investing images of landscape with violence as well as sustenance, Morrison reflects the ambivalence that characterizes her characters' relationships to nature.

In Beloved, through images of animals, Morrison portrays the dehumanizing effects of slavery upon Sethe and the men of Sweet Home, especially highlighting the sexual nature of their oppression. Paul D's enslavement, which forces him to labor arduously on the landscape, is evident through vivid descriptions of beasts of burden. When schoolteacher assumes authority over Sweet Home after Mr. Garner's death, he prompts those enslaved on the plantation to awareness of their less-than-human status in society: “. . . they were only Sweet Home men at Sweet Home. One step off that ground and they were trespassers among the human race. Watchdogs without teeth; steel bulls without horns; gelded workhorses whose neigh and whinny could not be translated into a language responsible humans spoke" (125). Confined on the plantation, prevented from natural and healthy relationships with women, the men of Sweet Home engage in bestiality with cows. As Trudier Harris reveals, even Mister, the rooster at Sweet Home, expresses a manhood that is withheld from those enslaved: "Mister . . . is an objectification of freedom and a metaphor for manhood. As the rooster swaggers around the barnyard, strutting for the hens present, he has more freedom and control over his existence than Paul D” (181).

Paul D internalizes and seems to project this less-than-human existence upon Sethe, leading to their estrangement: "'You got two feet, Sethe, not four,' he said. . . Later he 
would wonder what made him say it. The calves of his youth? .. . How fast he had moved from his shame to hers. ... Meanwhile the forest was locking the distance between them, giving it shape and heft" (165). bell hooks names estrangement from nature as the cause for African Americans' internalization of whites' racist mindset: "Working in conditions where the body was regarded solely as a tool (as in slavery), a profound estrangement occurred between mind and body. . . . Estrangement from nature and engagement in mind/body splits made it all the more possible for black people to internalize white-supremacist assumptions about black identity" (54-5). Not only do images of nature reflect slavery's effect upon Paul D's manhood and psychological condition, but also they reveal its disruption of healthy human relationships.

Paul D's denigrating words to Sethe strike a painful chord because she too has suffered humiliating subjugation at the hands of Schoolteacher and his pupils. Despite her captivity, Sethe manages to find some comfort in the beauty of the landscape at Sweet Home, musing of the growing season, "Something sweet lives in the air that time of year, and if the breeze is right, it's hard to stay indoors" (192). However, approaching the Sweet Home house from the grape arbor, a serene setting where Sethe has left her infant Beloved, Sethe overhears Schoolteacher instructing one of his students to list Sethe's human versus animal characteristics. Immediately, Sethe experiences a physical revulsion to what she hears, and nature displays her response and its relation to her daughter: "When I bumped up against a tree my scalp was prickly. ... I got to the grape arbor fast enough, but I didn't have the muslin. Flies settled all over your face, rubbing their hands. My head itched like the devil. Like somebody was sticking fine needles in my scalp" (193).

As Sethe explains to Beloved after her ghostly appearance at 124, Sethe's dwelling, the 
psychological impact of this episode is key to her decision to kill her daughter when Schoolteacher comes to Ohio to recapture her and her children: “... no one, nobody on this earth, would list her daughter's characteristics on the animal side of the paper" (251). The pupils' dehumanization of Sethe takes a more violent turn when they sexually assault her, beating her and taking milk from her breasts, treating her as if she were a cow. Episodes such as these emphasize the precarious role that the natural world plays in capturing characters' experiences, serving as a source of comfort, a glimpse of freedom, and an emblem of physical and psychological oppression.

As in Beloved, images of the natural world, especially animals, in Song of Solomon correspond to characters' experiences of subjugation as well as their visions of freedom. These images are especially impressive upon the novel's protagonist, Milkman Dead, and Guitar, Milkman's closest friend and, in many respects, his moral compass. At the beginning of the novel, Robert Smith's effort at flight from the rooftop of No Mercy Hospital is an example of one man's attempt for personal liberation yet at the same time is an instigation of both Milkman's and Guitar's recognitions of the limits upon their freedoms in racially segregated Detroit.

Smith's determination to "fly away on my own wings" (3) leads to a neighborhood gathering and becomes a milestone in the collective memory of the community. Newly arrived from the South, Guitar's first effort at speaking up to a white person, his correction of a nurse's incorrect spelling of the word "admissions," falls on deaf ears: "The North was new to him and he had just begun to learn he could speak up to white people. But she'd already gone, rubbing her arms against the cold" (7). Yet the event is also Guitar's introduction to Pilate, who sings a folk song that is later revealed to be a portrait of Milkman's family 
history and more broadly, the key to metaphorical flight through appreciation of one's cultural legacy. Pilate's singing fascinates Guitar: “. . . the cat-eyed boy listened to the musical performance with at least as much interest as he devoted to the man flapping his wings on top of the hospital" (7). Later, during a visit to Pilate and her daughters, when Guitar and Milkman again hear the song, which contains the line "Sugarman done fly away," Guitar's understanding of its significance is clear: "[Milkman] risked a glance at his friend and saw the setting sun gilding Guitar's eyes, putting into shadow a slow smile of recognition" (49).

For Milkman, musing on Smith's action initially causes his disillusionment regarding the limits of his potential within a racist society. In essence, Robert Smith at first represents Milkman's inability to contemplate a future: "Mr. Smith's blue silk wings must have left their mark, because when the little boy discovered, at four, the same thing Mr. Smith had learned earlier — that only birds and airplanes could fly—he lost all interest in himself. To have to live without that single gift saddened him and left his imagination so bereft ..." (9). This hopelessness, which is apparent in additional images associated with nature, pervades the Dead household. Milkman's sisters, Magdalene called Lena and First Corinthians, make red velvet rose petals to sell to Gerhardt's Department store, and the earnestness with which the sisters toil at these synthetic materials, mere approximations of flowers, that lie "in peck baskets for months" (10) highlights the lack of purpose that distinguishes the family.

Milkman is acutely aware of the stagnation of his "Dead" family, for which his father Macon carries much of the blame. While Macon is a prominent social fixture as owner of several of the homes in the community, Milkman disrupts any potential for domestic tranquility: "If he did manage to slip by his sisters and avoid their casual malice, he knelt in 
his room at the window sill and wondered again and again why he had to stay on level ground. The quiet that suffused the ... house then, ... was not peaceful, for it was preceded by and would soon be terminated by the presence of Macon Dead" (10). Macon's forcing the family to ride around town on Sundays in order to show off his automobile, which contains a statue of a winged woman as a hood ornament, further solidifies Milkman's inertia. As the boy gazes out the back window, his disposition is tied to images of flight: “. . . riding backward made him uneasy. It was like flying blind, and not knowing where he was goingjust where he had been—-troubled him" (32).

Macon's influence is also central to Guitar's inability to experience peace in his home with his grandmother, as Macon threatens to evict them. As Guitar and his siblings become aware of their landlord's threats, they move out of the sunlight and into the shadows, indicating in natural imagery the oppression that they experience. Again Morrison describes Guitar as catlike as he faces his grandmother's hardship: “'Do we got to move?' ... His cat eyes were gashes of gold. Mrs. Bains let her hand fall to her side. 'A nigger in business is a terrible thing to see"' (22). The gold that appears in Guitar's eyes suggests the profit-making drive that propels Macon and more generally typifies life in the North. Much like Paul D's internalization and projection onto Sethe of the dehumanization that demoralizes him at Sweet Home, Macon profits off of his neighbor's hardships, echoing the exploitative practices of whites.

As the novel progresses and Milkman eventually comes to awareness of the legacy of his ancestors, Milkman and Guitar, each in his own way, realizes the importance of appreciating his people. Images of birds mirror this progression to maturity. As they pattern, in reverse, Milkman's family's migration to Detroit, the two notice a white peacock which, like Robert 
Smith, is poised for flight on a rooftop. As the bird flies down, Milkman is ecstatic, feeling "again his unrestrained joy at anything that could fly" (178). However, like all peacocks, the bird, with its elaborate plumage, is not adept at flight. Commenting on the bird's condition, Guitar eloquently states: "All that jewelry weighs it down. Like vanity. Can't nobody fly with all that shit. Wanna fly, you got to give up the shit that weighs you down" (179). While the two have been on a quest to find gold that they believe has been left in a cave in Virginia, Guitar's words hint at the futility of this goal and Milkman's final rejection of the materialism that drives his father.

Milkman's self-discovery, a liberation that he achieves by tracing his family lineage to Solomon, his great-grandfather, whose flight back to Africa is the subject of his aunt Pilate's "Sugarman" song, culminates in his own flight at Ryna's Gulch. Milkman learns to value Pilate during this process of discovery, as she, who sings the family folklore and keeps her father's bones, is his closest link to the ancestors he never knew. He says of Pilate, "Now he knew why he loved her so. Without ever leaving the ground, she could fly" (336). Immediately after her death, as Guitar lies in wait for him, Milkman leaps: "As fleet and bright as a lodestar he wheeled toward Guitar and it did not matter which one of them would give up his ghost in the killing arms of his brother. For now he knew what Shalimar knew: if you surrendered the air, you could ride it" (337).

Animal imagery conveys both Milkman's and Guitar's fates, which are ambivalent. While Milkman's birdlike flight, a revelation of sorts, represents his ultimate maturation and capacity for love, on its most literal level, akin to Robert Smith's flight, it is possibly a suicide, perhaps indicating a man's inability to live a truly liberated existence within the confines of racism. Guitar's comparison to a cat suggests his development into a predator, 
which takes place because of his genuine, yet problematic, efforts to seek justice, through the Seven Days group, for crimes against African Americans such as Emmett Till. For both, these images reflect growing self-determination as well as the limits of, and violence associated with, that greater freedom. In this words of Barbara Christian, "Song of Solomon is structurally based on the conflict between this preoccupation with earthly matters and the need to fly, that is by nature a part of each of us" (77). The dualism evident in this evocation of the natural world as a gauge for personal liberation is emblematic of the ambiguity with which Morrison draws African Americans' relationships to nature.

The natural world in Morrison's novels is the setting for tremendous violence enacted against black communities, which complicates the idyllic presentations of nature that are typical of the tradition in American literature that includes writers such as Henry David Thoreau. Legler writes, "Where Thoreau treats other bodies, the Irish . . , his Indian guide . . ., or the 'ideal maiden'..., these raced and classed and sexed bodies are at the same time ironically 'naturalized' and removed from nature; they don't occupy the same privileged space in the landscape that Thoreau does because of his whiteness and his maleness" (76). While the legacy of violence in the land evokes similarly contradictory depictions of relations between African Americans and the environment in Morrison's works, this ambiguity should not preclude discussion of these texts as nature writing. Legler further explains why many critics remove African American literature from discussions of nature writing: “'Black bodies' have become, in the white mind, urban bodies, bodies that are alienated from natural landscape, and therefore have no place in the nature-writing canon-a canon that is meant to celebrate connection to land" (81). It would seem that nature writingand its critical discourse - do not offer escape from societal concerns, particularly 
accountability for violence that has been intimately tied to the landscape.

African American characters' inabilities to view nature primarily as refuge are directly tied to the power dynamics of society, which undermine understandings of "wilderness" as pristine or unaffected by the actions of humans. As Wallace and Armbruster determine:

Morrison's work as a whole may suggest that a respect for the dignity of wild things is superior to the drive to control nature, but what is even more notable is her focus on the different and often conflicting interpretations of nature espoused by various human communities and the ways dominant groups use these interpretations to control and subjugate both human and nonhuman others. By consistently representing clashing cultural perceptions of the natural world, Morrison emphasizes that any human perception of nature is a culturally mediated one rather than an inherent truth about the world. (213)

Morrison's characters' experiences of nature, infused with the dynamics of cultural clash, may thereby be understood to represent cultural hybridity, the "in-between spaces" that Bhabha defines as the center of identity and of the production of society. Characters' varying degrees of "wildness," their estrangement from versus their communion with nature, often propel their senses of identity as well as their relationships with others in their communities.

As Wes Berry notes, “"wild” places are far from being ahistorical” (159).

In Beloved, the natural world consistently reveals signs of great beauty as well as horrific violence that permeate the psychological conditions of the characters. For Sethe, memories of Sweet Home surface unexpectedly in flashbacks that are associated with nature:

She might be hurrying across a field, running practically, to get to the pump quickly and rinse the chamomile sap from her legs. Nothing else would be in her mind. . . . Nothing. . . . Then something. The plash of water, the sight of her shoes and stocking awry on the path where she had flung them; or Here Boy lapping in the puddle near her feet, and suddenly there was Sweet Home rolling, rolling, rolling out before her eyes, and although there was not a leaf on that farm that did not make her want to scream, it rolled itself out before her in shameless beauty. It never looked as terrible as it was and it made her wonder if hell was a pretty place too. Fire and brimstone all right, but hidden in lacy groves. Boys hanging from the most beautiful sycamores in the world. It shamed her-remembering the wonderful soughing trees 
rather than the boys. Try as she might to make it otherwise, the sycamores beat out the children every time and she could not forgive her memory for that (6).

These images, a mixture of the serene with the diabolical, cause Sethe to distrust her own psyche, as memories enforce her feelings of shame associated with her leaving Sweet Home without Halle as well as her guilt about killing Beloved.

The pervasiveness of violence in the forefront of Sethe's mind is coupled with her articulation of her "rememory," the collective history of her community. As Sethe explains to her younger daughter Denver, the horrendousness of her experience is not merely a recollection; instead, it continues to exist. This ever-present threat drives Sethe to warn Denver away from the past:

Places, places are still there. If a house burns down, it's gone, but the place - the picture of it - stays, and not just in my rememory, but out there, in the world. . . . Right in the place where it happened. Someday you be walking down the road and you hear something or see something going on. So clear. And you think it's you thinking it up. A thought picture. But no. It's when you bump into a rememory that belongs to somebody else. Where I was before I came here, that place is real. It's never going away. Even if the whole farm - every tree and grass blade of it dies. The picture is still there and what's more, if you go there-you who never was there-if you go there and stand in the place where it was, it will happen again; it will be there for you, waiting for you. So, Denver, you can't never go there. Never. Because even though it's all over - over and done with—it's going to always be there waiting for you. (36)

Sethe's attempts to divest her children from the past are her justification for killing Denver's older sister. Ironically, it is through a supreme act of violence, her cutting Beloved's throat, that Sethe acts to protect her from the terrorism of Schoolteacher's plantation. In her efforts to protect her children, Sethe thereby exacts what little power she can muster within a violent, oppressive society.

Sethe herself has been physically marked forever by the violence of Sweet Home, however, and this fact is visible in the scars on her back, which Amy Denver, the white 
woman who helps deliver Sethe's youngest daughter, compares to a chokecherry tree. Similar to the simultaneously beautiful and terrifying image of boys hanging from the sycamore trees of the plantation, the chokecherry tree both signifies extreme pain and facilitates tender healing. At Paul D's arrival, right after Sethe recounts the white boys' sexual assault of her at Sweet Home, the tree on her back is the focal point for Sethe's first experience of sexual intimacy since her marriage to Halle: “. . . she felt Paul D behind her and his hands under her breasts. She straightened up and knew, but could not feel, that his cheek was pressing into the branches of her chokecherry tree.... And he would tolerate no peace until he had touched every ridge and leaf of it with his mouth, none of which Sethe could feel because her back skin had been dead for years" (17-18). Again, the violence of enslavement on the plantation is ever-present in characters' experiences of intimacy. "Rememory" of this violent legacy thus affects Sethe's and Paul D's relationship, as their interactions mix the regenerative potential of human touch with a confrontation of physical brutality, all in language suggesting nature.

Guitar, in his explanation of his involvement in the Seven Days, acknowledges his own rememory of sorts, which is likewise pervaded by violence and tied to images of the landscape. When he explains to Milkman the group's retaliation against whites for murders of African Americans, Guitar articulates ways in which the landscape, as well as humansespecially blacks and Indians—-have been violated: "The earth is soggy with black people's blood. And before us Indian blood. Nothing can cure them, and if it keeps on there won't be any of us left and there won't be any land for those who are left. So the numbers have to remain static" (158). Guitar's intentions to impose balance on the oppressive society he inhabits are not born of malice, however. Similar to Robert Smith's suicide note, which 
reads, "I loved you all" (3), Guitar names love as the motivating factor behind his actions. He asserts to Milkman, “What I'm doing ain't about hating white people. It's about loving us. About loving you. My whole life is love" (159).

Guitar, who believes that there are no innocent people, perceives violence to be an inescapable reality among humans as well as the earth they inhabit. In this way, his view of nature encompasses both survival and destruction, and as for Smith and ultimately for Milkman, working toward liberation within that framework necessitates a degree of affection as well as violence. Philip Weinstein describes this paradox as "love under pressure," which expresses "the counterreality of racial grief and retaliation, of love cohabiting with murder and hate" (xvii). Weinstein concludes, "love emerges . . . as the most precious resource wasted, the only resource finally useful, in the confronting and telling of American race relations" (xvii). As is evident in Guitar's words as well as in Weinstein's reference to love as a resource, this love is of the earth as well as of the humans who inhabit it and whose blood has flown upon it.

Guitar's affection for and disillusionment concerning the natural world is an ambivalence that can be traced to his description of childhood hunting excursions. Paralleling the "Delta Autumn" section of Faulkner's Go Down, Moses, Guitar's realization that a deer he killed was a doe, a symbol of nature's regeneration, sullies the hunting ritual. As a child in woods of the South, Guitar inhabited the woods rather than simply entering them during the hunts: "Everybody said I was a natural. I could hear anything, smell anything, and see like a cat. . . After we moved up here with my grandmother, that was the only thing about the South I missed" (85). On a summer trip back home, Guitar realizes that he has become estranged from this synchronic connection to nature: "I felt . . . bad. You know what I mean? I killed a 
doe. A doe, man" (85). Guitar realizes that even the scene for his most positive memories is marked by violence of which he is not innocent, and this recognition fuels later actions, which culminate in his murder of Pilate. Guitar's killing of a doe may thereby be read as psychologically traumatic and as a precursor of his final destructive act.

The psychological trauma that marks Morrison's characters is expressed as "wildness," which is mainly the result of the pressures of an oppressive society. Wallace and Armbruster call this destructive wildness, which occupies characters who are unable to overcome hatefilled environments, “culturally induced wildness” (216). Some characteristics of wildness, however, are positive, valorizing nature's healing potential. Wallace and Armbruster characterize this wildness as extracultural, an "expansive wildness" (216). Both of these forms of wildness surface in imagery that brings to mind the earth and its natural processes. As borders between humans and nature collapse, wildness drives characters to momentous decisions and actions.

Enslavement creates wildness in many of the characters in Beloved, as confinement inhibits healthy human interaction and suggests a kind of savagery that reveals more about the oppressors than those oppressed. Slavery's impact is vividly illustrated in the carnival that Sethe, Paul D, and Denver attend shortly after Paul D's arrival. On display is a "Wild African Savage [who] shook his bars and said wa wa" (48-9). But this scene belies the truth of the "Savage's" humanity: "Paul told everybody he knew him back in Roanoke" (49). As the carnival display implies, the savagery consigned to African Americans is an invention that reveals a great deal about the psychological states of whites who sustain this invention. In the words of Stamp Paid:

Whitepeople believed that whatever the manners, under every dark skin was a 
jungle. Swift unnavigable waters, swinging screaming baboons, sleeping snakes, red gums ready for their sweet white blood. . . . But it wasn't the jungle blacks brought with them to this place or the other (livable) place. It was the jungle whitefolks planted in them. And it grew. It spread. In, through and after life, it spread, until it invaded the whites who had made it. Touched them every one. Changed and altered them. Made them bloody, silly, worse than even they wanted to be, so scared were they of the jungle they had made. The screaming baboon lived under their own white skin; the red gums were their own. Meantime, the secret spread of this new kind of whitefolks' jungle was hidden, silent, except once in a while when you could hear its mumbling in places like 124. (198-9)

Stamp Paid's words capture the way in which boundaries between oppressor and oppressed are unstable. In the same way that Paul D internalizes and attempts to exact power over Sethe by reminding her that she has two feet instead of four, whites encompass the negative wildness that they imagine for African Americans in their justification for enslaving them.

Stamp Paid also alludes to the destructive wildness that comes to occupy Sethe's household at 124, embodied in the ghostly figure of Beloved. Beloved represents the drastic action that Sethe believes is necessary to disrupt schoolteacher's ability to enslave her children, and thus, she in a sense represents the "rememory" of slavery, particularly its disruption of families. This disruption occurs when Beloved seduces Paul D, pleading with him "to touch me on the inside part and call me my name" (116). Paul D then abandons Sethe, and when at the end of the novel he returns, Stamp Paid's mention of Beloved immediately evokes the past, sending a shudder through Paul D: "He didn't know it if was bad whiskey, nights in the cellar, pig fever, iron bits, smiling roosters, fired feet, laughing dead men, hissing grass, rain, apple blossoms, neck jewelry, Judy in the slaughterhouse, Halle in the butter, ghost-white stairs, chokecherry trees, cameo pins, aspens, Paul A's face, sausage or the loss of a red, red heart" (235). This description of Paul D's rememory mingles images of bondage and sustenance, a conflicted response to the environment and its 
connection to the horrific past that Beloved signifies.

Beloved comes between not only Paul D and Sethe, but also between 124 and the local community. Sethe becomes estranged from her neighbors, who are afraid of the "wild" supernatural force at 124 . Ultimately, however, members of the community save Sethe from Beloved's parasitic presence, in effect exorcising the house and ensuring a new beginning for Sethe when they draw Denver and Sethe outside:

For Sethe it was as though the Clearing had come to her with all its heat and simmering leaves, where the voices of women searched for the right combination, the key, the code, the sound that broke the back of the words. Building voice upon voice until they found it, and when they did it was a wave of sound wide enough to sound deep water and knock the pods off chestnut trees. It broke over Sethe and she trembled like the baptized in its wash. (261)

This intervention suggests the power of the African American community to overcome negative wildness, or "rememories." As the violence of the past has become a fixture in the landscape, so African Americans' power over their destinies is strikingly evident in the natural world, with a force strong enough to "sound deep water."

In contrast to Beloved's haunting influence, Sixo espouses a wildness that is positive, or “expansive" in Wallace and Armbruster's formulation. Sixo, referred to repeatedly as the "wild man," is unique in his preservation of non-European culture. Importantly, he draws on American Indian culture in his rejection of the dominant culture. When he makes elaborate arrangements for a meeting at a stone structure with Patsy, christened his "Thirty Mile Woman," he first asks “the Redmen's Presence if he could bring his woman here," and "It said yes" (24). For Sixo, this Redmen's Presence is tied to nature, and the woods offer him a refuge from the tactics of his oppressors. After his rendezvous with the Thirty Mile Woman, Sixo is able to escape the whip by "melt[ing] in the woods" (25). According to Paul D, "Sixo 
went among trees at night. For dancing, he said, to keep his bloodlines open, he said.

Privately, alone, he did it" (25). Sixo tells stories of his actions in the woods to Halle and the Pauls in a "way that made them cry-laugh" (25), lifting their spirits in an otherwise desperate existence. Eventually, Sixo's storytelling ends because he decides to stop speaking English "because there was no future in it" (25), an overt rejection of the culture of his oppressors. Sixo's ultimate triumph over those who seek to destroy him is the Thirty Mile Woman's pregnancy, which insures that Sixo's legacy will endure after his captors kill him. As the white men burn him, he laughs, exclaiming "Seven-O! Seven-O!” (226), an image that is forever impressed upon Paul D. In the words of Trudier Harris, “Sixo's solitude, occasional preference for nature over human beings, unusual behavior, and aura of derring-do bring to mind such folk figures as Big Sixteen and Stagolee. ... this breed of man, Garner or no Garner, cannot be contained by a system called slavery" (179). Sixo's wildness is thereby key to his ability at least to metaphorically survive oppression and exert control over his own life, and this wildness is linked to Sixo's embrace of American Indian legacies in the geographical space he inhabits. For Sixo, "rememory" is thereby positive, endowing him with the capacity for resistance.

In Song of Solomon, negative wildness, ensuing from her inability to command Milkman's love, leads Hagar to behave with feverish jealousy and ultimately to commit suicide. Milkman's mother Ruth observes that "there was something truly askew in this girl. That here was the wilderness of Southside. Not the poverty or dirt or noise, not just extreme unregulated passion where even love found its way with an ice pick, but the absence of control" (138). As Guitar tries to explain to Hagar, her greatest mistake in her relationship with Milkman is her desire to own him: “'You can't own a human being. . . Could you 
really love somebody who was absolutely nobody without you? ... You're turning over your whole life to him. Your whole life, girl. And if it means so little to you that you can just give it away, hand it to him, then why should it mean any more to him?" (306). Because in Southside, lacking a sense of purpose or hope for the future, Hagar is unable to control her own destiny, she tries to exert control over Milkman, which Morrison describes as "anaconda love" (137). This "wild" behavior echoes the control that whites have historically sought to impose upon African Americans, and in this sense, she has internalized the structure that oppresses her.

Conversely, Hagar's mother, Pilate, exhibits wildness that, like Sixo's example to the other men of Sweet Home, is inspiring, especially to Milkman. Like Sixo, Pilate rejects behaviors that are tied to the dominant culture and lives more closely in tune with the natural world. Living without electricity or gas, Pilate and her daughters exist "pretty much as though progress was a word that meant walking a little farther down the road" (27). Physically, Pilate displays particularly nourishing signs of nature. At his first visit to her house, Milkman notices that she smells like pine trees, and he "knew he could have watched her all day: the fingers pulling thread veins from the orange sections, the berry-black lips that made her look as though she wore make-up" (38). Pilate's woodsy sensibility can be traced to her and Macon's time living in the forest after the death of their father. Unlike Macon, who responds to his father's death by putting his heritage permanently in the past and maximizing his profit-making potential, Pilate retains the influence of her roots in Virginia, which runs counter to the predominant lifestyle in her Detroit community.

Many of the female characters in Paradise also display expansive wildness in engaging in lifestyles outside of the strictures imposed by the "Fathers" of Ruby, an all-black Oklahoma 
town originally named "Haven." Connie and the other inhabitants of the Convent, a former school for Arapaho girls that has become a refuge of sorts for a variety of women who are estranged from their families, reject traditional Catholicism represented in the Convent as well as the Christian fundamentalism practiced in nearby Ruby. Instead, the women practice an alternative religion that seems to draw on Connie's Brazilian ancestry, and at the end of the novel, they are murdered in part because of this rejection of Christianity. As Wallace and Armbruster explain, their alternative spirituality "helps the women confront wounds from their pasts and teaches them to love themselves. Christ-like, the women reappear after their deaths to those who love them. . . their sacrifice may have taught Ruby the way to redeem itself by making room for wildness rather than walling it out" (223).

Their influence is indeed compelling for Billie Delia, a young outcast who is labeled as "wild" because of her sexual arousal during a horseback ride. While most of the community forces her to "carry the burden" (151) of apparently having loose morals, as Billie sees it, the women are an affront to the town: "When will they reappear, with blazing eyes, war paint and huge hands to rip up and stomp down this prison calling itself a town? ... A backward noplace ruled by men whose power to control was out of control. . . who had seen in lively, free, unarmed females the mutiny of the mares" (308). Like Sixo's and Pilate's rejection of cultural mores associated with Europeans, the women's rejection of Western religion is inspiring to at least one resident of Ruby. Expressing their religion for the first time in "the rain's perfume. . . like lotion on their fingers. . like balm on their shaved heads" (283), this culturally expansive act is tied to the natural world.

Characters' responses to the natural world are intimately tied to the prevalence of migration as a theme in Morrison's novels and as a broader reality in African American 
history. Morrison patterns movements between rural and urban, bondage and freedom, revealing the psychological and spiritual implications of dislocation. As with her depictions of violence and wildness, Morrison's images of geography are tied to characters' senses of identity and are infused with realities of race, class, and gender. Finally, this integration of humanity and geography reflects hybridity, especially the cross-cultural experiences of African Americans and American Indians.

Paul D's escape from slavery in Alfred, Georgia and journey to 124 in Ohio marks the character's varied responses to his environment, including his sense of rootlessness, which is portrayed in images of nature. Paul D expresses this journey as a shared reality for African Americans:

During, before and after the War he had seen Negroes ... Who, like him, had hidden in caves and fought owls for food; who, like him, stole from pigs; who, like him, slept in trees in the day and walked by night; who, like him, had buried themselves in slop and jumped in wells to avoid regulators, raiders, paterollers, veterans, hill men, posses and merrymakers. . . . Move. Walk. Run. Hide. Steal and move on. (66)

This arduous journey to escape enslavement forces individuals to steel themselves psychologically against the vulnerability of family connections. Paul D's feeling of emotional isolation is apparent in his description of migration: “. . . he wanted simply to move, go, pick up one day and be somewhere else the next. Resigned to life without aunts, cousins, children. Even a woman, until Sethe" (221). Ultimately for Paul D, captivity is the inability to love freely: "A woman, a child, a brother-a big love like that would split you wide open in Alfred, Georgia... . to get to a place where you could love anything you chose — not to need permission for desire—well now, that was freedom" (162).

The transience that characterizes Paul D's approach to the landscape is informed by his 
inability to experience a sense of rootedness, or home, on it. Though he displays a visceral response to the beauty of the natural world, Paul $\mathrm{D}$ also knows that he may never be able to put down roots safely on that land: “. . . he could not help being astonished by the beauty of this land that was not his. He hid in its breast, fingered its earth for food, clung to its banks to lap water and tried not to love it.... Anything could stir him and he tried hard not to love it" (268). Berry ties this dissociation directly to the character's inability to own property: "By emphasizing Paul D's schizoid attraction to and dissociation from the land, Morrison forces us to consider how the impulse to possess land may be more complex for historically marginalized people" (151). However, Paul D's emotional response to the earth transcends wishes to own it; his experiences of bondage and escape have been marked by living close to this land. Rather than wishing to own acreage, Paul D instead seeks identification with the land, a sense that it represents him in the same way that it is the site of American Indian heritage. Since African Americans have been forcibly removed from the continent of their ancestry, it is difficult for those enslaved like Paul D to view America, the setting for such violence, as a homeland.

While Paul D's escape to freedom drives him to resist the emotional investment of permanency, Sethe's journey instead prompts her to insist on that permanency. She explains, "I got a tree on my back and a haint in my house, and nothing in between but the daughter I am holding in my arms. No more running — from nothing. ... I took one journey and I paid for the ticket, but let me tell you something, Paul D Garner: it cost too much! Do you hear me? It cost too much. Now sit down and eat with us or leave us be" (15). Significantly, Sethe names Denver as the only positive outcome of her migration North, and her wishes to remain at 124 despite its haunting reinforce her insistence on a permanent home. Sethe draws a 
strong contrast between this imperfect life in Ohio and the one she fled in the South, indicating the naivete with which she imagined her life there with Halle as stable domestically, “. . . as though Sweet Home really was one. As though a handful of myrtle stuck in the handle of a pressing iron propped against the door in a whitewoman's kitchen could make it hers" (23). Whereas Paul D initially resists domesticity, Sethe seems to embrace it as representative of her survival and as her only possibility for grounding on such a problematic landscape.

Like Sethe, Baby Suggs's sense of freedom is tied to her children, particularly her son Halle. Halle, who performs additional labor to save enough money to purchase Baby Suggs from Mr. Garner, is the source of his mother's greatest pride. In her words, “A man ain’t nothing but a man ... But a son? Well now, that's somebody" (23). Her loss of Halle, as well as the way in which her other children are scattered in various locations because of the slave trade, represent to Baby Suggs the "nastiness of life" (23):

... in all of Baby's life, as well as Sethe's own, men and women were moved around like checkers. Anybody Baby Suggs knew, let alone loved, who hadn't run off or been hanged, got rented out, loaned out, brought up, brought back, stored up, mortgaged, won, stolen or seized. So Baby's eight children had six fathers. What she called the nastiness of life was the shock she received upon learning that nobody stopped playing checkers just because the pieces included her children. (23)

For Baby Suggs, slavery's commodification of people parallels commodification of landscape. The geographical separation of her family causes dislocation in a literal sense and at the same time prevents the psychological comfort of home.

Though Milkman is not subject to the slavery experienced by the characters in Beloved, commodification of land similarly influences his life in Detroit, which is the result of his family's migration from the South to the North. Though Detroit is an urban area, it is 
nonetheless relevant to discussions of Morrison's depictions of the natural environment, as it reflects Legler's concept of "twentieth-century urban wilderness" (80). Morrison's description of the city as in an in-between space because of its precarious relation to water highlights the discomfort with which its residents occupy it:

... the people living in the Great Lakes region are confused by their place on the country's edge - an edge that is border but not coast. They seem to be able to live a long time believing, as coastal people do, that they are at the frontier where final exit and total escape are the only journeys left. But those five Great Lakes which the St. Lawrence feeds with memories of the sea are themselves landlocked, in spite of the wandering river that connects them to the Atlantic. Once the people of the lake region discover this, the longing to leave becomes acute, and a break from the area, therefore, is necessarily dream-bitten, but necessary nonetheless. (162)

For the residents of Southside, especially the Dead family, Detroit is not truly home, as it is far removed from the location of their ancestors. Like the Great Lakes' memories of the sea, memories of these originary lands, the South and ultimately Africa, linger and ultimately characterize Milkman's journey to the South.

The sense of dislocation that permeates Detroit is evident in the actions of Macon Dead. While rural plantations such as Sweet Home carve the land into properties governed by an all-powerful overseer, Macon Dead's rental properties in Detroit concentrate the wealth of Southside into similarly singular hands. In addition to controlling almost all of the property in the area, Macon seeks to expand his fortune in real estate by building summer homes next to the water. When his daughter Corinthians questions the relevance of this endeavor to the residents of Southside, Macon answers, "People will drive to a summer house. White people do it all the time"(35). When Corinthians then asserts "Negroes don't like the water," Macon replies, "They'll like it if they own it" (35). Macon sees the development of business ventures as critical to his individual success regardless of community concerns, an impulse 
that no doubt resembles the guiding principles of the nearby plastics manufacturing plant that has sullied the lake with chemical waste. It is this drive for material success, a production of "civilization" that is also a focus of Faulkner's texts, that Macon believes is his most important legacy to Milkman.

Milkman's relationship to his father is marked by this drive for wealth, leading Milkman to wonder about Macon's relationship to his own father. In answering Milkman's questions about this father-son relationship, Macon recalls his traumatic reaction to his father's murder: “... something wild ran through him when he watched the body twitching in the dirt. His father had sat for five nights on a split-rail fence cradling a shotgun and in the end died protecting his property" (50-1). Macon cherishes proud memories of his father, and this pride results chiefly from Macon Sr.'s ownership of Lincoln's Heaven, a 150-acre farm in Pennsylvania that Macon Sr. established after his emancipation.

Macon Sr.'s property ownership differs significantly from Macon's, however. Whereas in Detroit, Macon is driven mostly by large profits, which lead him to develop open areas of land, Macon Sr.'s farm north of the Susquehanna River, eighty acres of which were woods, was mainly undeveloped, a family farm that featured a pond and stream full of fish, an abundance of deer and wild turkey, and fruit trees. Lincoln's Heaven thus allowed the Deads to sustain themselves through a more harmonious relationship to the natural environment than the existence that later generations of Deads endure in Detroit. As Wallace and Armbruster point out, Macon Sr.'s farm "signified volumes to the community" (225), evoking a sense of pride that Macon does not inspire in the residents of Southside. In this way, Macon Sr. evidences a freedom that is intertwined with his experience of the natural world: “. . Macon Dead Sr.'s pride in his farm shows us how loving the land can result from 
a stewardship made possible by legal ownership, a helpful reminder to environmental thinkers, nature writers, and ecocritics who have too quickly equated ideologies of land use with land abuse" (226).

Macon Sr.'s farm is the center of Macon's sense of heritage as well as the inspiration for Macon's acquisition of properties in Detroit. During the early years of his marriage to Ruth, Macon would reminisce about the farm, "re-creat[ing] the land that was to be his" (52). While this description suggests the literal transfer of property to Macon that should have occurred, more importantly, it indicates the way in which the farm was the site of Macon's metaphorical grounding, his home, the location of his heritage. Lincoln's Heaven is thus the location of Macon's "rememory," the collective history of his people's emancipation, represented especially in the names of animals such as President Lincoln, the mule:

... when he was just starting out in the business of buying houses, he would lounge around the barbershop and swap stories with the men there. ... now he was doing it again, with his son, and every detail of that land was clear in his mind: the well, the apple orchard, President Lincoln; her foal, Mary Todd; Ulysses S. Grant, their cow; General Lee, their hog. That was the way he knew what history he remembered (52).

Macon has left this history largely untold, however, as he admonishes his children to stay away from Pilate, in many ways the keeper of the family history, and tells Milkman very little about his family's origins in Virginia.

Macon overreaches when it comes to the concept of ownership, ignoring the other responsibilities for the land that Macon Sr. upheld. He cautions Milkman: "Pilate can't teach you a thing you can use in this world. Maybe the next, but not this one. Let me tell you right now the one important thing you'll ever need to know: Own things. And let the things you own own other things. Then you'll own yourself and other people too" (55). Macon's desire 
to own other people is hauntingly similar to the very plantation system that held his father captive for so many years. In the words of Weinstein, "Macon Dead Jr. still lives the fallout of that antebellum dispossession. His urban properties bring him only anomie and hunger, no connection with the land they lodge upon or with fellow blacks whom he views through a capitalist lens as tenants, not distant kinfolks" (80).

Milkman's migration to the South eventually reverses the disassociation from the land, specifically Lincoln's Heaven, that typifies the Deads after their migration to Detroit. Milkman begins the journey, however, very much driven by the promise of material wealth in the form of gold. Milkman's internalization of Macon's example, that of projecting an air of privileged social standing, comes to bear on his interaction with those he meets in his travels. As Weinstein argues,

... the town of Shalimar will let Milkman discover something new, but . . it will also recognize something old: his unconscious assumption of class superiority. . . If Faulkner's wilderness is shaped to transcend class and gender demarcations, Morrison's Shalimar is shaped to make them erupt. Macon Dead's entire middleclass project comes to its logical dead end here, as his urban, moneyed, deracinated son confronts the people he has sought to leave behind. This is the black underclass he is meant to be superior to, to collect rents from. (137)

While Milkman's journey into Shalimar shares obvious parallels to Ike McCaslin's initiation to the wilderness in Faulkner's Go Down, Moses, Milkman's initiation is more explicitly tied to community concerns, uniting thoughts about and interactions with humans with a solitary experience in the deepest recesses of the woods.

Milkman's ego dissolution, which occurs during a hunting expedition instigated by Calvin and other local men in Shalimar, is prompted by his realization that the men are able to communicate with the hunting dogs, signifying a synchronous relationship between them and the natural environment. Like Ike, who must surrender his watch and compass before being 
fit to enter the woods of Yoknatapawpha, Milkman realizes his material possessions are of no use to him in the forest of Shalimar: "There was nothing here to help him—not his money, his car, his father's reputation, his suit, or his shoes. In fact they hampered him. Except for his broken watch, and his wallet with about two hundred dollars, all he had started out with on his journey was gone" (277).

Realizing that his father's upper class way of life is of no use to him, Milkman is immediately able to hear the men and dogs talking to one another, an almost mystical exchange:

All those shrieks, those rapid tumbling barks, the long sustained yells, the tuba sounds, the drumbeat sounds, the low liquid howm howm, the reedy whistles, the thin eeeee's of a cornet, the unh unh bass chords. It was all language. ... Language in the time when men and animals did talk to one another, when a man could sit down with an ape and the two converse; when a tiger and a man could share the same tree, and each understood the other; when men ran with wolves, not from or after them.... It was more than tracks Calvin was looking for-he whispered to the trees, whispered to the ground, touched them, as a blind man caresses a page of Braille, pulling meaning through his fingers.... He felt a sudden rush of affection for them all, and out there under the sweet gum tree, within the sound of men tracking a bobcat, he thought he understood Guitar now. Really understood. (278-9)

Milkman's contemplation of this relationship between men and the earth, a recollection that is akin to his father's musings about Lincoln's Heaven, is his own rememory of an African American legacy that is in effect indigenous to the landscape. Importantly, Milkman's description of this pre-modern language evokes images of the instrumentation of jazz, which is often referred to as America's indigenous music.

Perhaps most importantly, Milkman's experience allows him to feel empathy for people in his community, a virtue that he has been especially lacking in his relationships with Hagar and Guitar. According to Berry, “Milkman's rejuvenation involves much more than a bonding with so-called 'nature'; it also involves his growing respect for a human community 
and its history" (155). In this way, beyond Ike McCaslin's greater appreciation of wilderness through the hunt, Milkman gains a deeper understanding of reciprocity through his integral moment in the woods. This realization distinguishes Milkman's episode from the adventures of characters in other texts commonly classified as nature writing. According to Patrick D. Murphy, “. . . interanimation - the ways in which humans and other entities develop, change and learn through mutually influencing each other day to day_can be emphasized ... over traveling through, visiting or 'going-out-to-experience nature' approaches" (42-3). After his epiphany, or recognition of empathy through interanimation, Milkman discovers a new sense of affiliation with the landscape: “. . .he found himself exhilarated by simply walking the earth. Walking it like he belonged on in it; like his legs were stalks, tree trunks, a part of his body that extended down down down into the rock and soil, and were comfortable there — on the earth and on the place where he walked. And he did not limp" (281).

Milkman's newfound identification with the earth prepares him for gutting the bobcat, a ritual he participates in with the men of the local community. As Milkman joins this ritual, he is reminded of Guitar's explanation of his disillusionment at the injustice of whites' treatment of African Americans and his attempts to rectify that injustice through the Seven Days. As the men castrate and remove the heart from the bobcat, Milkman seems finally to understand his friend, who throughout the text has been associated with cat imagery. Guitar's words are at the forefront of Milkman's mind: "It is about love. What else but love?" (282). Though Guitar threatens Milkman's life at the end of the novel, Milkman acknowledges his love for Guitar, who is finally called his "brother" (337). This "rush of affection," achieved through Milkman's reversal of his family's northern migration, prompts Milkman's final act, which symbolically replays the legendary flight of Solomon, his ancestor and Shalimar's 
namesake, back to Africa, an additional reversal of the family's migration.

In his rejection of his father's materialistic drive, Milkman accepts the influence of Pilate, who more closely espouses the lifestyle that Macon Sr. displayed at Lincoln's Heaven. Indeed, even though Macon rejects Pilate, her singing reminds him of "fields and wild turkey and calico" (29), and the ginger smell, evocative of something "both intimate and far away" (85), that is particularly pervasive near her brown house in Detroit make Milkman and Guitar think of "the way freedom smelled, or justice, or luxury, or vengeance" (85). According to Harris, Pilate becomes Milkman’s “. . . spiritual guide into a world where commitment replaces detachment and where materialistic pursuits are dwarfed by inner fulfillment" (8990). Milkman's adoption of Pilate's norms is most clearly evident in his singing the song that she has sung so often in his presence, the song that details his ancestry in Virginia and accompanies a children's game, which Milkman refers to as "my game now" (327). Further, Milkman at last understands why Pilate keeps her name written on a piece of paper in a snuff box that hangs from her ear: "When you know your name, you should hang on to it, for unless it is noted down and remembered, it will die when you do" (329). Because of their migration across various landscapes, from Africa to America, South to North, rural to urban, members of Milkman's family have experienced dislocation that threatens a sense of freedom, home, and ultimately identity. In this context, one's name becomes a locus for permanency and takes on larger cultural significance. This importance of naming continues in African American and American Indian traditions.

While Song of Solomon focuses on Milkman's journey from North to South, in Paradise, the westward migration of African Americans to various locations in Indian Territory reflects the importance of establishing a permanent home to a sense of freedom. Like Paul D's 
arduous journey north from Georgia, Haven's Old Fathers undertake a difficult journey in their search for a place where they may create a town unhampered by Jim Crow strictures:

On the journey from Mississippi and two Louisiana parishes to Oklahoma, the one hundred and fifty-eight freedmen were unwelcome on each grain of soil from Yazoo to Fort Smith. Turned away by rich Choctaw and poor whites, chased by yard dogs, jeered at by camp prostitutes and their children, they were nevertheless unprepared for the aggressive discouragement they received from Negro towns already being built. (13)

Importantly, this description links the Freedmen's rejection to "each grain of soil," emphasizing the way in which these individuals are literally without a land.

Once the Old Fathers find a site in the Creek Nation, their construction of a gigantic Oven, which becomes a gathering place and cherished symbol of the town, signifies their insistence on domestic permanency. This permanency, however, is inextricably linked to the processes of the natural world, which in Oklahoma take shape in wide open space, "an amplitude of soul and stature that was freedom without borders and without deep menacing woods where enemies could hide. ... Here freedom was a test administered by the natural world that a man had to take for himself every day" (98). Fittingly, one Old Father's legendary refrain, "Oklahoma is Indians, Negroes and God mixed" (56), indicates Haven residents' feeling that this land is now theirs, perhaps chiefly because of their association with indigenous American Indians.

Characters' search for permanency, or "rootedness" on the landscape accompanies a desire to claim a cultural legacy that is indigenous to America. Achieving this metaphorical grounding necessitates a degree of synergy with American Indian experiences, and many of Morrison's characters identify this synergy as key to their abilities to overcome the pervasive effects of slavery. This union of African American and American Indian cultural legacies, as 
well as the affiliation of these legacies with the natural world, indicate a collapse of cultural and geographical borders. Cultural hybridity thereby instigates resistance, which allows characters to progress toward psychological healing.

Sixo, the "wild" man of Beloved, displays behavior that is presumably ancient or tribal yet non-specific. His dancing to "keep his bloodlines open" (25) could be retained from a culture in Africa or adopted from an American Indian tribe. Or perhaps Sixo's dancing is his invention, his own imagining of something vaguely indigenous. Similarly, Sixo's language, for which he abandons English, has an unclear origin but is portrayed as distinctively nonWestern. Though the sources for Sixo's practices are indeterminate, what is clear is that Sixo believes in an ability to commune with an enduring American Indian presence on the land, a presence which he consults in order to meet with the Thirty Mile Woman. His belief in his access to this presence, coupled with his desire to retain a heritage apart from that forced upon him by his European oppressors, suggest a kinship between Africans and Natives, one which he weds to the American landscape he toils upon. Sixo's efforts to establish this "grounding" in America are evident in his meticulous attempts to cook both white and sweet potatoes to the "peak of perfection" (21) in an earthen pit. Like potatoes, rooted in the earth, Sixo ultimately achieves a legacy that will endure after his murder in the person of his child, whom he presumes will be a son named "Seven-O!" (226). Sixo's son is thereby a symbol of regeneration that is realized by establishing "roots" on the landscape.

Similar to Sixo, Sethe and Halle are also able to experience grounding in America through access to the indigenous. When Sethe and Halle are married, though Sethe is disappointed in the lack of ceremony that the Garners attribute to the occasion, the consummation of the couple's marriage takes place in a cornfield in a ceremony that signifies a connection to 
American Indians. As the Pauls and Sixo watch "corn stalks dance at noon" (27), Sethe clutches husk and cornsilk, two materials which are of particular use to Native people. That evening, the characters participate in a "feast of new corn," cooking "ears too young to eat" (27), suggesting Cherokees' annual green corn ceremonies. In this way, Sethe's and Halle's marriage, which is able to endure for longer than most marriages of those who are enslaved, seems somehow blessed by an indigenous legacy that is likened to the "Redmen's Presence" that Sixo consults. Like Sixo's son, the children that Sethe and Halle produce are Sethe's means of achieving permanency amid the transience of slavery.

In addition to the American Indian presence that seems to bless Sethe's marriage, an African tradition seems to inform Sethe's pregnancy with Denver, whom she refers to as the "little antelope" (30) in her belly. Sethe describes the antelope as "an invention held on to from before Sweet Home, when she was very young" (30). Sethe's memories of her childhood are blurry, yet these memories are permeated by the folk traditions of her community: "Of that place where she was born (Carolina maybe? Or was it Louisiana?) she remembered only song and dance" (30). Sethe explains further that the antelope was a dance participated in by both men and women, a dance which created in them a sense of freedom: "They shifted shapes and became something other. Some unchained, demanding other whose feet knew her pulse better than she did. Just like this one in her stomach" (31). According to Weinstein, "The antelope in Sethe's belly points simultaneously backward and forward. . It thus epitomizes the sense of Sethe's moment-by-moment movement as ... rooted in an African diaspora ... and heading toward a difficult yet unstoppable future" (81). Denver thereby represents a freedom that is rooted in an African folk culture, demonstrating, as Harris notes, "how saturated the folk materials are within her texts" (13). Importantly, 
however, as the episode in the corn field displays, these folk materials are drawn from more than one source.

Like Sethe, Baby Suggs has suffered the trauma of separation from and survival beyond her many children, yet also like Sethe, Baby Suggs's access to an indigenous presence on the landscape facilitates her efforts toward healing. Baby Suggs becomes a lay preacher of sorts in a wooded area called the Clearing, "a wide open place cut deep in the woods nobody knew for what at the end of a path known only to deer and whoever cleared the land in the first place" (87). The location for Baby Suggs's ministry is evidently a space previously inhabited by American Indians; in effect, she seems to be drawing on a presence that remains in that space in order to inspire members of her community through "her great heart beating in their presence" (87), a beat that suggests the strong drum of both African and American Indian ceremonies. According to Wendy Faris, Suggs's activities in the Clearing achieve "some symbolic communal reforestation.... While this success of Baby Suggs' legacy largely reflects Morrison's concern with history (ultimately, with culture), the revision of that history is strengthened by its alliance with nature" (179). Adding to Faris's assessment, Baby Suggs's success is also tied to an alliance with the legacy of indigenous peoples. In this way, Baby Suggs celebrates a cultural convergence in the woods, an act of resistance that is the site of healing.

Paul D's difficult escape from his captors causes him to shun the kind of familial ties that are so important to Baby Suggs and Sethe; however, his refuge with American Indians at least in part allows him eventually to overcome the psychological and physical wounds that he has endured under slavery. After his escape from Alfred, Georgia, Paul D and some of his fellow captives take refuge with Cherokees who have resisted removal to Oklahoma. 
Forming a maroon community of sorts, an "in-between space" (2) in Bhabha's formulation, Paul D recognizes a kinship with these individuals, who have suffered the kind of devastation and dislocation from their original homelands that have so traumatized enslaved African Americans. After recuperating with the tribe, Paul D receives instruction from the Cherokees as to how to find the way to the North. Significantly, the Cherokees unite the path to freedom with the delicate flowering of the natural world: "The flood rains of a month ago had turned everything to steam and blossoms.... 'Follow the tree flowers, he said. Only the tree flowers. As they go, you go"” (112).

Paul D is rejuvenated by his time with American Indians, and their influence, particularly their legacy of resistance, remains with him even after he arrives in Cincinnati, where his path to work takes him through a Miami cemetery "as old as sky, rife with the agitation of dead Miami no longer content to rest in the mounds that covered them.... they growled on the banks of Licking River, sighed in the trees on Catherine Street and rode the wind above the pig yards" (155). This resistance that Paul D observes and internalizes among American Indians seems key to his ability to preserve his sanity despite the horrors he has endured. As Sethe remarks, though others who have worn the bit have displayed a disturbing wildness, she sees no trace of such psychosis in him: “When I look at you, I don't see it. There ain't no wildness in your eye nowhere" (71). Like Baby Suggs and Sethe, Paul D is able to affiliate with indigenous Americans, a cultural confluence that contributes to his final ability to permanently reside with Sethe, to "put his story next to hers" (273).

In Song of Solomon, Milkman's embrace of Pilate's influence, which contrasts sharply with Macon's example, is also an acceptance of his ancestral heritage, which features blackIndian hybridity. While Pilate's folkloric singing carries on the story of Milkman's roots in 
Shalimar, it also likens her to Singing Bird, Milkman's American Indian grandmother. As Pasqueretta indicates, "music, singing, and the blues are associated with the black-Indian experience" (283). Pilate lives as close to the rhythms of nature as is possible in Detroit, smelling of pine and generally living counter to the encroachment of progress, but in earlier years, she roamed the country, "planting her feet in each pink, yellow, blue or green state" (148). Pilate's traveling impulse recalls the journey that Singing Bird made to "the promised land," the North, on a wagon full of ex-slaves, including her soon-to-be husband Jake. It also reflects her love of the landscape, as her favorite book is a geography text that her childhood teacher gave her.

Once Milkman discovers that Singing Bird is part of the story that the children of Shalimar sing, the missing piece to fully understanding his origins, he is eager to share his discovery with Pilate. On his trip back to Detroit, as he patterns the trip North that his grandmother and grandfather made, Milkman develops his own appreciation for geography. His probing of the significance of geographical names parallels his new appreciation for Pilate:

Far away from Virginia, fall had already come. Ohio, Indiana, Michigan were dressed up like the Indian warriors from whom their names came. Blood red and yellow, ocher and ice blue. He read the road signs with interest now, wondering what lay beneath the names. The Algonquins had named the territory he lived in Great Water, michi gami. How many dead lives and fading memories were buried in and beneath the names of the places in this country. Under the recorded names were other names, just as 'Macon Dead,' recorded for all time in some dusty file, hid from view the real names of people, places, and things.... Pilate had taken a rock from every state she had lived in - because she had lived there. And having lived there it was hers - and his, and his father's, his grandfather's, his grandmother's. Not Doctor Street, Solomon's Leap, Ryna's Gulch, Shalimar, Virginia. (329-30)

Milkman's meditation on geography conflates American Indian and African American experiences through the historical force of names, and this "rememory" of indigenous legacies allows him to claim the landscape as his own. According to Weinstein, "The 
sounded song rehearses a hundred years of remembered black culture, locating the lost tribe of wandering Deads as sprung from the mythic ancestor Solomon" (64). While Weinstein's assessment is perceptive, it is important not to overlook the song's evocation of black Indian culture, which is a permanent fixture on the land.

This amalgamation of African Americans and American Indians also prompts discussion about cultural origins in Paradise. The citizens of Ruby, who every Christmas sustain a local folklore as they relay the story of the "eight rock families," the founders of the all-black town, insist on and celebrate their racial purity, in part as compensation for their ancestors' expulsion from another black town on the basis of their dark skin tones. Pat, who embarks on a massive project to document the genealogies of the fifteen families who currently compose the town, discovers that this lineage is much more tangled than she realized. Instead of wellorganized family trees, Pat discovers trees that are "upside-down trees, the trunks sticking in the air, the branches sloping down" (187), and she finds that these trees necessitate explanatory notes to accurately document the complicated families, some of which contain incestuous relationships. Intertwined with the legacies of the eight-rock families is an American Indian ancestor, Thomas Blackhorse, who exhibits the coveted feature of "stickstraight hair" (198). In consulting the Blackhorse Bible, Pat is convinced "that a new species of tree [is] needed to go further, to record accurately the relationships among the fifteen families of Ruby, their ancestors in Haven and, further back, in Mississippi and Louisiana” (188).

Pat's genealogical project spurs a debate with Reverend Richard Misner about the importance of recognizing Africa as the location of origin for Ruby's families, an argument that emphasizes the characters' need for rootedness. Richard warns Pat, "If you cut yourself 
off from the roots, you'll wither" (209), to which Pat retorts, "Roots that ignore the branches turn into termite dust" (209). Richard calls Africa "our home" (210), while Pat calls Africa "a foreign country, in fact ... fifty foreign countries" (210). Richard is so protective of the idea of Africa as a symbolic home because of the eight-rock families' dislocation from the American landscape, evidenced in their many failures to establish a free existence with other communities before incorporating their own town in Indian Territory.

Richard emphasizes the importance of an African home in references to a landscape unsullied by the violence of slavery or colonialism. He argues:

... can't you even imagine what it must feel like to have a true home? I don't mean heaven. I mean a real earthly home. Not some fortress you bought and built up and have to keep everybody locked in or out. A real home. Not some place you went to and invaded and slaughtered people to get. Not some place you claimed, snatched because you got the guns. Not some place you stole from the people living there, but your own home, where if you go back past your great-great-grandparents, past theirs, and theirs, past the whole of Western history, past the beginning of organized knowledge, past pyramids and poison bows, on back to when rain was new, before plants forgot they could sing and birds thought they were fish, back when God said Good! Good! - there, right there where you know your own people were born and lived and died. Imagine that, Pat. That place. Who was God talking to if not to my people living in my home? (212)

Richard recognizes that while the Creek Nation has enabled Ruby's residents to establish their own brand of "paradise," the necessity of appropriating land from American Indians in order to approximate a sense of indigenousness to America is problematic. For Pat, however, Blackhorse ancestry is in part the key to the grounding of Ruby's residents in this country, allowing her to definitely refer to America as "their home; mine too" (213).

While Pat and Richard probe the degree to which Ruby retains a definitive racial and cultural ancestry, the nearby Convent community is marked by diversity. Each of the women has a unique history, and Morrison carefully prevents definitive characterizations of the 
individuals' racial backgrounds. The one exception is Connie, an indigenous Brazilian with "smoky, sundown skin" (223), whom Sister Mary Magna brought to America to raise in the boarding school for Indian girls. While providing sustenance to the women through gardening and baking, Connie is able to overcome the effects of her confining relationship to Mary Magna through her recollection of her Brazilian ancestry. This recollection leads her to instigate the women's practice of alternative religion. This worship is tied to the earth's processes, like "dancing in hot sweet rain" (283).

The Ruby men's murder of the Convent women reveals the force of the women's influence and the failure of the Old Fathers' attempts to preserve a sense of black nationhood. As Katrine Dalsgard explains, "Morrison. . . rejects rather than keeps alive the dream of a 'true' (African) Americanism.... the small community's—and the larger nation's—violent attempt to preserve itself by destroying its other is not in conflict with, but is an inextricable part of, its ideal vision" (241). Tellingly, the landscape under the all-black town responds to this destruction of the "other": "Rain cascading off the Oven's head meets mud speckled with grout flakes washed away from bricks. The Oven shifts, just slightly, on one side. The impacted ground on which it rests is undermined" (287).

Ultimately, the Convent women are the more genuine exemplars of Paradise, specifically because of their unity, which indicates a collapse of racial borders as well as a synchronic relationship to the natural world. Morrison depicts these qualities through an image of Piedade, or "piety":

In ocean hush a woman black as firewood is singing. Next to her is a younger woman whose head rests on the singing woman's lap. Ruined fingers troll the tea brown hair. All the colors of seashells-wheat, roses, pearl-fuse in the younger woman's face. Her emerald eyes adore the black face framed in cerulean blue. There is nothing to beat this solace which is what Piedade's song is about, although the 
words evoke memories neither one has ever had: of reaching age in the company of the other; of speech shared and divided bread smoking from the fire; the unambivalent bliss of going home to be at home - the ease of coming back to love begun. When the ocean heaves sending rhythms of water ashore, Piedade looks to see what has come. Another ship, perhaps, but different, heading to port, crew and passengers, lost and saved, atremble, for they have been disconsolate for some time. Now they will rest before shouldering the endless work they were created to do down here in Paradise. (318)

Largely through recognition of American Indian ancestry, the residents of "the one all-black town worth the pain" (5) as well as those of "Christ the King School for Native girls" (224) probe the meanings of cultural hybridity, of grounding on the landscape and in nature, and of home. Overall, both communities engage these important "in-between spaces" as acts of resistance.

Toni Morrison's Beloved, Song of Solomon, and Paradise are highly regarded as genuine accounts of a variety of African American experiences in America, which are informed by the historical realities of slavery, segregation, and survival. Less critical attention is paid to the complex ways in which these novels investigate identity — national and moral identities as well as racial identity. While folklore, through which characters discover "rememory" of their roles in a collective cultural legacy, undoubtedly provides the crux of much access to African American identity, additionally, though perhaps more subtly, it also suggests points of convergence with American Indian culture. This more pluralistic approach to heritage raises awareness of societal norms, environmental responsibility, and spiritual sensibility. In effect, cultural hybridity, embodied by black Indians, spurs "the location of culture" in Bhabha's formulation. Transcending facile categorization, this cultural convergence resists not only the strictures of an oppressive dominant society, but also it has the potential to transform literary scholarship. 


\section{CHAPTER V: ALICE WALKER'S ECO-"WARRIORS"}

Challenging accepted notions of identity, studies of black Indians in history and culture are particularly relevant to explorations of contact and amalgamation across racial, cultural, and national borders in the Americas. The historical alliance of blacks and Indians takes on explicit personal, environmental, feminist, and spiritual significance in the works of Alice Walker. Walker bases many of her culturally hybrid characters on accounts of leaders of black Indian communities which, according to William Loren Katz, afforded women more rights than were common in European cultures, often elevating women to positions of leadership (12). Jonathan Brennan also describes ways in which Seminoles created a unique African-Native culture more readily than other tribes, exemplifying "culturally and racially mixed communities" where "distinctions between African and Native began to blur" (7-10). Additionally, Katz relays the legacies of Seminole leaders in Florida, who, unlike other Southern tribes, resisted adoption of slavery and accepted various groups of American Indians and Africans, allowing them to establish independent villages within the community that were based on rice farming practices of Sierra Leone and Senegambia (50-2). Osceola, Wild Cat, and John Horse, the most legendary Seminole leaders, led resistance to U.S. efforts to impose slavery on the tribe and remove them to Indian Territory, and Walker draws on their efforts as inspiration for several of the visionary individuals in her fiction.

The cultural exchange resulting from black-Indian amalgamation, which Mary Ellison calls "affinity over alienation" (44), informs folklore, including music and spiritual tradition 
that play a prominent role in Walker's works. According to Tiya Miles, this "fusion of cultural ways" (29) was a defining characteristic in the lives of members of the black Indian Shoeboots family, who were a product of the proximity of Africans and Cherokees under slavery. As Miles explains, African Americans enslaved by Cherokees often acted as mediators between the Indians and Europeans, roles that she describes as "fragmented moments within a context of ever-shifting relations" (96). As Cherokees increasingly became acculturated to European encroachers, they accepted "blackness" as a racial category and hampered the rights of blacks and Afro-Cherokees (108). Significantly, Miles names disconnection from a shared landscape in the Southeast, imposed through Cherokee removal, as critical to the decline of black-Cherokee affiliation: "The ties of kinship, respect, and affection between Cherokees and individual blacks who had survived the early stages of slavery were weakened ... In a new landscape devoid of embedded mutual memories, the people were separated by a cavernous divide of race and caste" (160-1). Through her essays and novels, Walker attempts to restore these black-Indian ties and heal the fragmentation that accompanies rigid black or white racial classifications, aims that she achieves in part by recovering human bonds to the landscape and purporting an ecologically sound relationship to the earth.

Walker's own identification of Cherokee ancestry demonstrates her celebration of African American connections to indigenous peoples in America and her conception of humans as an amalgamation of multiple cultures and influences. According to Brennan, "Walker consciously creates space for and develops an African Cherokee identity as well as a relationship to a pan-Indian identity" (32). Naming her Cherokee great-great grandmother, as well as friends Bill Wahpepah (Kickapoo) and Dennis Banks (Anishinaabe) as at the 
forefront of her consciousness as she confronts the despair of racism and environmental denigration, Walker locates American Indians as inspiration for resistance to these destructive forces. In the words of Patricia Riley, Walker "celebrate[s] her identification of herself as a multicultural and multiracial person as opposed to the monoracial identification assigned to her by the dominant society," espousing an "African-Native American Subjectivity" (242). In Walker's writings, including her essay collection Living by the Word (1988) and novels Meridian (1976), The Color Purple (1982), The Temple of My Familiar (1989), and Now is the Time to Open Your Heart (2004), this African-Native subjectivity spurs decolonization of the mind and resistance to oppression, revised understandings of human relationships to animals and the natural world, empowerment of women to affect environmental and social justice, and achievement of mystical experiences and spiritual fulfillment.

bell hooks, in her study Black Looks: Race and Representation (1992), emphasizes the importance that control over imagery related to race holds for establishing the kind of cultural authority that Walker approaches in her works. In her words, “. . . for black people, the pain of learning that we cannot control our images, how we see ourselves (if our vision is not decolonized), or how we are seen is so intense that it rends us. It rips and tears at the seams of our efforts to construct self and identity" (3-4). For hooks, recognition of black Indians, whom she calls "Revolutionary 'Renegades,"' is an act of resistance: "For Native Americans, especially those who are black, and for African Americans, it is a gesture of resistance to the dominant culture's ways of thinking about history, identity and community for us to decolonize our minds, reclaim the word that is our history as it was told to us by our ancestors, not as it has been interpreted by the colonizer" (184). Rejecting the colonizers' 
interpretations of history, hooks calls for recovery of kinship between African Americans and American Indians, a process that she calls "giv[ing] ourselves back memory" (193). hooks ties this memory most explicitly to respect for the earth and spiritual reverence for ancestors' legacies on the landscape. Walker expresses this movement toward decolonization both personally and in her fiction, suggesting alternative representations of race and complicating boundaries between humans and the natural world.

In her essay "My Big Brother Bill," describing herself as having been "hit hard" (43) by the murders of Civil Rights leaders, the injustices on reservations and in ghettos, and the election of Ronald Reagan, Walker explains that she copes with such tragedies by embracing American Indian material culture, studying Cherokee folklore, and, curiously, surrounding herself with Edward S. Curtis's photographs of American Indians. The photos lead her to investigate "the merits of the teepee" and the "nomadic life style Indians enjoyed" (44). Clearly, Walker views American Indian cultures, particularly those aspects that relate to African American folklore, as vehicles for empowerment against oppressors, or for decolonization of African American mindsets, efforts which may necessitate living literally close to the land. She goes on,

in the folklore Indians are still acting colored and telling jokes, and in the photographs they are still looking out at the world and at the white man with infinitely expressive faces and not managing to keep all that they are thinking to themselves. Of what devastation, to the environment and to other human beings, we are now witnessing did their incredulous expressions forewarn! (44)

Ironically, though Walker links the Curtis photographs to resistance, those photographs in many respects reflect a colonial imagination of Indians as proud but nonetheless vanishing peoples. ${ }^{12}$

${ }^{12}$ For more discussion of Edward S. Curtis's photographs and their cultural contexts, visit the Library of Congress site: http://memory.loc.gov/ammem/award98/ienhtml/curthome.html 
Though it is understandable that the writer admires these artful images, she apparently lacks awareness of the histories surrounding them, which points toward her sometimes problematic characterization of a monolithic Indian aesthetic, one that serves her purpose but does not necessarily reflect a genuine grasp of the breadth and diversity of American Indian cultures. For example, Walker describes her friendship with Bill Wahpepah as inspired by her "locating the Indian within myself" (49). Together, Bill and Walker "affirm the connection between 'Indians of the Americas' and Indians [Africans] of Africa” (49), enjoying the appearance of Nelson Mandela and Leonard Peltier on T-shirts together and sharing the belief that "all indigenous people are, by their attachment to Mother Earth and experience with Wasichus, Conquistadors, and Afrikaners, one" (49). While these realizations allow Walker to overcome disillusionment and locate sources for rejecting oppression, they do not indicate a uniquely Cherokee identity for the "Indian within" her, as Cherokees typically did not inhabit teepees or appear in Curtis's photographs. In this way, Walker attempts to develop a universal indigenous sensibility that in some ways is her own creation, one that supports her environmental philosophy and unites diverse peoples in their struggles against colonial oppressors.

Walker's concept of universal American identity describes acceptance of multiplicity as being necessary for people's manifestations of their complete selves. She writes in her essay "In the Closet of the Soul," "We are the mestizos of North America. We are black, yes, but we are 'white,' too, and we are red. To attempt to function as only one, when you are really two or three, leads, I believe, to psychic illness: 'white' people have shown us the madness of that" (82). Further, Walker depicts this hybrid crossing as characterized by reciprocity, wherein oppressor and oppressed are affected intimately by the system in which they 
function:

We are the African and the trader. We are the Indian and the settler. We are the slaver and the enslaved. We are oppressor and oppressed. We are the women and we are the men. We are the children. The ancestors, black and white, who suffered during slavery - and I've come to believe they all did; you need only check your own soul to imagine how-grieve, I believe, when a black man oppresses women, and when a black woman or man mistreats a child. They've paid those dues. Surely they bought our gentleness toward each other with their pain. (89)

This description of universal yet hybrid identity, which serves to inspire greater crosscultural understanding, thereby typifies self-actualization.

Hybrid identity does not espouse multiplicity that is only racial, however. Walker also names reciprocity between humans, animals, and plants as necessary for true liberation from oppression. In her essay "Everything is a Human Being," Walker imagines the responses of trees to humans' disregard for the sustenance and survival of foliage, linking ecological responsibility to accountability for human oppression. Calling Earth "the nigger of the world” (147), Walker argues, “The Earth holds us responsible for our crimes against it, not as individuals, but as a species — this was the message of the trees. . . the Earth is wise. It has given itself into the keeping of all, and all are therefore accountable" (142). Importantly, Walker connects this response by the natural world to American Indians. Contemplating her guilt at the killing of a small snake in her garden and finally concluding that the snake was the rightful inhabitant of that garden, Walker asserts, "Like the little snake in my garden, many of the Indians returned again and again to their ancient homes and hunting grounds, only to be driven off with greater and greater brutality until they were broken or killed" (144). Animals are thereby portrayed as indigenous in a sense, suggesting that humans and animals share an interest in preserving individual rights that complicate rigid borders between "wilderness" and "society." 
This association of American Indians with pursuit of liberty surfaces throughout Walker's fiction, including the author's most acclaimed novel, The Color Purple. Central to the text is Celie's most important challenge - resisting her oppressors. In the beginning of the story, Celie describes her sister Nettie's faith in her capacity for learning, faith which fuels Celie's hope that the sisters will someday escape Albert's abuse. A sign of Celie's cleverness appears in her disregard for the story of Columbus's arrival in America, in many ways a national creation myth. She explains: "I know I'm not as pretty or as smart as Nettie, but she say I ain’t dumb. The way you know who discover America, Nettie say, is think bout cucumbers. That what Columbus sound like. I learned all about Columbus in first grade, but look like he the first thing I forgot" (19). While Nettie is the first person to instill a degree of self-confidence in Celie, a seed for Celie's later emancipation, unfortunately their relationship is strained by Nettie's departure for missionary work in Africa, Celie's inability to escape with her, and Albert's hiding Nettie's letters from Celie.

Nettie experiences her own transcendence above colonial representations of peoples of color as she comes of age in Africa, a process that she relates to perceptions of American Indians. Nettie learns that Christians frequently characterize indigenous peoples to whom they minister in America and Africa as "savages who didn't wear clothes" (123), suggesting that Samuel and Corrine, her adoptive missionary parents, have similarly held this belief. However, once she arrives in Africa, and Nettie observes black people thriving on a landscape that she views as her ancestors' sacred homeland, she is filled with pride. She writes, "Celie, try to imagine a city full of these shining, blueblack people wearing brilliant blue robes with designs like fancy quilt patterns. ... I felt like I was seeing black for the first time" (131). Similarly, seeing the African coast for the first time, Nettie reveals that viewing 
"the land for which our mothers and fathers cried — and lived and died" (132-3) evokes in her a powerful response: "Something struck in me, in my soul, Celie, like a large bell, and I just vibrated" (132). Nettie's gratification at living on her homeland, which she is able to see for her own eyes rather than through images in history books written by Europeans, prompts her rejection of iconography that suggests colonial representations of Africa: "In my trunk I have pictures donated to us by the missionary societies in England and America. Pictures of Christ, the Apostles, Mary, the Crucifixion. Speke, Livingstone, Stanley, Schweitzer. Maybe one day I'll put them up, but once, when I held them up to my fabric and mat covered walls they made me feel very small and unhappy, so I took them down" (147).

Further evidence of Nettie's resistance to European colonization occurs in her identification of cultural links between Africans and African Americans as well as with American Indians. Comparing their labor on cacoa fields to the plantation system that African Americans toil under, Nettie recognizes Africans' singing as inspired by experiences of hardship that are akin to hers and her sister's: "As tired as they are, they sing! Celie. Just like we do at home. Why do tired people sing? I asked Corrine. Too tired to do anything else, she said. Besides, they don't own the cacoa fields, Celie, even president Tubman doesn't own them. People in a place called Holland do" (132). Additionally, when Nettie travels to the African village that will become her home, she is enthusiastic about her shift from transport on a large ship to travel via boats "that are really dug-out canoes, like the Indians had, the ones you see in pictures" (138).

As she carries out their ministry in the village, Nettie grows closer to Corrine, and though the two exhibit tension due to Corrine's mistaken belief that Adam and Olivia are Nettie's children and not Celie's, Nettie ultimately admires Corrine, ostensibly because she rescues 
Nettie from dire conditions in Georgia but more particularly because she displays a disposition that Walker believes to be characteristically Cherokee. Nettie writes, "I always felt her Indianness. She was so quiet. So reflective. And she could erase herself, her spirit, with a swiftness that truly startled, when she knew the people around her could not respect it" (209). Corrine's example is a source of strength to Nettie as, after Corrine's death, she eventually takes her place as wife to Samuel and mother to Celie's children. Finally, when Nettie returns to Georgia and reunites with Celie, the previously stratified family is symbolically made whole again in a feast that features barbecue, food that is common to both Georgia and Africa but that originated with Seminole Indians.

Like Nettie, Celie also is saved from Albert's brutal oppression, which echoes Europeans' violent enslavement of African Americans, by a relationship with a woman who is associated with American Indians. Shug Avery, like Nettie, teaches Celie to believe in herself, which is crucial for her psychological freedom from Albert's colonization of her mind and body, yet Shug's instruction departs from academic knowledge and encompasses sexual education. Celie is immediately physically attracted to Shug, and Shug's appearance is enhanced by images from the natural world that are typical of American Indian dress. Seeing her in a poster advertisement, Celie observes, "Shug Avery standing upside a piano, elbow crook, hand on her hip. She wearing a hat like Indian Chiefs. Her mouth open showing all her teef and don't nothing seem to be troubling her mind. Come one, come all, it say. The Queen Honeybee is back in town" (33). When Celie sees Shug in person, she notices, "she dress to kill. She got on a red wool dress and chestful of black beads. A shiny black hat with what look like chickinhawk feathers curve down side one cheek, and she carrying a little snakeskin bag, match her shoes. She look so stylish it like the trees all round the house draw themselves 
up tall for a better look" (50). In these descriptions, Shug, who later feels right at home in her son's reservation adobe house, strikes a somewhat defiant pose, one that suggests synchronicity with nature, and exhibits her resistance to others' control of her, a statement that is inspirational to Celie.

Shug's control of her own destiny, a characteristic that is atypical amid African American women's confinement within racist societies, leads Celie to greater understanding of her individual worth. This feeling of validation facilitates Celie's own path toward throwing off oppression. When Celie first attends one of Shug's performances at Harpo's club, Shug acknowledges Celie publicly, calling her name repeatedly and singing a song for her: "Shug saying Celie, Miss Celie.... She say this song I'm bout to sing is call Miss Celie's song. ... I look at her and I hum along a little with the tune. First time somebody made something and name it after me" (75). The love that Shug displays for Celie, the first Celie has experienced, is empowering: "Nobody ever love me, I say. She say, I love you, Miss Celie" (109).

This exchange leads to physical intimacy between the two women, Celie's first positive sexual experience. Their close bond leads Shug and Celie to affirm responsibility to one another, or alliance against subjugation. Describing her relationship with Albert, Shug explains that her lover's active spirit has been subdued in his abuse of Celie, emphasizing the way in which those who dominate are negatively affected by their assertion of power over others. Thereafter, Shug prioritizes loyalty to Celie, standing up for her to Albert and helping her to retrieve the letters from Nettie that Albert has hidden. The strength that Celie draws from Shug also allows her to finally stand up to Alphonso, her abusive stepfather: "I'm pore, I'm black, I may be ugly and can't cook, a voice say to everything listening. But I'm here. Amen, say Shug. Amen. Amen" (187). 
Celie's love for Shug underscores her growing sense of obligation to the other women in her life, including Harpo's wife Sofia. Soon after Harpo's marriage to Sofia, Celie observes that their marriage is quite different from her own: "I like Sofia, but she don't act like me at all. If she talking when Harpo and Mr. ----- come in the room, she keep right on. If they ast her where something at, she say she don't know. Keep talking. I think bout this when Harpo ast me what he ought to do to her make her mind. ... I think about how every time I jump when Mr. ----- call me, she look surprise. And like she pity me" (42-3). Celie's jealousy of Sofia leads her to recommend to Harpo that he beat his wife, a mistake that Celie later understands to be a "sin against Sofia['s] spirit" (45). Not one to shrink from others' abuse, Sofia fights Harpo, leaving him bruised and scarred, and pays a visit to Celie. Sofia explains, "All my life I had to fight. ... But I never thought I'd have to fight in my own house. ... Now if you want a dead son-in-law you just keep on advising him like you doing” (46). Standing with her hand on her hip, recalling the picture of Shug, Sofia asserts, "I used to hunt game with a bow and arrow" (46). Like Shug, Sofia's self-assurance seems to derive from her link to an indiscriminate American Indian culture. Thus, cross-cultural hybridity, particularly association with American Indians, spurs Walker's characters' efforts at selfpreservation.

Collapsed borders between American Indians and African Americans are also an impetus for efforts at decolonization that permeate Meridian. The novel's beginning, which features an epigraph in addition to dictionary definitions of the word "meridian," immediately foregrounds this cross-cultural contact. The epigraph is excerpted from Black Elk Speaks:

I did not know then how much was ended. When I look back now ... I can still see the butchered women and children lying heaped and scattered all along the crooked gulch as plain as when I saw them with eyes still young. And I can see that 
something else died there in the bloody mud, and was buried in the blizzard. A people's dream died there. It was a beautiful dream . . . the nation's hoop is broken and scattered. There is no center any longer, and the sacred tree is dead.

The passage, relaying Black Elk's remorse at the loss of so many of his Oglala Lakota family and community members during wars against Indians in the late nineteenth century, reflects a sentiment that is similar to the sense of loss that accompanied the murders during the 1960s and 1970s of Civil Rights leaders such as Martin Luther King, Jr., who himself so eloquently described his vision as a "dream."

According to Anne Downey, Black Elk's epigraph creates a spiritual vision that inspires the novel's protagonist, Meridian Hill, to stay in her homeland, the South, to work toward the betterment of humanity despite the oppression and violence that her people suffer (38). Similarly, Patricia Riley highlights "African-Native American Subjectivity” that illustrates "the collective struggle for freedom undertaken historically by Native American and African American peoples" (242). Together, the epigraph and the definitions of the word "meridian" draw on Black Elk's vision as well as point toward the results of replicating a vision of hybridity and liberation in Meridian's community during the Civil Rights Movement. Meridian's power to affect change is represented in the words "highest point of power" and "distinctive character," while the geographical definition "a great circle of the earth" reflects the unity of humanity across artificial divides. This universal movement toward liberation is manifest on Meridian's southern homeland in both tangible and intangible forms in Walker's novel.

As in The Color Purple, women, marked by psychological and physical oppression, are the ones who are most in need of freedom from their current, sometimes desperate, situations, and crossing cultural boundaries often sheds light on paths to resistance. As Pirijo Ahokas 
explains, "the borders and border crossings between the dominant white culture and racialized minority cultures make it possible for oppressed female subjects to find new strategies for freeing themselves from inequalities of subordination" ("Constructing" 200). The ways in which all women are stifled within racist societies are strikingly illustrated in the person of Marilene, a white woman who, accustomed to luxury, "owned a washing machine, furs, her own car and a full-time housekeeper-cook" and was expected only to "lay back and be pleasured" (20).

When Marilene has an extra-marital affair, her husband Henry kills her and her lover and throws them in the Salt Lake, a crime for which his community exonerates him of blame. Years later, when Marilene washes ashore, Henry displays her mummified body to the public "to make a little spare change in his ol' age" (22). Curiously, the body's exposure to salt darkens her skin, leaving her husband to assert her whiteness by pointing toward her straight, red hair. Her darkening skin signifies kinship with many African American women who have also suffered violence at the hands of men, yet her dismal fate also suggests the tainted nature of material wealth that is based upon the exploitation of African Americans. Marilene, described as an "ideal woman" (20) in life, eventually leaves a ridiculous, hideous legacy in her death.

Denigration of women within a white patriarchal system also is apparent in the character Lynne Rabinowitz, a Jewish Civil Rights worker who struggles with her own racism, with the sexism that she faces within the male-dominated Movement, and with the anti-Semitism of the South. As a young woman, Lynne comes to Georgia from the North and eventually marries Truman Held, who despite his professed admiration for black women's bodies, continually dates thin white women. Lynne exhibits a racist fascination with the lives of poor 
Southern blacks, whom she romanticizes, and her pity for African Americans plays a role in the description of her rape by one of Truman's friends. As she ages, Lynne experiences greater hardships, including divorce from Truman, who proclaims her to be "guilty of whiteness" (133), and the abuse and death of her daughter Camara. These trials move her toward a more critical view of herself, one that she shares with Meridian.

Though Lynne is privileged in American society, she suffers in part because of her crossing of cultural boundaries. Her occupation of an in-between space is described in her meditation about entering a Jewish deli:

In the beginning she had actually been able to hear the intake of their breaths: the matronly woman who stood at the cash register, the younger woman who stood over the black cooks in the kitchen, the youngish man who, in the end (by the time Camara was ready to be born) spoke kindly to her, but with a kind of fear of her, like a fear for his own life, his precarious safety.... They made her conscious, heavily, of her Jewishness, when, in fact, they wanted to make her feel her whiteness. . . . It was just that they knew, as she knew about them. That they were transplanted, as they had always been, to a place where they fit like extra toes on a foot. Where they were trusted by no one, exploited, when possible, by anyone with political ambitions. $(179-80)$

Because of her crossing of cultural boundaries, after learning to admit her own faults and biases, Lynne finally is able to develop a true friendship with Meridian, and as Faith Pullin notes, "Both Lynne and Meridian change their attitudes towards each other, getting beyond white and black female stereotyping" (200). Discussing what she has learned from her days in the Movement, specifically her relationship with Truman, Lynne explains to Meridian that because of that relationship, at least she "can never be as dumb as my mother was" (181) and can resist becoming a member of the oppressors. Lynne's self-confrontation approaches the "ways of looking [that] must be fundamentally altered" (7) in hooks's formulation, an act of decolonization that is achieved through cross-cultural contact. 
Meridian also experiences transformation over the course of the novel, and her ability to resist forces that hinder her partly results from her exposure to other African American women who have experienced hardship. As a young child, Meridian expresses keen insight into denials of black representation and the effects that those denials exact upon the girls in her community. She witnesses this lack of affirmation of black lives primarily through movies that feature "Blondes against brunettes and cowboys against Indians, good men against bad, darker men" (75). These cinematic displays create a sense of unreality among her peers: "So they moved, did the young girls outside her window, in the dream of happy endings: of women who had everything, of men who ran the world. So had she. But these thoughts, which were as random and fleeting as clouds, were simply the outside layer of skin on a very large onion" (75). Later, as a student at Saxon College, which occupies the former Saxon plantation, Meridian's unique perception sets her apart from other, more prim and proper students, as she decorates her surroundings with "large photographs of trees and rocks and tall hills and floating clouds, which she claimed she knew" and seems "to contain the essence of silence" (38).

At Saxon, Meridian is strongly impressed by the tragic story of Louvinie, which has become part of campus legend. The story goes that after one of the Saxon children dies of a heart attack as a result of listening to one of Louvinie's scary stories, Master Saxon cuts out Louvinie's tongue. Louvinie then takes her tongue, "like a thick pink rose petal" (44), smokes it, and buries it under a feeble magnolia tree. The tree eventually grows to be the biggest of its kind in the country, is believed to possess magic, and is called "The Sojourner." Over the years, The Sojourner hides those who have escaped from slavery and serves as a hidden place to make love. 
The Sojourner is also the locus for a ceremony of female unity on the Saxon campus, the Commemoration of Fast Mary of the Tower, which memorializes Fast Mary's pregnancy, commitment of infanticide, and ultimate suicide:

Any girl who had every prayed for her period to come was welcome to the commemoration, which was held in the guise of a slow May Day dance around the foot of The Sojourner (which had been, it was said, Fast Mary's only comfort and friend on the Saxon campus). It was the only time in all the many social activities at Saxon that every girl was considered equal. On that day, they held each other's hands tightly. (44)

During her first year at Saxon, The Sojourner, which is humanized and described as female, is also a comfort and friend to Meridian. She "draw[s] comfort from her age, her endurance, the stories the year told of her, and her enormous size. When she sat beneath The Sojourner, she knew she was not alone" (93). Meridian's understanding of herself as wild, part of a legacy of resistance that is symbolized by The Sojourner, spurs her own efforts at resistance.

Meridian's earliest acts against authority figures occur in her response to the plight of The Wild Child. The abandoned girl, who is pregnant, is a societal outcast, feeding on garbage and emitting a powerful odor. When Meridian first encounters Wild Child, she is clearly upset, withdrawing to her room at Saxon and lying on the floor like a corpse. But soon Meridian takes action: she offers the girl refuge by housing her in her dorm. According to Karen Stein, Meridian's ardent efforts to help The Wild Child illustrate “both Meridian's humane compassion and her need to affirm her own wildness" (136). Meridian's efforts incur rebuke by the house mother, who refuses to allow Wild Child to stay, chiefly because of concern that her unsightly appearance will negatively affect the other girls. The woman's beauty rituals, which seem to project unnatural disguise of her natural African American features, illustrate the betrayal that she is exhibiting toward the young girl: "The house 
mother's marcel waves shone like real sea waves and her light-brown skin was pearly under a mask of powder. Wile Chile trembled to see her and stood cowering in a corner" (37).

When The Wild Child is killed by a speeder, and the students are not allowed to hold her funeral in the Saxon Chapel, the young women are enraged: "They shook loose their straightened hair, and all the while they glared at the locked chapel door with a ferocity that was close to hatred" (47). The situation prompts riots, and unfortunately, though Meridian begs the rioters to destroy the president's house, instead, the girls destroy The Sojourner. The young women's misguided act emphasizes the ways in which Meridian is a kind of seer, displaying insight that her peers lack. This insight contributes to her rejection of many of the counterproductive forces that accompany the larger Movement and as Riley points out, strengthens her kinship with Black Elk, who observes, "the sacred tree is dead" (250).

Spurred by her insight into women's selfhood, Meridian also works for civil rights and social justice in her hometown because of her recognition of American Indian acts of resistance, many of which feature alliance with African Americans. On her father's farm rests the Sacred Serpent, a landscape of burial mounds in the shape of a snake that encapsulates American Indian legacies. Meridian's father is fascinated with the experiences of American Indian resistors, including Sitting Bull, Crazy Horse, and Geronimo, and his workshop is full of photos of leaders such as these as well as books on Indian land rights, reservations, and wars. Meridian learns that her father has been in touch with Walter Longknife, an Oklahoman and descendant of Cherokees who originally inhabited the area, and has turned his land deed over to him, much to the irritation of Meridian's mother. Meridian observes in Longknife a figurative if not literal shared heritage with her father: "He was a wanderer, a mourner, like her father; she could begin to recognize who her father was 
by looking at him" (54). While Meridian's father desires to reverse the adverse results of history by handing over the deed, Longknife seeks redemption for killing people during World War II, to "keep his historical vision of himself as a just person from falling apart" (54). After spending a summer camping on the Sacred Serpent, Longknife has apparently received the clarity he was searching for, and he moves on and returns the deed to Meridian's father. The exchange between the two men is a powerful example to Meridian of a mutual, black-Indian endeavor of resistance to colonization.

Later, Meridian too experiences a transformative incident at the Sacred Serpent, one that mirrors the example of Feather Mae, her father's grandmother. Meridian learns the story of her great-grandmother's love of the Sacred Serpent, including her habit of sitting on its tail while sucking on a weed stem. One day, after following some squirrels to the center of the serpent's tail, a forty-foot deep pit, Feather Mae has an out-of-body experience, a feeling of spiritual intoxication that empowers her to reject convention: "Later, Feather Mae renounced all religion that was not based on the experience of physical ecstasy—-thereby shocking her Baptist church and its unsympathetic congregation — and near the end of her life she loved walking nude about her yard and worshiped only the sun" (57). Seeking affiliation with her great-grandmother as well as greater understanding for her father, who often enters the pit himself and leaves "with his whole frame radiating brightness" (58), Meridian enters the Serpent's tale as well.

Though at first she is scared and isolated, Meridian remembers Feather Mae's example, "willing her fear away" (58). Soon her spirit also leaves her body:

... in this movement she saw the faces of her family, the branches of trees, the wings of birds, the corners of houses, blades of grass and petals of flowers rush to ward a central point high above her and she was drawn with them, as whirling, as 
bright, as free, as they. Then the outward flow, the rush of images, returned to the center of the pit where she stood, and what had left her at its going was returned. When she came back to her body — and she felt sure she had left it - her eyes were stretched wide open, and they were dry, because she found herself staring directly into the sun. ... It seemed to her that it was a way the living sought to expand the consciousness of being alive there where the ground about them was filled with the dead. It was a possibility they discussed, alone in the fields. Their secret: that they both shared the peculiar madness of her great-grandmother. (58-9)

Meridian's affiliation with Feather Mae, and more indirectly, with the Cherokees who lived in Georgia, enables her to envision survival amid destruction, a positive view that encourages her as she confronts the violence of white oppressors and of the Movement. Importantly, Meridian now exhibits continuity where Black Elk's dream ends. In Downey’s words, “Black Elk's epigraph is the call, and Meridian is the response" (38).

Meridian's view of positive resistance causes her to reject the violence espoused by some members of the Movement and leads her to celebrate other examples of cross-cultural alliance against oppression. Wearing a railroad cap and dungarees, visibly countering artificial signs of femininity, she begins to understand that the hardships that she witnesses are part of broader pattern of violence exacted by white patriarchy against a diversity of peoples. According to Riley, through this lens, "Walker reminds readers of the frequently forgotten historical violence that was perpetrated against indigenous peoples and asks them to consider this event as a continuation of an American tradition of violence against people of color that has simply risen up in a new form" (244). An example of Meridian's insight into a broader view of oppression occurs when, the night before a house used by civil rights workers is bombed, she dreams of Indians and concludes: "And so it was that one day in the middle of April in 1960 Meridian Hill became aware of the past and present of the larger world" (73). Similarly, Meridian becomes aware of resistance as part of a broader narrative 
of a sustaining folk culture while sitting outside a church:

The nearby families told their children stories about the old days before black people marched, before black people voted, before they could allow their anger or even their exhaustion to show. There were stories, too, of Southern hunts for coons and 'possums among the red Georgia hills, and myths of strong women and men, Indian and black, who knew the secret places of the land and refused to be pried from them. (185)

Meridian thereby possesses a broader view of humanity, including its hardships and its sources of strength, than her peers, a view that comprises cultural hybridity and its legacy of resistance.

Walker's The Temple of My Familiar likewise celebrates cultural hybridity and its role in allowing characters to view their roles in society and on earth more broadly, fueling their capacities for resistance to the dominant paradigm. As in Meridian, this novel includes descriptions of white women who are able to make progress toward freeing themselves from colonial mindsets. Mary Jane, a privileged young white girl who grew up in the suburbs, signifies her break from the lifestyles of her parents by faking her own death after an extended visit to South America. Mary Jane allows her ship, aptly named "Recuerdo," to sink, prompting newspapers to condemn her "youthfully misguided, race-mixing radic-lib escapades" (206) in her death notice. Mary Jane then sets sail in a new ship entitled "The Coming Age."

Eventually, Mary Jane visits her great-aunt in Britain, who acquaints her with the writings of her great-great-aunt, Eleanora Burnham, a woman who spent many years working in Africa. Mary Jane is surprised to find that, despite her complaints about "bugs, leeches, and niggers" (212), Eleanora deeply loved Africa. Reviewing the Eleanor Burnham collection, Mary Jane discovers several photographs of African Americans that profoundly move her, 
reminding her of Edward Curtis's photographs of American Indians: “The women's hairstyles, with their interwoven cowrie shells and feathers, were fabulous and made them look, at the same time, serene, regal, and wild" (217). These photographs prompt Mary Jane to investigate further Eleanora's experiences overseas, and by reading about Eleanora's coming to awareness of the world beyond her limited European bias, Mary Jane reaches greater understanding as well.

The focus of Mary Jane's further inquiry is M'Sukta, an African woman who years ago had been shut up at the Museum of Natural History in London. Like the other individuals that appear in the photographs, M'Sukta displays a likeness to American Indians, as she wears colorfully beaded, soft leather slippers and brightly colored cloth marked with symbols akin to those on the mud walls of her hut. Reading Eleanora's diary, Mary Jane learns that her great-great-aunt's discovery of M'Sukta's location in the museum was the impetus for her reconsideration of fundamental "truths" that were the basis of her education. Her entry reads,

The history I knew was not hers, the geography I knew placed an elephant herd where her village had been, the science I knew did not teach me how to make dyes and medicines and the other things M'Sukta could do; the literature I read talked about savages and blackamoors, and that was when it was being polite. The languages I knew failed me entirely when I stood before her. (229)

Eleanora's entry thereby reveals her insight into her own ignorance, a critical admission for becoming an ally in a movement against colonization of Africa.

M'Sukta's photograph reveals a creed associated with her Ababa tribe: "ME TAO ACHE DAKEN SOMO TUK DE," which in translation reads “THEY CANNOT KILL US, BECAUSE WITHOUT US THEY DIE.” According to Eleanora's diary, this philosophy piques her interest in genuinely understanding the people it represents, prompting her to release M'Sukta from her captivity and return with her to Ababaland. Unfortunately, there 
are no remaining members of the tribe, leaving M'Sukta as the sole speaker of Ababa and preserver of tribal heritage. However, Eleanora, and later her daughter, continue to live and work with the Olinka, participating in their struggles against colonists until their eventual confinement to reservations, a tragedy that mirrors American Indians' experiences. By confronting her own ignorance and recalling American Indian legacies, Eleanora is empowered to work with M'Sukta and other Africans in constant and concerted resistance, emphasizing cross-cultural alliance.

The novel's depiction of struggles against colonization also extends to South America, where generations of indigenous women, grandmother Zede, Zede, and Carlotta, seek to retain cultural traditions of the "old country." Grandmother Zede, “a sewing magician” (3), makes capes made of feathers that have been a part of village ceremonies for centuries. Her daughter, also called Zede, is charged with collecting feathers used for the capes. While at first, little Zede gathers feathers that are plucked from beautiful cockatoos, parrots, and peacocks, who emit a "sound like a soul in torment" (3), eventually she receives found feathers from a peaceful woman who believes that each is a God-given gift and transmits special power to spiritual ceremonies. This idyllic existence is soon threatened by the reach of a banana plantation for which Zede's works. In Walker's depiction, traditional festivals are soon forbidden, tribal priests become purposeless, and the people are forcibly contained in an Indian village confiscated for papaya cultivation, a prison where Zede's daughter Carlotta is born. Like M'Sukta's people, Zede's people are nearly destroyed by colonialism, and also like M'Sukta, Zede and Carlotta are the few embodiments of links to indigenous cultures in their native countries.

With the help of Mary Jane, Zede and Carlotta eventually escape the colony and make 
their new home in San Francisco, where, though Carlotta is able to acclimate better than her mother, the two thrive, creating the feathered capes, which become all the rage with 1960s rock stars. Their lives are changed forever when Carlotta delivers a cape to Arveyda, a black Indian who wears a headband and looks faintly like her: "It was his Indianness that she saw, not his blackness.... the calm, detached concentration of a shaman" (7). Some of the other buyers recognize the affiliation with American Indians that is also visible in Carlotta, making them think of "dry, arid spaces closer to home" (8), but unlike them, Arveyda is also interested in the culture that the cape represents.

As Arveyda becomes closer to both Zede and Carlotta, he sees in them "the stress of oppression, dispossession, fight" (18), perceiving a connection to his own history, which is similarly marked by loss. Like the feathered capes that retain ties to heritage in South America, Arveyda's music is his access to identity: "He played for his dead mother and for the father he'd hardly known; the longing for both came out of the guitar as wails and sobs. There was a blue range in his music that he played when he was missing them" (24). Through their embodiment of creativity and vitality that Arveyda associates with indigenous people, Carlotta, whom Arveyda imagines as the color yellow, evoking the endurance and optimism of autumn leaves and flowers, and Zede, whom he imagines as peach/pink/coral, "the womb colors," inspire him to express his own heritage through transcendent guitarplaying.

At the same time that the culture of the two women inspires Arveyda, Arveyda's cultural sensibilities also have a transformative effect on them. As Carlotta and Arveyda develop a love affair, he shares with her his diet, distinguished by his love of South American fruits, and introduces to her the "'exotic' ethnic groups" (10) of the Bay area during jogs through 
Golden Gate Park. In a painful episode, after Arveyda and Carlotta have been married three years and have had two children, Zede reveals that she and Arveyda are in love. Their connection is largely due to Arveyda's likeness to Jesus, Carlotta's father, also a black Indian: “'It is as if you went out,' Carlotta's mother sobbed after that first meeting, 'and brought your father home. . . 'He was Indio, your father, and his hair was rough'” (19). Arveyda and Zede then travel together through South America, enjoying the richness of the natural world, and for Zede, Arveyda's presence is "the ear that might at last reconnect her to her world" (45). The opportunity to reconnect with her native land leads Zede to seem more comfortable, more articulate, and more willing to speak openly about the cultural traditions she remembers.

Most importantly, Zede's sorrowful recollection of the captivity and death of Jesus, who was the protector of the sacred stones of the Indian village, reveals the true significance of the feathers that she uses for her capes. Releasing her from the hut where she was imprisoned with Jesus's body, Jesus's fellow tribesmen, always on the run from colonists, had hid her with Indians who made trinkets for white tourists, which paved the way for her flight to California. Of the tribesmen's departure, Zede explains: "they gave me the last remaining symbols of who they were in the world-feathers from the red African parrot for my ears, this parrot that had been brought to their village so many years ago by the men with rough hair, from a continent they called Zuma, or Sun, and they gave me, for Carlotta, three pigeonegg-size-stones"” (76). Zede's description of her last days with the tribesmen indicates that she and her daughter possess a legacy of alliance between Africans and indigenous (South) Americans, a legacy which they rediscover and preserve through their relationship to Arveyda. In this way, the three characters cross borders (national, cultural, sexual, familial, 
and racial) and reflect hybrid, black-Indian identity that empowers them to resist negative forces, particularly imposed by a dominant white patriarchal society, in their lives.

Like Zede, Arveyda, and Carlotta, Fanny, the granddaughter of Celie and Shug, occupies plural racial identities that allow her to achieve keener perception of her purpose in the world, yet unlike the other characters, she comes literally to embody the spirits of a diversity of individuals across genders and time periods. During therapy, Fanny's husband Suwelo comes to grips with the unusual behavior that his wife displays: "Fanny Nzingha found the spirit that possessed her first in herself. Then she found the historical personage who exemplified it. It gave her the strange aspect of a trinity—she, the spirit, the historical personage, all sitting across the table from you at once" (186). Perhaps most troubling to Suwelo is her occupation of the identity of Chief John Horse, the celebrated Seminole leader. Jealous, Suwelo does some research on Chief John Horse, reading William Loren Katz's Black Indians and giving a copy to Fanny for her birthday. When he questions her about her fascinations with historical figures, Fanny responds,

“They open doors inside me. It's as if they're keys. To rooms inside myself. I find a door inside and it's as if I hear a humming from behind it, and then I get inside somehow, with the key the old ones give me, and are, and as I stumble about in the darkness of the room, I begin to feel the stirring in myself, the humming of the room, and my heart starts to expand with the absolute feeling of bravery, or love, or audacity, or commitment. It becomes a light, and the light enters me, by osmosis, and a part of me that was not clear before is clarified. I radiate this expanded light. Happiness." And that, Suwelo knew, was called "being in love." (186)

Like Meridian's affiliation with Feather Mae and Cherokees, Fanny's access to Chief John Horse and Seminoles prompts a metaphoric out-of-body experience that allows her a broader view of personhood and of the boundless character of love. And like Zede's parrot feathers, Chief John Horse represents alliance of blacks and Indians against oppressors and 
enslavers - an embodiment of resistance. With Chief John Horse as an entrée, Fanny thereby experiences decolonization of the mind — and spirit — through hybridity.

Fanny's African father Ola, a playwright, provides much of the philosophy that informs Fanny's love for Chief John Horse and others whose spirits empower her. This philosophy springs from the subject of his next play: Elvis. According to Ola, in Elvis, who loved buckskin, fringe, and silver and was probably Choctaw, "white Americans found a reason to express their longing and appreciation of the repressed Native American and black parts of themselves. Those non-European qualities they have within them and all around them, constantly, but which they've been trained from birth to deny" (188). Fanny extends Ola's thesis further: "Suppose that behind those blue eyes and full lips, and under that thick black Indian hair, there was another: the old, ancient Indian. . . . Suppose that little bump-and-grind the crowds loved so was originally a movement of the circle dance.... Suppose that little hiccupy singing style of his was once a war whoop. Or an Indian love call" (188-9). In this meditation on Elvis, Walker seems to associate the feeling of ecstasy — what some viewers of Elvis's performance on the "The Ed Sullivan Show" would call hysteria—with American Indian spirituality, a connection that she likewise establishes in her illustration of Feather Mae's experience at the Sacred Serpent in Meridian.

A troubling dimension to these portrayals, however, is the lack of specificity that typifies Walker's representations of Indianness. Walker comments on this lack of tribal specificity in The Temple of My Familiar, arguing,

Now all of these tribes try to maintain their own tribal identities, and that is natural to man, who perpetuates his genetic identity by controlling woman he uses for production of his children, but it is not necessarily natural to nature, who will produce for anyone. So over time a lot of racial boundaries are crossed and new people created. What is fascinating is to see the love or hatred that is expressed for 
these new people, who don't, after all, have a firm tribal category in which to be imprisoned. (187)

In accordance with Walker's association of tribalism with imprisonment, there is no mention of Choctaw religion or unique Choctaw ways of being in the world despite Fanny's suggestion that Elvis is Choctaw. Likewise, though in both novels the Trail of Tears is mentioned, there is no reference to actual Cherokee cultural practices in Meridian despite the Cherokees' role as spiritual inspiration. Further, Walker's description of celebrating her Cherokee heritage in “My Brother Bill” echoes Fanny's words about uncovering Elvis’s repressed Indianness, and it similarly lacks the anchor of Cherokee culture.

Walker's idea of recovering repressed Indian identities as key to decolonization thereby suffers from vague notions of what those identities entail. Despite her claim that tribal identity is limiting, such distinctive identity is critical to the central concept of tribal sovereignty that is valued across Indian country, which encompasses hundreds of unique Indian nations. Walker is apparently unaware of the supreme importance of this concept to Indian people, or she ignores it. At any rate, however, the unifying principle throughout these texts, despite their unilateral characterization of Indian identities, remains alliance with indigenous peoples for the purpose of resistance, a consistent message. Based on this trope, for Walker, American identity is located in hybridity that contests a polarizing and oppressive dominant paradigm. Therefore, imagining Elvis, a somewhat universal American icon, as a figure that embodies multiracial identity is itself an act of resistance to whitewashed views of American culture.

Walker similarly portrays multiracial identity as the locus of American identity in her novel Now is the Time to Open Your Heart. Throughout the novel, references to American 
Indian iconography are the overarching synthesis for Kate Nelson's relationships to others as well as her contemplations of her own sense of varied identity. After much time in therapy, Kate concludes that she must journey along the waters of the Americas to achieve personal and spiritual fulfillment. First, she sets sail with several other women on a boat trip down the Colorado River. There, among the canyons, she finds a human handprint, a locus for affiliation with Hopi Indians: "She had felt the impact of that small handprint as if it were a handshake. Someone from the centuries, perhaps thousands of years, past, reaching out to her" (50). Later, Kate embarks on a journey to the Amazon, a trip that is the novel's focus.

At the airport, Kate immediately recognizes the others who will join her in the rainforest, calling them "Medicine Seekers" because "They had the look of people deliberately distancing themselves from the center of things, as their own culture defined it. Seeking the edge, the fringe. But also, paradoxically, the heart" (50). While in the rainforest, Kate consults a shaman, Anunu, who is African-Amerindian and whose healing songs communicate the message "Now is the time to open your heart" (66). Using a drug called yagi in order to reach greater understanding of this message, Kate becomes aware that existence "on the fringe" is truly American: "I am an American, Kate thought. Indigenous to the Americas. Nowhere else could I, this so-called Black person-African, European, Indio - exist. Only here. In Africa there would have been no Europeans, no Native Americans. In Europe, no Africans and no Indians. Only here; only here. ..” (53).

Kate, who renames herself "Kate Talkingtree," thereby calls cultural hybridity, particularly occupation of American Indian identity, the most genuine demonstration of having an open heart and locates the Americas as the most appropriate location for this kind of selfactualization. As in the other novels, indigenous identity, or American identity on "the 
fringe," allows an alternative, or a means of resistance, to the stratification that is imposed by a racist and patriarchal society. And also like the depictions of Indians in her other writings, this novel's portrayal of Hopis and other non-specific indigenous peoples do not reflect Indian cultures by any other means than pan-Indian shamanism or rather generic earthfriendly sensibilities. This problematic characterization of Indianness, and more broadly, cultural identity, is in part the source of harsh reviews of the book. For example, Michiko Kakutani of the New York Times asserts that the text is "less a novel than a cloying collection of New Age homilies, multicultural pieties and trippy Carlos Castaneda-ish riffs, hung like politically correct Christmas ornaments on the armature of Kate's torturous journey from self-pity to self-congratulation" (2). Though these criticisms are valid, it seems that Walker's purpose is not to explore American Indian identity thoroughly but to celebrate the usefulness of that identity for achieving the central aim of decolonization, that of imagining an alternative existence.

Release from colonial ways of thinking, achieved by imagining indigenous ways of being, spurs characters to greater environmental consciousness, particularly animal rights activism, in Walker's texts. Christine Gerhardt examines this connection of human liberty to ecological sensibility, explaining, "The notion of hybridity, in particular, serves as a useful tool for conceptualizing the position of black protagonists in such texts as highly unstable, since they find themselves simultaneously at the margins and the center of two overlapping systems of power (i.e., racism and ecological exploitation)" (520). In Living by the Word, in her essay "Am I Blue?," Walker ponders racism against African Americans and Indians and relates it to the treatment of animals, including her neighbor, a horse named Blue. As she pauses to feed Blue some apples, she notices him observing her, perhaps indicating his boredom with 
his life inside a pen. Walker's observation of Blue reflects her belief in the animal's ability to communicate and her acknowledgement of a "common, underlying pattern in which those in power forget 'deep levels in communication' that at one time bound them to the powerless with bonds of respect and love" (Ulman 231).

As she works with her partner's son on a quilt, the writer thinks of the ways in which white children learned to love black women, their "mammies," but were also taught to rebuke that love by considering it natural for those women to be objects of possession, sold from family to family. She also criticizes belief in animals' inferiority to humans, pointing toward American Indians to illustrate her complaint: "about the Indians, considered to be 'like animals' by the 'settlers"' (5-6). In this way, Walker links racism to the confinement and commodification of animals, and in Gerhardt's words, "effectively criticizes continued collective abuse of nature as 'dark' other" (530). In “The Universe Responds," commenting on her essay about Blue, Walker makes this association explicit, referring to animals as "suffering, fully conscious, enslaved beings" (188) and describing her adoption of vegetarianism as a demonstration of this belief. She states that after writing the essay, she immediately developed a relationship with two horses across the road who display "a spark of recognition" (188-9).

For Walker, affirming hybrid identity, across divisions between humans and animals as well as across racial borders, allows characters to overthrow patterns of abuse and reverse the threat of ecological degradation. In her essay "Everything is a Human Being," Walker details how to act responsibly toward animals, again using American Indians as the impetus for this upright behavior. She references James Mooney's Myths of the Cherokee and Sacred Formulas of the Cherokees, which provides an account of Cherokees' 'interesting practices. . 
. of asking pardon of slain or offended animals" (149). Following that tradition, Walker asks pardon of a snake that she killed in her garden, hoping that her public request for forgiveness will prevent others from needlessly taking the lives of animals. The writer further suggests that it is this appreciation for the natural world that is the source of her veneration of Indian people: "No one has better appreciated Earth than the Native American. Whereas to the Wasichus only the white male attains full human status, everything to the Indian was a relative. Everything was a human being" (150-1). Walker then concludes the essay by quoting from Black Elk, "Give me the strength to walk the soft earth, a relative to all that is!" (151), linking her positive outlook to the words of the Lakota shaman.

Walker solidifies her connection to Black Elk by suggesting that a reciprocal sustenance ensues from preservation of the natural world. Walker draws on the events at the end of Black Elk Speaks, in which the Great Spirit sends rain as acknowledgement of Black Elk's prayers for his Lakota people, to reinforce her idea that animals communicate with and respond to those who form a positive relationship with them. She writes, "The truth is, in the country, where I live much of the time, I am virtually overrun by birds and animalsraccoons, snakes, deer, horses (occasionally)" (190), describing a harmony with the natural world that is evidence of her kind deeds toward animal friends. As Gerhardt argues, this idyllic lifestyle reverses the dissociation from nature that characterized slavery, as Walker expresses "a necessary reconfirmation of black people's relationship to the earth, a move back to nature that will promote collective black self-recovery" (528-9).

Walker also relays the story of George, a lost dog who shows up at her doorstep, to illustrate human responsibility for animals who are imperiled, calling her house George's hoped-for stop on the underground railroad. Unfortunately, like her killing of a snake in her 
garden, Walker's refusal to provide George a home is a decision that she regrets. Ultimately, Walker argues, "The Universe responds. What you ask of it, it gives. . . Ironically, Black Elk and nuclear scientists can be viewed in much the same way: as men who prayed to the Universe for what they believed they needed and who received from it a sign reflective of their own hearts" (192). Thus Walker concludes that saving the earth is indeed an act of selfrecovery, an act of resistance, inspired by American Indians, that counteracts destructive forces.

In Walker's formulation, once decolonization and harmony with the natural world have been achieved, one may fully contemplate the divine in a way that she believes is similar to indigenous spirituality. In her essay "My Brother Bill," referring to her writing as prayer, Walker explains that shared spiritual beliefs distinguish her close friendship with Bill Wahpepah: "I always felt very comfortable talking with Bill about prayer and Mother Earth and the spirits that, if you are open to them, are ever present. He has such empathy with the suffering of the Earth ... that when he spoke about her you thought it was some human being he knew" (47). In "The Universe Responds," Walker more specifically formulates these beliefs, calling prayer "the active affirmation in the physical world of our inseparableness from the divine; . . . everything, especially the physical world, is divine" (192). She continues, “'God' answers prayers. Which is another way of saying, 'the Universe responds"”(193).

In The Color Purple, affirmation of processes of the natural world likewise results from resistance to oppression, and more specifically, this environmental consciousness accompanies greater female empowerment as well as a transformed view of God. In the beginning of the novel, the seed of Celie's resistance to Albert is observable in her 
recognition of her bond with nature. When Albert gets the belt and prepares to beat her, she steels herself against crying: "I make myself wood. I say to myself, Celie, you a tree. That's how come I know trees fear man" (30). Celie's female bonds, especially with Sofia, whom she observes chopping woods and mending the roof-flying in the face of traditional gender roles_-facilitate her resistance to Albert. Moreover, these bonds, apparent in signs in the natural world, strengthen once her liberation is sound.

Finally knowing that Alphonso is not her natural father or the owner of the homestead any longer, Celie, accompanied by Shug, returns to her childhood home. Celie notices the lushness of the natural vegetation that affirms her rightful place in this space:

the first thing us notice soon as we turn into the lane is how green everything is, like even though the ground everywhere else not warmed up good, Pa's land is warmed and ready to go. Then all along the road there's Easter lilies and jonquils and daffodils and all kinds of little early wildflowers. Then us notice all the birds singing they little cans off, all up and down the hedge, that itself is putting out little yellow flowers smell like Virginia creeper. It all so different from the rest of the country us drive through, it make us real quiet. I know this sound funny, Nettie, but even the sun seemed to stand a little longer over our heads. . . . It was so pretty I thought that us stop and just set looking at it. What kind of trees all them flowering? Ast Shug. I don't know, I say. Look like peach, plum, apple, maybe cherry. But whatever they is, they sure pretty. All round the house, all in back of it, nothing but blooming trees. Then more lilies and roses clamming over everything. And all the time the little birds from all over the rest of the county sit up in these trees just going to town. (164-5)

In accordance with Walker's philosophy, Celie, who throughout the text has written letters to God, prayers that reflect her upright heart, receives an abundance of signs affirming her prayers. The universe indeed responds.

Celie's liberation is therefore bound to her verification of the active presence of the natural world, an acknowledgment that accompanies her full embrace of Shug as her life partner and family. As Celie leaves her new home, which is now exorcised from its violent past, and 
searches for location of her parents' gravesites, suddenly the environment seems lifeless: "By the time us got to the cemetery, the sky gray. Us look for Ma and Pa. Hope for some scrap of woods that say something. But us don't find nothing but weeds and cockleburs and paper flowers fading on some of the graves" (167). Arbitrarily marking a spot to confirm the resting place of Celie's parents, Shug and Celie stick a horseshoe in the ground. Shug then indicates that Celie's past, portrayed by nature as dead, should be forgotten and that Celie should enter the future with her: "Us each other's peoples now" (167). Thereafter, Celie's and Shug's existence is almost completely gynocentric, a living that enjoys the blessings of nature. Together, the women celebrate a symbiotic relationship to nature, feasting on "stuff that's fresh" (189).

As both Nettie and Celie are eventually able to witness the universe responding, they characterize God in a way that differs from their earlier Judeo-Christian beliefs. While in Africa, Nettie learns about the beliefs of Olinka people, which center on the roofleaf plant, their source of sustenance. In a welcoming ceremony for Nettie and her adoptive parents, Joseph, the Olinka leader, interprets the tribe's origin story. He explains that the people believed that their landscape is a sacred space, one that they have always inhabited. As the story goes, the land produces in abundance until one greedy man wants to plant more and use the surplus in trade with white men. Eventually, his greed causes him to transform roofleaf into a commodity, which disturbs the elders, whom he appeases with trinkets. When a storm destroys the roofs of the village, there is not enough roofleaf to repair the damage, and members of the Olinka community begin to die of exposure. After many years, the roofleaf is finally restored, and the community begins to celebrate, worshiping the essential plant. Joseph explains Olinka spiritual beliefs as follows, "We know a roofleaf is not Jesus Christ, 
but in its own humble way, is it not God?" (142). In her letter to Celie, Nettie explains, "So there we sat, Celie, face to face with the Olinka God. And Celie, I was so tired and sleepy and full of chicken and groundnut stew, my ears ringing with song, that all that Joseph said made perfect sense to me" (143). The Olinka creation story, similar to the story of Jesus in its presentation of salvation, thereby gets Nettie thinking about her spiritual beliefs and her work with indigenous people in Africa.

As Nettie becomes more accustomed to Olinka society, she feels a sense of discomfort with Christian beliefs, a sign of her maturation and journey toward liberation. As she explains to Celie, Christian iconography seems out of place in the Olinka community: "Even the picture of Christ which generally looks good anywhere looks peculiar here. We of course have all of these pictures hung in the school and many of Christ behind the altar at church. That is enough, I think. .." (147). By the end of the novel, after Nettie has grown into a woman, has worked against colonial forces, and has become wife to Samuel and mother to Celie's children, she embraces a new conception of the divine:

God is different to us now, after all these years in Africa. More spirit than ever before, and more internal. Most people think he has to look like something or someone - a roofleaf or Christ — but we don't. And not being tied to what God looks like, frees. When we return to America we must have long talks about this, Celie. And perhaps Samuel and I will found a new church in our community that has no idols in it whatsoever, in which each person's spirit is encouraged to see God directly, his belief that this is possible strengthened by us as people who also believe. (227)

In The Temple of My Familiar, Walker traces the implications of this religious transformation for Olivia, Celie's daughter. Olivia explains that in Africa, “'God' was not a monolith, and not the property of Moses, as we'd been led to think and not separate from us, or absent from whatever world one inhabited. Once this channel was cleared, much that our people had been taught about religion, much that diminished them and kept them in oppression, would 
naturally fall away" (146). Olivia, like Nettie, welcomes spiritual practices that are grounded in the earth.

Celie's rejection of patriarchal oppression and affirmation of her connection to the natural world leads her to a new understanding of God. Expressing frustration with the God that she has learned to pray to, the addressee of the letters she writes throughout the text, Celie explains, "the God I been praying and writing to is a man. ... If he ever listened to poor colored women the world would be a different place, I can tell you" (175). Seeking to convince Celie that God is indeed a loving presence in the world, and not "the old white man," Shug asserts, "God ain’t a he or she, but a It" (177-8). Shug further explains that God "loves everything you love" (178), including sexuality, and rejoices in admiration, particularly admiration for the natural world. In perhaps the text's most powerful image, she offers, "I think it pisses God off if you walk by the color purple in a field somewhere and don't notice it" (178). With Shug's reassurance, Celie works toward divesting God of association with men: "Now that my eyes opening, I feels like a fool. Next to any little scrub of a bush in my yard, Mr. ___ 's evil sort of shrink" (179). This passage recalls Walker's own theology as, in the words of Chauncey Ridley, animistic, a revocation of "all divine sanctions for paternalism" (33).

Once Celie has learned to appreciate God as "a It," she expresses a more vigorous spiritual life, one that, in addition to the feasts she shares with Shug, suggests American Indian ceremonies. Inhabiting her childhood home, which she now owns, Celie, according to Shug, is "doin' all right. ... God knows where [she] live" (217). In preparation for Nettie's return, Shug and Celie perform a smudging: "Us started at the very top of the house in the attic, and us smoked it all the way down to the basement, chasing out all the evil and making a place 
for good" (217). This ceremony allows Celie to imagine the space as a true home. Finally, when Nettie returns, Celie expresses the kind of admiration for God that Shug explained. Her last letter is addressed, "Dear God. Dear stars, dear trees, dear sky, dear peoples. Dear Everything. Dear God" (249), signifying her avowal of the physical world as divine and circular.

In Meridian, resistance also necessitates appreciation for the integrity of the earth, which is likewise tied to women's fates as well as to spiritual transformation. Meridian contemplates this fundamental responsibility for protecting the sacredness of the land and its inhabitants as she observes an archaeological exhibit at a museum of Indians: "she peered through plate glass at the bones of a warrior, shamelessly displayed, dug up in a crouched position and left that way, his front teeth missing, his arrows and clay pipes around him. At such sights she experienced nausea at being alive" (59). As Charlotte Zoe Walker aptly observes, the display mirrors the gothic display of Marilene and the briny lake that enshrined her for so many years: "the husband's declared ownership of his wife even in death harshly satirizes the white culture's 'ownership' of the Indians whose lives and culture it destroyed" (50). More explicitly, Meridian recognizes that as the Sacred Serpent, containing the Indian burial mounds as well as Meridian's father's vegetable garden, is bulldozed and turned into a theme park for tourists, the degradation of the environment has significant human consequences, particularly for women.

Meridian's connection at the Sacred Serpent to Feather Mae, who similarly rejects conventional roles for women, signifies the importance of "wild" spaces to female empowerment. Meridian's mother, with whom Meridian does not have a close relationship, seems to be lacking the genuine spiritual life that Meridian's father, a descendant of Feather 
Mae, experiences. Meridian observes, "for all that her father sang beautifully, heartbreakingly, of God, she sensed he did not believe in Him in quite the same way her mother did" (29). The contrast between her parents' conceptions of God is evident in their argument about the Indians buried at the Sacred Serpent. Meridian's father says of Indian ways, "It was a life, ruled by its own spirits" (29), to which her mother responds, "I never worry myself about such things. There's such a thing as progress. ... As far as I'm concerned those people and how they kept off mosquitoes hasn't got a thing to do with me" (29). Because of her mother's lack of appreciation for the Sacred Serpent, Meridian's beliefs clearly align more closely with her father's and those of Feather Mae, "who renounced all religion that was not based on the experience of physical ecstasy" (57). As Riley states, when Meridian takes up Feather Mae's mantle, she is carrying out a "shamanistic tradition running through [her] family" (246).

Meridian's differences with her friend Anne-Marion, like her differences with her mother, also highlight Meridian's role as spiritual referent for her community. While the source of Meridian's wisdom seems to be her appreciation of the natural world, which she exhibits in the pictures she tapes to her dorm room, in contrast, Anne-Marion is portrayed as "rounded and lush, brash and eager to argue over the smallest issues. Her temper was easily lost" (38). The friendship between the two women is threatened when Anne-Marion participates in the destruction of The Sojourner Tree, the mystical symbol of female power and unity. The relationship is further strained due to Anne-Marion's acceptance of violence as a part of the Movement, a step that Meridian is never able to take. Further, Anne-Marion resents Meridian's decision to return to the South, and her own decision to remain in the city, largely divorced from the natural world, suggests her severance from rural life, apparently resulting 
from her actions against The Sojourner.

Finally, the only sign of reconciliation between the two women comes at the end of the novel, when Truman attempts to return to Meridian after his years of disloyalty. Truman discovers a note from Anne-Marion in Meridian's room: "It contained one line: 'Who would be happier than you that The Sojourner did not die?' She had written, also in a minute script, 'perhaps me,' but then had half-erased it" (217). Understanding that Meridian's example is too powerful to deny, Truman expects Anne-Marion's return as well as becomes transformed himself: "One day, after Truman —who was beginning to experience moments with Meridian when he felt intensely maternal—had wiped her forehead with a cloth soaked in cold water, Meridian wrote: there is water in the world for us / brought by our friends / though the rock of mother and god / vanished into sand / and we, cast out alone / to heal / and re-create ourselves" (213). Struck by her words, Truman has his own moment of spiritual ecstasy similar to ones depicted at the Sacred Serpent. Putting on Meridian's cap, Truman symbolically takes up her cause. According to Joseph Brown, Truman's actions replay a common theme in Walker's writings, that of "re-creating a world in which men become complete only when they become female" (319).

As in Meridian, The Temple of My Familiar illustrates ways in which resisting the reach of colonialism prompts responsibility for the environment, which accompanies female empowerment. The strong connection between women and animals is most evident in descriptions of sacred creatures, or spiritual emblems, called "familiars." For Zede and Arveyda, identification of a "familiar" necessitates recovery of Zede's people's creation story, a community narrative that precedes the infiltration of Europeans. According to Zede, woman and the toucan were created at the same time, and woman, "through the process of 
life and change," produced man, "a being somewhat unlike herself" (48). Eventually, the man went off to seek others like him, and this community of men corroborated stories of women who wore colors and feathers, apparently toucan feathers. These men conclude that women must be directly related to a goddess, the author of earth, who "must possess great and supernatural powers" (49). According to Madelyn Jablon, dream memories such as these in Walker's texts are revisions of history that empower those who recall them (139). Reflecting Jablon's analysis, for Arveyda, recollection of a female creation myth is inspirational.

Zede's experiences lead Arveyda to understand that as a musician and artist, he has a special responsibility to unite the world, especially in an effort to preserve its creatures and vegetation. Beyond his earth-friendly vegetarian lifestyle, Arveyda learns that his singing about the lush natural environment of South America and "a country that wore green as its favorite dress" (125) is the source of his power to affect change. He discerns that his mission "must be that the pain he brought to others and to himself. . . would lead not to destruction, but to transformation" (125). Pouring his heart out, Arveyda sings to Carlotta about her mother's love for her and wishes to restore their relationship, as well as of her people's origins in South America. He sings of the pain as well as the triumph that has distinguished her people, who, after their "great" civilizations fell, have lived simply, "Hunting and fishing and praying and making love and having babies" (126). In his song, Arveyda also celebrates the red feathers that they wore in their ears, "symbolic of their essence" (126), which he calls their familiar. The red feathers are thereby the natural demonstration of liberation from oppression, particularly women's empowerment, and they suggest humans' responsibility for ensuring the continuance of that liberation. 
Like Zede, Lissie Lyles also recalls a creation story that reverses the vilification of women in the biblical Adam and Eve story. Her story centers on the violence that a white man introduces to an idyllic, environmentally harmonious, setting. In relaying this creation story, Lissie, who like Fanny has the capacity to embody the spirits of various other individuals, explains that she has inhabited the spirit of the white man in the story. According to Lissie, as a youngster, the white boy was carefully tended by his mother, who rubbed ointments created from berries and nuts into his skin. His mother's familiar, a large lion, had a family of his own, and the boy intermingled with the family of cubs. However, this peaceful existence is disturbed when, after making love with a female friend, the boy discovers that he is white. As his friend tries to comfort him, he picks up a stick and chases her away, the earth's first incidence of violence. Before the girl escapes, Ba, her familiar, acts to protect her, and the boy strikes Ba with a club, breaking its neck. Lissie's unique knowledge of the earth's matriarchal origins, which privileged women of color, as well as her recognition of the environmental havoc that can be traced to a white male, prompts her unconventional behavior in the present world.

Lissie, who has identified her own familiar, communicates the importance of protecting this familiar to her partner Hal. Continuing a well-established pattern in the text, the temple for Lissie's familiar is associated with American Indian dwellings, "very adobe or Southwestern-looking, with poles jutting out at the ceiling line and the windows set in deep. . .. painted a rich dust coral and ... [with] lots of designs — many, turquoise and deep blue, like Native American symbols for rain and storm — painted around the top" (118). According to Lissie, the creature is unusual, possessing a myriad of qualities previously unobserved in one animal: "my familiar — what you might these days, unfortunately, call a 'pet'—was a 
small, incredibly beautiful creature that was part bird, for it was feathered, part fish, for it could swim and had a somewhat fish/bird shape, and part reptile, for it scooted about like geckoes do.... Its movements were graceful and clever, its expression mischievous and full of humor. It was alive!" (118). When Lissie seeks to keep it in a metal washtub cage, "the little familiar [breaks] through the bottom of the tub and out into the open air," and looks at Lissie "with pity" (120). This episode leads Lissie to acknowledge her betrayal of the familiar and pledge not to repeat her mistake.

Lissie's efforts at self-preservation as well as her commitment to harmony with the natural world lead her to resist patriarchal conventions, and this resistance sometimes causes tension with Hal. Throughout the text, the relationship between Lissie and Hal has its ups and downs, such as Hal's wish that she wear high heels. By the end of the novel, Suwelo finds Lissie's last few paintings, including parts of a series on lions as well as a depiction of a tree of life. Indicating the truly egalitarian, reciprocal existence that Lissie and Hal have attained, the painting that Suwelo takes as a keepsake features Lissie in the form of a lion, donning a "very gay, elegant, and shiny red high-heeled slipper" (416).

Because of the transformative power of liberation, Fanny, like Lissie and Arvyeda, is open to - and even embodies - the experiences and spirits of others, and this broad view of cultural and ecological hybridity cements her bond to the natural world. For instance, Fanny's earliest memory is of a red bird, which can be read as her familiar, and of "two old ladies kissing" (168). As she explains to her sister Nzingha, the bird was a gift from Celie and Shug, her grandparents, who used the fake bird to teach her about the living birds outside her window. As she grew, Fanny witnessed other examples of this care for animals at Shug's and Celie's house: “if you stepped on an ant in Mama's Celie's presence and didn't beg 
forgiveness, you were just never invited to her house again" (169). Celie's love for the natural world was something she learned "from Mama Shug" (169) according to Fanny, as Celie's liberation from abuse at the hands of Albert and Alphonso was necessary first.

After Celie's and Shug's example, Fanny expresses similar, ecologically harmonious living in her adult life. Suwelo and she live for a time in a yurt, a structure traditionally inhabited by nomadic Mongol people, on five acres. Their dwelling is surrounded by lush forest and creatures of every kind. Additionally, according to Suwelo, "Fanny from time to time thought she saw Indians" (275). Though Suwelo can't see them, Fanny describes two Pomo Indian boys: “brown skin, long black hair, very round, 'moon' faces, she said. Loincloths. . . As still as deer, they were,' she avowed, 'and as hard to see'” (275). Because of her admiration for Indians, and her association of them with pre-industrial, ecologically responsible living, Fanny later explains to her father Ola that she rejects as unenlightened the building of skyscrapers, the mining of uranium or plutonium, or the unearthing of artifacts for archaeological purposes. Fanny's counteraction of colonial influences thereby prompts her environmental activism.

Like the relationship of Lissie and Hal, Fanny's and Suwelo's relationship improves as they throw off the conventions of a patriarchal society. Together, Fanny and Suwelo read Eleanora Burnham's writings, which include M'Sukta's description of Ababa ways. According to M'Sukta, "After thousands and thousands of years of women and men living apart, the Ababa had, with great trepidation, experimented with the two tribes living, a couple to a household, together. Each person must remain free, they said. That is the main thing. And so they had designed a dwelling shaped like a bird" (395). Like the people that frame the 
other plotlines in the novel, Fanny and Suwelo look to an alternative existence, or an alternative history in Jablon's reading, to live out equality and harmony in the natural world.

In an apparent rejection of monogamy as an oppressive patriarchal convention, Suwelo and Carlotta, as well as Fanny and Arveyda, ultimately become lovers as well, and the foursome share a dwelling amid lush vegetation. This result, a gynocentric challenge to convention, is a prominent feature of Walker's writings, which, according to Greta Gaard, can be understood as a "cross-cultural ecofeminist ethics" (82). In Gaard's formulation, "older traditions emphasize ... the well-being of the people in harmony with nature-their own physical natures and the nature of this physical world. The women who lead the return to these older, life-affirming traditions are the subject of criticism because they are perceived to be challenging the very identity of their culture" (88). Fanny, Lissie, and Zede, as well as Mary Jane — whose sailboat is embroidered with a turquoise snake—reflect just such ethics as they resist oppression and live peaceful existences on earth.

Now is the Time to Open Your Heart, like The Temple of My Familiar, also affirms environmental consciousness as a natural result of personal, particularly female, liberation. On her first "journey," which takes her to the Colorado River, Kate is supported and inspired by a female friend who shares her feeling of concern for and connectedness with other creatures on the earth:

It seemed to her that humans were now in the position of deer or antelope or Buffalo or polar bears. There wasn't any longer a safe place for them.... She knew that if human beings, on a global level, gave in to the fear of being wiped out, disposable, like all other creatures, they would never be able to think and feel their way out of their dilemma. And so she had sat in a car crossing a long silver bridge, holding a new friend's hand. This was a woman who seemed to be exactly where she was. In a state of near catatonic panic. Let's go ask the trees! this woman had said, the first time Kate had looked her in the eye and said Hi, what's happening?? (63). 
Significantly, Kate must spend this journey apart from her boyfriend Yolo, in the company of women, to deliberate on this question of how to save the earth.

On her second journey, in the Amazon, Kate is again in a female-dominated setting, participating in purification rituals with other women as well as with transvestites from Hawaii who intend to live as women until patriarchy on earth is overthrown completely. This experience with females allows Kate to better attune herself to the processes of the natural world. After her arrival in the Amazon and her deliberation, under the influence of yage, about her American identity "on the fringe," Kate decides that she must greet the rainforest in the same way that one would meet human hosts in a new land. Resting in her hut, she "listened to this Being, the rainforest" (53), comparing it to the frenetic activity of New York City:

It was the loudest thing she'd ever heard. ... And every sound she heard that was not made by the vegetation, giant trees and tree-sized vines, groaning as they rubbed against one another, was made by creatures. Every Being was chatting, talking, whistling, singing. Singing. Lots of that. And everything was in motion. If she listened closely she could distinguish slithering, sliding, jumping, hopping, ambling, crawling, flying. (53-4)

Further describing Kate's belief in the equality of the natural world and humanity, Walker writes, "She had an instinctive understanding, perhaps from birth, that people and plants were relatives. As a child she had spent hours talking to, caressing, sitting in, kissing, and otherwise trying to communicate with trees" (69). As an individual who seeks a broader understanding of humanity, evidenced in her discussion of American identity, Kate seems also to be predisposed to an enlightened response to her environment.

Kate's view of earth as her relative drives her relationship with Hugh Brentforth, who mourns a development teams' unearthing of Hopi people's bones under a lake bed on his 
ranch. In the past, Hugh was visited every year by a Hopi elder who gathered a bit of water from a spring above the burial site, an action that Hugh did not understand. Because of Kate's enlightened state, however, Hopi people visit her in a dream, and she is thereafter able to explain to Hugh the old man's prayer for his people for which he used the water. She explains: “. . . he stood in the center of what had been the graveyard of his tribe and of people he and his more recent ancestors had known. He knelt to pray. After praying he rose and sprinkled the water over the ground and over himself. He was trembling with exhaustion and sadness, but he was weeping with love" (133). Later, the Hopis again visit Kate in a dream, communicating their collective story of life above and below ground and referring to their belief in the earth's abundance. Inspired by the love that the Hopi elder displays as well as the reverence that his people hold for the natural world, Kate's heart is now truly open, and she is better able to share her love with her boyfriend Yolo.

As Yolo and Kate plan an unconventional wedding, they share American Spirit cigarettes, which, because they believe these products do not contain toxic chemicals, apparently proves their bond to the earth. Unfortunately, however, Kate and Yolo, and apparently Alice Walker, have been duped. American Spirit, a tobacco company based in Santa Fe, New Mexico, is owned by R.J. Reynolds, and it has no affiliation with American Indians, though its marketing strategy is to feature a man in a headdress prominently on all of its packaging and ads. As individuals who claim to celebrate decolonization of the mind, Yolo and Kate are the very definition of hypocrisy in this scene, buying into R.J. Reynolds's stereotypical, abstract appropriation of American Indian people for profit and disregarding the harrowing prevalence of death from lung cancer among American Indian communities.

According to Lawrence Shorty (Dine/Choctaw) of the State of North Carolina Tobacco 
Control and Prevention Branch, American Spirit disproportionately targets American Indian youth in its advertising campaigns, conducting giveaways at rodeos, pow-wows, and other cultural gatherings and giving incentives to tribes for setting up smoke shops on reservations, enacting the epitome of environmental racism. Yolo and Kate also overlook the critical distinction between ceremonial and commercial uses of tobacco, the former involving burning leaves - not cigarettes, which even in American Spirit form, contain thousands of addictive additives. Though Walker's message, that of loving the earth by loving one's multiple, generically Indian-influenced selves, remains consistent, here it is simply offensive and irresponsible.

Smoking aside, Yolo's and Kate's wedding ceremony is blessed by nature, especially in the presence of a serpent, that age-old symbol of human fear of the processes of nature and the author of women's association with evil. Since Armando, Kate's spiritual guide in the Amazon, can not make it to her wedding, he promises to send a spirit in his place. In another dream, the serpent visits Kate, instructing her that overcoming fear necessitates making friends with it, echoing the message of the Buddha. In the same dream, Kate learns of the futility of spraying chemicals to rid her home of pests, as her spraying causes her to perceive "each individual ant growing larger" (211). Following the advice of the snake, her familiar of sorts, Kate revisits her altar room and uncovers her Buddha icon. Together, she and Yolo face the altar and meditate under a large ficus tree. Completing the scene, Kate retrieves a clock in the shape of an anaconda and places it in the Buddha's lap. Fully affected by their journeys to self-acceptance, journeys which foreground an embrace of hybrid identities, Kate and Yolo are now prepared to make friends with the earth's creatures without fear, ensuring their spiritual transcendence. 
Throughout Alice Walker's texts, American Indians serve as the inspiration for resistance to a dominant white patriarchy, resistance which instigates harmony with the natural world, female alliance and empowerment, and spiritual fulfillment. Though Walker's presentations of American Indian societies are often problematic, her message of seeking liberation through "wild" creatures and peoples is nonetheless consistent. Walker thereby portrays selfactualization as a process of embracing hybridity and crossing cultural and temporal boundaries, situating herself as a writer of the borderlands. 


\section{CHAPTER VI: \\ THE EARTH REMAINS: PLACE AND PROPHECY IN LESLIE MARMON SILKO'S ALMANAC OF THE DEAD}

Leslie Marmon Silko's Almanac of the Dead (1991) is a departure from her earlier novel, Ceremony (1977), which garnered much popular and critical praise for its vision of a young veteran's redemptive return to his Laguna home after experiencing the psychological traumas of World War II. While Ceremony has securely and rather seamlessly come to be considered "canonical," becoming a favorite in high school and college English classes, Almanac of the Dead, in its more than seven hundred graphic pages of drug abuse, violence, and wideranging settings and characters, has been less popular. Perhaps the most important distinction between the two texts lies in their differing structures, Ceremony following typical novelistic conventions, making it more palatable to an array of readers, and Almanac of the Dead literally taking form as an almanac, a format that is unusual and frustrating for some. Silko's masterful experimentation with form is indeed an attempt to subvert readers' expectations; in the words of the author, she wanted to write something that would "horrify the people at MLA" (Barnes 83-4).

Almanac of the Dead's expansive — and subversive — structure is appropriate for the allencompassing vision that the novel creates for a variety of the peoples of the Americas, including Anglos, Latino/as, African Americans, and Native peoples. Weaving together narratives that range widely, both in content and in setting, Silko presents in Almanac of the Dead a concept of being "in place" that differs from novels usually associated with particular geographies, such as Sherwood Anderson's Winesburg, Ohio, Thoreau's Walden, or other 
texts by American Indian writers, such as Louise Erdrich's Love Medicine and N. Scott Momaday's The Way to Rainy Mountain. In Almanac of the Dead, Silko invites a challenging understanding of the Americas as both an all-encompassing geography, blurring national and ethnic or racial borders, and as a specific landscape, offering Native and, more particularly, Laguna orientations as the source of a prophecy that portends Natives' literal reclamation of land. This thematic result moves beyond metaphorical celebrations of Indian cultures, which are popular conventions in literature, and along with the novel's unusual format, is the source of many readers' discomfort. As Creek writer Craig Womack asserts, “America loves Indian culture; America is much less enthusiastic about Indian land title" (11). Silko's almanac is therefore cleverly akin to yet radically different from farmer's almanacs and naturalist diaries; it is ecological writing that breaks the mold in both form and content. By portraying violence and destruction as inherent parts of a broader process of decolonization, countering the violence accompanying "Manifest Destiny," Silko reveals hope within trauma, intertwining the fates of various peoples, animals, and landscapes to reconfigure accepted histories and point toward a global, yet still Laguna, future.

While American Indians have long been associated with images of wilderness in literature written by European Americans, including in works by James Fenimore Cooper, Henry David Thoreau, and William Faulkner that may be approached as "nature writing," American Indian literature does not contain many texts that are especially characterized as eco-writing or that respond neatly to its accepted conventions. According to Daniel White, "To many Native American authors, the nature-essay form may imply an artificial division between the human and nonhuman compartments of the world. ... traditional native peoples have never needed to leave town to seek out an experience in nature; nature is their town" (141). 
Referencing Silko's essay “Interior and Exterior Landscapes," White goes on to describe Silko's presentation of European views of nature as emblematic of a "loss of integration," "a primary affliction of Euro-American culture as well as a growing threat to young Native Americans" (142).

White's reading contradicts Lawrence Buell's contention in his text The Environmental Imagination (1995) that Native views of nature parallel masculine, European depictions. Buell states:

No inquiry can call itself informed which does not recognize that the idealization of nature in American literary mythography has historically been more a masculine pursuit than a female-sponsored endeavor, and that attitudes toward exurban space differ considerably among American cultural groups, the tendency to idealize it having run far stronger, by and large, in white and Native American writing than in Jewish American, Asian American, African American, and even American Latina/Latino writing. (16)

While in his recent The Future of Environmental Criticism (2005), Buell revises his view of environmental aesthetics to include more of a concentration on environmental justice and welcome more of an emphasis on "the interpenetration of metropolis and outback, of anthropocentric as well as biocentric concerns" (22-3), he nonetheless still distances Silko's work from an exclusively Native grounding, characterizing her "Pueblo example as paradigmatic rather than as uniquely culture-specific" (49).

Buell's interpretation of Silko's rendering of environment draws on his conception of the difference between "space" and "place." For Buell, "Place entails spatial location, ... a spatial container of some sort" and is ascribed with meaning, while space "connotes geometrical or topographical abstraction" (63). According to Buell's distinction, Native Americans on reservations inhabit spaces rather than places. He asserts, "The Native Americans ... lost both space and place, until remanded to federally defined spaces 
('reservations') more like internment camps than decent substitutes for the pre-settlement home place or range" (64). While Buell is correct that the United States' "removal" and "relocation" policies enforced a sense of dislocation upon tribes, accompanied by sadness and tragedy at the loss of traditional homelands as well as members of tribal communities, his evaluation overlooks the ways in which American Indian reservations - as well as other Native communities—-have indeed become "places." Especially for Silko, Laguna legacies on a particular landscape are maintained through stories, which in the author's words allow individuals to "hear who we are" ("Through").

For American Indian writers such as Silko, the process of storytelling affirms grounding on particular landscapes, including reservations, as parts of American Indian destinies that include survival and sustainability in addition to hardship. Choctaw writer and scholar Louis Owens highlights these "other destinies" as central to American Indian literature, which draws on oral traditions of Indian singers or storytellers within the European genre of prose narratives (10). Therefore, Indian literature comes to exist as a kind of hybrid yet subversive form, through which, according to Owens, "American Indian novelists—examples of Indians who have repudiated their assigned plots - are in their fiction rejecting the American gothic with its haunted, guilt-burdened wilderness and doomed Native and emphatically making the Indian the hero of other destinies, other plots" (18). Native writers thereby maintain a focus that reflects David Landis Barnhill's definition of being in place, or "living with the land and its processes" (5) that is similar to yet more specific than Buell's formulation.

American Indian writers' portrayals of "other destinies" involve active participation, through oral traditions, in the ecologies, whether idyllic or toxic, of specific places. This process is what moves American Indian literature beyond the idealization that Buell 
describes and provides its framework for American Indian conceptions of self. As Donelle Dreese explains, “... stories ... describe specific landscapes from which a tribe derives its means for survival, its cultural symbols, its sense of self, and its spirituality" (8). Further, Dreese characterizes American Indian writers' evocations of oral traditions as "mythic reterritorializations," which occur "when writers salvage the stories and places from the past and rewrite them in order to claim an identity and to establish a place concurrent with their present sense of self" (24). Writing and telling these reterritorializations in "their own voices, on their own terms, and in their own places" (44), Native writers, according to Dreese, express resistance.

While Dreese's discussion of active inhabitation of Native places as resistance is apt, she privileges pristine imaginings of American Indian cultures as the source of that resistance, which has the potential to promulgate the kind of romanticism that so many Indian writers are working against. In her words, "Most of the landscapes ... are strongly altered by technology and progress so that a return to place could only be metaphorical or imaginative. . .. a return to cultural purity would be impossible. Reterritorialization, then, can act as a decolonization process that is often highly nostalgic and spiritual" (114). Though Dreese is correct that many Indian writers evoke images of homeplaces that are constant despite the negative effects of colonization, these places need not be frozen in time to persist as positive sources for Native selfhoods. Drawing on the example of his Creek community, Womack offers a more integrative view of change, arguing "Indian cultures are the only cultures where it is assumed that if they change they are no longer a culture. In most other cultures, change is ... a sign that the culture is vibrant and alive .... Creeks provide an interesting historical example ... [of] flourish in the face of change" (31). For Silko especially, change, 
especially the effects of technology, as well as contact with other cultures, come to be part of storytelling, of being in place that sustains indigenous communities. In this way, Silko expresses what Krista Comer calls a "revisionist trend in environmental thought," which "connect[s] environmental with human exploitation" (219), but also portrays ways that responses to that exploitation become vibrant parts of enduring cultures.

As Robert Nelson explains in his reading of Ceremony, though many critics privilege the quality of imagination or thought as "endow[ing] certain places with specialness" (11), it is also possible for the relationship between this thought, or vision, and place to be reciprocal. He states, "vision can ... grow out of place, so that place, in the sense of physical landscape, provides a reader a referent that allows verification or confirmation of the accuracy of the vision" (11). This reciprocal understanding of place and vision acknowledges that changes, especially changes on the land, do not upset American Indian identities, but rather inform them. Nelson concludes, "cultural identity, for the individual as for the People, depends on keeping the stories alive — by re-telling them, by reliving them, and even by revising or adding to their ensemble to accommodate the new realities and 'shape' of the world as it changes" (39). Focusing on the land itself as invested with meaning that can affect tribal visions in the here and now supports Karen Waldron's contention that Silko's works portray land as consciousness, detailing "the land, not the self moving into landscape" (179). Waldron thereby determines that "Almanac of the Dead uses its wandering, dislocated characters, to make this point historical and prophetic; the earth's being has vision and consciousness far beyond that of any human" (196).

Paula Gunn Allen, a Laguna Pueblo contemporary of Silko's, affirms the significance of ritual in American Indians' active inhabitation of particular places, emphasizing the 
reciprocity to which Nelson alludes. According to Allen and her Micmac colleague Patricia Clark Smith, "One major part of people's ritual responsibility is to speak with these nonhuman entities and to report the conversation; American Indian literature records echoes of that ongoing dialogue" (177). For Laguna Pueblos, spiritual rituals center on Thought Woman, whose presence is embodied in many forms, including Old Spider Woman, Corn Woman, and Earth Woman. In her landmark text The Sacred Hoop, Allen explains:

She appears on the plains, in the forests, in the great canyons, on the mesas, beneath the seas. To her we owe our very breath, and to her our prayers are sent blown on pollen, on corn meal, planted into the earth on feather-sticks, spit onto the water, burned and sent to her on the wind. Her variety and multiplicity testify to her complexity: she is the true creatrix for she is thought itself, from which all else is born. (13)

Thought Woman is at the heart of the Keres creation story, which describes Thought Woman's singing into life her daughters, Naotsete and Uretsete. Uretsete gives birth to twin boys, one of whom marries Naotsete, and the Pueblo people emerge from this marriage. As in Allen's writing, Silko's novels, including Almanac of the Dead, respond to the presence of these spirit beings in Laguna places, even amid violence and destruction. Allen puts it simply: "We are the land. . that is the fundamental idea that permeates American Indian life; the land (Mother) and the people (mothers) are the same" (119).

Echoing Allen's description, Silko's integration of land and consciousness, while tied to particular Laguna places, is critical to her portrayal of Pueblo identity. In her essay, "Interior and Exterior Landscapes," Silko divests the Migration story of Pueblos' arrival in the Fifth World, the present world, from anthropological evaluation and focuses on its mythic significance. She describes the Emergence in the following way:

The people found the opening into the Fifth World too small to allow them or any of the small animals to escape... The antelope tried to butt the opening to enlarge it, but the antelope enlarged it only a little. It was necessary for the badger with her 
long claws to assist the antelope, and at last the opening was enlarged enough so that all the people and animals were able to emerge up into the Fifth World. . . . Life on the high, arid plateau became viable when the human beings were able to imagine themselves as sisters and brothers to the badger, antelope, clay, yucca, and sun. Not until they could find a viable relationship to the terrain - the physical landscape they found themselves in-could they emerge. (163)

Silko characterizes this terrain, specifically the eight miles between Paguate and Laguna, as taking on an imaginative quality that permeates Pueblo identity. She explains, "The narratives linked with prominent features of the landscape between Paguate and Laguna delineate the complexities of the relationship that human beings must maintain with the surrounding world if they hope to survive in this place" (163). In this way, Laguna Pueblos are "in place" through stories and rituals that affirm reciprocity with land.

Understanding the connection between humans and environment as a relationship of mutual survival and change, one marked by a specifically Laguna physical and cultural grounding, sheds light on Silko's rendering of environmental awareness that is sustaining if not idyllic. In her essay "Fifth World: The Return of Ma ah shra true ee, the Giant Serpent," Silko again emphasizes the earth's permanence: “the old people laugh when they hear talk about the 'desecration' of the earth, because humankind, they know, is nothing in comparison to the earth. Blast it open, dig it up, or cook it with nuclear explosions: the earth remains. Humans desecrate only themselves. The earth is inviolate" (334). Her evidence of earth's endurance in the face of human failings is the mysterious appearance of a giant stone snake amid the Jackpile uranium mine near the Paguate village, a figure that plays prominently in Almanac of the Dead.

According to Silko, the snake, whose head points west, relates to the old stories, which describe a giant snake, a messenger for the Mother Creator, who has been missing since all the water in the lake disappeared (335). Though this biomorphic creature appears in the most 
unlikely of places, Silko reveals how the figure makes the uranium mine a sacred place, as a chain-link fence is erected to protect the snake from cattle and photographers and offerings of spirit food are sprinkled over its head. The sacred serpent is thereby now part of a ritual that is culturally specific: "the Laguna Pueblos go on producing their own rich and continuously developing body of oral and occasionally written stories that reject any decisive conclusion in favor of ever-increasing possibilities" (339). Overall, the serpent is both a holy and subversive figure: "The traditional notion of the wondrous in a splendid setting befitting its claim is subverted here in this landscape where the wondrous can be anywhere and is everywhere. Even in the midst of a strip-mining operation" (340). The sacred snake, then, is Silko's articulation of the persistence of Laguna prophecy despite the inroads of Europeans in the Americas, an affirmation of the covenant between Natives and earth's spirit beings that will outlast European customs.

In Almanac of the Dead, Silko, like her fellow Laguna storytellers, rejects "attempts to confine the meaning of the snake to an official story suitable for general consumption" ("Fifth" 339), making the text itself somewhat loose-ended in its shifting yet interwoven storylines and somewhat open-ended conclusion. Yet, as in her essays, Silko elucidates ways in which European cultures have existed as dislocated inhabitants of the Americas, particularly in their divestment from the environment, and illustrates that dislocation as part of an American Indian prophecy, transmitted through the recordings of Yoeme, a Yaqui grandmother, that unites indigenous peoples of the Americas. The almanac begins with a "Five Hundred Year Map" illustration that centers on Tucson and points outward to Alaska, New Jersey, Mexico, South America, Haiti, and Cuba, placing the names of characters in various locations appropriate to their individual stories. The map's heading explains that 
"The future is encoded in arcane symbols and old narratives," emphasizing a non-linear conception of time, and the prophecy is articulated as follows: "Ancient prophecies foretold the arrival of Europeans in the Americas. The ancient prophecies also foretell the disappearance of all things European." Finally, the map's insert on the right firmly sets forth the reality of decolonial efforts, reading, "The Indian Wars have never ended in the Americas. Native Americans acknowledge no borders; they seek nothing less than the return of all tribal lands." Thus, Silko's text immediately and visually stresses the mobility of scenes upon a broad American geography while zeroing in on the borderlands near to the writer's own Laguna Pueblo. This delineation, in the form of a map, of European dislocation from a particular geography is in Ann Brigham's words "a subversive rhetorical move" (304) in that it uses a method usually employed to assert colonialism for a decolonial aim.

Within the narrative, Silko continues to display ways in which Europeans are divided from the American landscape, a divisiveness that in the future will lead to their disappearance. Perhaps the most emphatic statements about European dislocation from a sense of "place" in America refer to political and military conquests of areas already inhabited by indigenous peoples. The Yaqui character Calabazas explains, "The whites came into these territories. ... They went around looking at all the best land and where the good water was. Then they filed quiet title suits. . The people .. . couldn't conceive of any way they could lose land their people had always held" (213). This pattern of terrestrial and ecological conquest continues in the present, as mafia wife Leah Blue exacts plans to make Venice, Arizona, a "city of the twenty-first century" (374). Ignoring the adverse effects of drilling precious water merely for cosmetic purposes, Leah intends fraudulently to obtain deep-well drilling permits to pump water from Tucson for canals and a golf course in the planned community. Zeta, the Yaqui 
twin sister of Lecha, the keeper of the almanac, names this kind of land and resource theft as justification for breaking laws, particularly laws preventing drug smuggling. To Zeta, "There was not, and there never had been, a legal government by Europeans anywhere in the Americas. .. . Because no legal government could be established on stolen land. . . . All the laws of the illicit governments had to be blasted away" (133). Europeans' lack of legitimacy in the Americas causes their dislocation and inspires indigenous resistance.

Because of their roles as occupiers in a foreign land, Europeans, in Silko's formulation, display spiritual bankruptcy that portends their eventual downfall. This emptiness is directly linked to their presence in American "space" rather than "place," a lack of connection to a particular, meaningful geography. This alienation is immediately apparent in anthropologists' theft of stone figures that the kachina spirits gave to the Laguna people at the beginning of the Fifth World. For the Lagunas, the figures are "not merely carved stones, these were beings formed by the hands of the kachina spirits" (33). After Pueblo, Navajo, and Apache medicine people are contacted, Lagunas learn that the stones are located in a Santa Fe museum. When the Lagunas, including the old cacique, travel there, the curator refuses to return the figures, and within a month the cacique is dead. Articulating Europeans' inability to comprehend the spiritual significance of earthly elements such as the stone figures, a Yaqui community of elders, including Old Mahawala, explains to Calabazas: “. . . once the whites had a name for a thing, they seemed unable ever again to recognize the thing itself. . .To them, a 'rock' was just a 'rock' wherever they found it, despite obvious differences in shape, density, color, or the position of the rock relative to all things around it" (224). This inability to achieve orientation on the landscape of the Americas allows Apaches and Yaquis to escape white soldiers, a small victory in an enduring war against colonialism. 
Similar to Calabazas's experience of communal storytelling, Menardo, whom Silko calls a "mestizo," learns of the frailty of European spirituality from his Yaqui grandfather's telling of an elder's stories. According to Menardo:

That old man ... thought their stories accounting for the sun and the planets were interesting only because their stories of explosions and flying fragments were consistent with everything else he had seen: from their flimsy attachments to one another and their children to their abandonment of the land where they had been born. He thought about what the ancestors had called Europeans: their God had created them but soon was furious with them, throwing them out of birthplace, driving them away. The ancestors had called Europeans 'the orphan people' and had noted that as with orphans taken in by selfish or coldhearted clanspeople, few Europeans had remained whole. They failed to recognize the earth was their mother. Europeans were like their first parents, Adam and Eve, wandering aimlessly because the insane god who had sired them had abandoned them. (258)

The elders' stories of Europeans achieve multivalent and important functions. Like their integration of the uranium mine into storytelling, Yaquis explain and transmit their perceptions of Europeans across generations. This process allows these characters to account for changes in their communities, such as the entrance of outsiders and migration from Mexico to Arizona, describing them as fulfilling patterns affirmed by the ancestors and reinforcing their sense of being "in place." Further, while pinpointing European beliefs that are aberrant from Yaqui culture, elders are able not only to emphasize to younger ones appropriate ways of being in the world, but also they may highlight alliance with other Indian cultures in an expansive notion of resistance.

The emphasis on orphans in this intergenerational narrative is key to Indian prophecies of European disappearance, as evidenced in Lecha's observations about the implications of whites' severance from the land. Lecha recalls that her grandmother Yoeme cited the violence committed by Christians during the Inquisition as proof that "Christianity was somehow inadequate in the face of the immensely powerful and splendid spirit beings who 
inhabited the vastness of the Americas" (718). In her work as a psychic, Lecha encounters individuals who seem terrified despite their devotion to the Catholic church, people who display "a deep sense that something had been lost" (718). As Ja-mo Kang reveals, "The fact that people who claim to be 'devout believers' seek consolation in secret from Lecha working as a psychic rather than from priests shows that the church has lost its role as the center of salvation for injured spirits" (744). According to Lecha, this spiritual injury results from absence of a covenant with the earth. She reveals, "They all feared illness and physical change; since life led to death, consciousness terrified them, and they had sought to control death by becoming killers themselves. Once the earth had been blasted open and brutally exploited, it was only logical earth's offspring, all the earth's beings, would similarly be destroyed" (718).

This reference to the annihilation of offspring is carried out in the life of Seese, a drugaddicted white woman whose child, Monte, is missing. Involved in abusive relationships with the acquaintances of Monte's father David, especially David's lover Beaufrey, Seese has had an abortion under duress. In a nightmare about the procedure, Seese associates her abortion with flowers, remembering the light as "creamy yellow, the color and texture of roses" (52). Silko illustrates the abortion through natural imagery, writing, "they had cut the little tendril" (52). Her experience of loss draws Seese to Lecha, who on a TV talk show relays an image of infanticide in Mexico: "trash cans are stuffed with newborns. Garbagemen in Mexico City find four hundred fetuses and dead newborns each day, not counting the ones found floating facedown among the water lilies in fountains outside the presidential palace" (47). These violent images of infant death, linked with separation from nature, fulfill Yoeme's statement that "humans had been raping and killing their own nestlings at such a 
rate ... [that] humans might not survive" (718-9). But importantly, while humans' fates are in question, the earth's is not, according to Yoeme: "the earth would go on, the earth would outlast anything man did to it, including the atomic bomb" (718). The earth's endurance thereby portends the persistence of spirit beings, which, in Yoeme's words, arise from vegetation: "Out of the dust grew the plants; the plants were consumed and became muscle and bone" (719).

While youngsters are disappearing because of Europeans' alienation from earth, the spirit beings nonetheless endure and point toward the fulfillment of the almanac's prophecy. These spirits, which intermingle with images of the natural world, are tied to legacies of Indian ancestors, many of whom were killed by colonial armies. According to Calabazas, Yaqui ghosts, the souls of ancestors who refused to acknowledge the Mexican government, remain on earth, slowly following the Yaqui migration pattern north to an area near Tucson. These spirits are agitated, Calabazas says, because of the absence of natural resources: "They are just now reaching Tucson as the water and the land are disappearing. . . . Now the ghosts have come, and they want to know where the lake they were always hearing about has gone. The lake their brothers and sisters were bragging about. Plentiful fresh water in Tucson” (190).

Similarly, once Menardo becomes owner of the Universal Insurance Company, Tacho, his Indian chauffeur, is followed by macaw spirit beings who by the end of the novel inspire tribal people to renounce all things European and return to Mother Earth, the fulfillment of the ancient prophecies. These spirits address Tacho as "Wacah" and shriek, from dawn to dusk: "Wacah! Big changes are coming!" (339). Tacho, along with the macaws, is a constant, unsettling presence to Menardo, who has been passing as a white man. Tacho warns that 
Europeans are "part of the worldwide network of Destroyers who fed off energy released by destruction" (336), the same Destroyers that Yaqui ancestors fled north to avoid. But Menardo denies this warning, concluding, "Tacho believed all that tribal mumbo jumbo Menardo's grandfather had always talked about" (336). While Menardo tries to bury his suspicions about his assistant, he begins having omens of a "doomed man" (339) in his dreams who kills a silver rattlesnake. This snake is likely a representation of Quetzalcoatl, the snake spirit being south of the U.S.-Mexico border that is reminiscent of Maah'shraTrue-Ee, the sacred snake at Laguna. Eventually during a test of Menardo's bullet-proof vest, Tacho "accidentally" shoots him, and Menardo presumably becomes food for Destroyers that "must be fed with the blood of the rich and the royal" (337). As Ann Folwell Stanford observes, "those who distance themselves from indigenous origins become, like the EuroAmericans, heartless, passionless machines of greed and destruction" (28).

Silko's portrayal of Menardo as a doomed man corresponds with Louis Owens's analysis of American Indian literature as representative of "other destinies." While in books by European authors such as James Fenimore Cooper and William Faulkner, characters such as Natty Bumppo and Ike McCaslin are better able to endure on the American landscape, or establish a sense of "place" in the wilderness, because of their affiliation with American Indians, in Silko's text, Indian characters who are too accommodating to Europeans, ignoring the wishes of ancestors and spirits, are the ones who are doomed. In Silko's vision, it is impossible for Anglo culture to persist precisely because white people lack indigenous ancestors in America, and as a result, lack a reciprocal relationship with the earth. As Tacho's twin brother El Feo says, "In the Americas the white man never referred to the past 
but only to the future. The white man didn't seem to understand he had no future because he had no past, no spirits of ancestors here" (313).

This lesson is impressed upon the Laguna character Sterling, who could be called the novel's protagonist, if indeed one can be named for this unusual text. At the beginning of the novel, Sterling, an orphan, wanders into Tucson by accident and gains employment as Lecha's and Zeta's gardener. Though from the beginning, Sterling expresses a gentle nature and respect for both human and animal life, he is out of touch with his Laguna community, in part because of his travel for the railroad and immersion in western fiction and crime magazines, but primarily because Lagunas blame him for allowing outsiders from Hollywood to photograph the Sacred Serpent during a movie shoot. But by the end of the novel, after witnessing Tucson's growing chaos over the coming revolution, he is a changed man: "Sterling had never been disrespectful of the old folks' beliefs, he just had not cared either way about religion.... But now, after Tucson with all the violence and death, after everything Lecha had revealed, Sterling felt as if he knew too much, and he would never be able to enjoy his life again" (754). However, with Lecha and Seese, on the way to South Dakota to join Wilson Weasel Tail's effort, Sterling catches a glimpse of Mt. Taylor, which Laguna people call "Woman Veiled in Rain Clouds" (756). Realizing that the mountain signifies his rightful place, Sterling is overcome with emotion, and he asks Lecha to let him out of the car so that he can return home.

Back on Laguna land, Sterling contemplates the implications of being "in place," at home. He experiences a rebirth of sorts after lying stunned for three days at the family sheepcamp, and thereafter, he can no longer look at his old magazines or shopping bags, reminders of Anglo culture. He spends time walking "alone with the earth" (757), and as the old people 
did, he feeds some tiny black ants, "messengers to the spirits" who "carried human prayers directly underground" (757). As he walks, he is strengthened, and he remembers Lecha's words about Lakota prophecy, which predict the return of buffalo. As Sterling has learned, the buffalo herds are indeed gradually increasing, roaming farther across the plains, an affirmation of the beliefs of his ancestors:

He did not care if he did not live to see the buffalo return; probably the herds would need another five hundred years to complete their comeback. What mattered was that after all the groundwater had been sucked out of the Ogalala Aquifer, then the white people and their cities of Tulsa, Denver, Wichita, and Des Moines would gradually disappear and the Great Plains would again host great herds of buffalo and those human beings who knew how to survive on the annual rainfall. (759)

Finally, Sterling approaches the Sacred Serpent. After meditating on the meaning of his past, from his former belief in the uselessness of the old ways to his chaotic experience in Tucson, he accepts the endurance of the earth and its spirit beings. In a passage that directly mirrors Silko's words in "The Fifth World," Sterling finally understands, "Spirit beings might appear anywhere, even near open-pit mines. The snake didn't care about the uranium tailings; humans had desecrated only themselves with the mine, not the earth.... he knew what the snake's message was to the people. The snake was looking south, in the direction from which the twin brothers and the people would come" (762-3). In this way, Sterling is ultimately able to face the future because of an acceptance of his past, awareness that is only possible because of his grounding, through ancestral ties, on the earth.

Preparing for the future by understanding the past is one of the most important lessons of the almanac, a living almanac that reveals truths through natural phenomena. Zeta observes the presence of ancient prophecies from the almanac in meteor showers: "She thought about the old ones and Yoeme and how they had watched the night skies relentlessly, translating sudden bursts and trails of light into lengthy messages concerning the future and the past" 
(178). Having been preserved during the people's arduous journey north, the almanac is a tangible connection to Indian ancestors who fled the government of Mexico during the dawn of the dangerous epoch of Death-Eye Dog, a "'book' of all the days of their people [that] were all alive, and . . . would return again" (247). Caren Irr calls this balance of future and present, observable in the meteor showers, "the paradox of time," explaining, "Like the almanac, we are reminded, a memory calls on the past but is retained in an image available in the present. In form and in content, then, the almanac stresses the interpenetration of past and present, promising a renewal that will lessen the weight of dead fellow travelers" (226). The sacredness of the book, its promise amid pain, is apparent to the three young girls and small boy, the last of their people, who are chosen to carry the almanac to the North and are actually protected on their journey by its pages.

The children's experience with the almanac highlights the importance of responding to change - and sometimes danger - creatively. Facing starvation as the three spend the night with a mysterious woman before arriving at their destination, the eldest girl uses a page made of horsegut to flavor a stew, which sustains them for several days. While the children are horrified at the loss of the page of records, the girl discovers that she remembers the information preserved on this lost page, signifying the endurance of its prophecies not only in tangible form, but also in the oral tradition of the people. Later, when one girl remains behind as the others continue their journey, the eldest girl returns to find her hanging from the crossbeams of a ceremonial structure. She secretly takes the murdered girl's dress, which contains more pages, and wears it over her own, preserving its contents. As Yoeme explains, "it had been the almanac that had saved them. . The first night, if the eldest had not 
sacrificed a page from the book, that crippled woman would have murdered them all right then, while the children were weak from hunger and the longer journey" (252-3).

Thus, characters' encounters with the almanac, which reveals prophecies through relationships between humans, animals, and their creator, demonstrate the reciprocity between indigenous people of many generations and the earth, affirming the sense of "place" that Europeans can never achieve. While this place centers on reservations surrounding Tucson, including Laguna and Yaqui lands, it also arises out of migration across ineffectual national borders, encompassing and translating change initiated by contacts with other communities. In Irr's words, the almanac, which includes the one within the narrative as well as Silko's text itself, “occupies a transitive ground between past and future as well as between English and Spanish, and official and folk religion.... Both are commemorative and prophetic; both cross linguistic and national borders between the U.S. and Mexico; both correlate religious and ecological events" (226).

Silko's evocation of a specific yet transitive "place" in Almanac of the Dead corresponds to her own experience growing up at Laguna, itself an area of "borders." As Robert Nelson explains in his analysis of her autobiographical Storyteller, “in Silko's work, as at Laguna, the site of ... transformative contact appears as a place of comfort and regenerative energy, . . . occupying as she does a marginal site with respect to both Laguna 'within' and the dominant Anglo mainstream 'out there"' (16). More specifically, Nelson points toward the cross-cultural encounters of Silko's family members, including the intermarriage of her Laguna ancestors with surveyors from Ohio; her relatives' attendance at far away educational institutions, such as Carlisle Indian School; and her father's status as tribal council treasurer during the coming of the uranium mine as evidence of her ancestry as "a story of outsiders 
who became insiders and of insiders who became outsiders - a story about the arts of cultural mediation, from both sides of the imaginary borderline" (17). Arturo Aldama highlights ways in which Laguna people themselves are a hybrid of many bands of Keresan peoples, explaining,

Laguna are of a mixed background sharing many other Puebloan principles and ceremonies while retaining their own unique identity and language systems. Being hybrid and geographically more expansive than just one Mesa - not to mention having a history of intermarriage among different tribal cultures before the onslaught of European colonialism — does problematize the concept of a 'pure' origin. (87-8)

In addition, the Yaqui people, who with Lagunas are the tribes that Silko attends to most fully in her novel, were "recognized" by the U.S. government as a Pueblo community (however problematically), establishing common ground between the two groups. This sense of Laguna as a place of mediation is perhaps what makes it such fertile ground for storytelling, a longstanding tradition in the Marmon family that is linked to the Laguna landscape.

Though as Nelson reveals, Silko's success as a storyteller is due in large degree to her diverse background, the positive way in which she draws this family background does not discount the tension, portrayed in Almanac of the Dead, that accompanies the contacts of various indigenous peoples with European colonizers in her homeplace. Perhaps the distinction between negative and positive implications of this cross-cultural contact lies in the degrees to which European newcomers, such as Silko's Marmon ancestors, come to accept and fit in with American Indian cultures rather than seeking to obliterate or control those cultures, and the degree to which American Indians comply with colonial values rather than living out their own cultures. Aldama addresses the implications of cultural nexus in the following way: "Perhaps Silko is forcing us to think less about who we are racially and our 
relative percentages of Indian, Anglo, or Spanish blood quantums, ... and to think more about where we stand in relation to the witchery of the destroyers" (93). Like Silko, Gloria Anzaludua, who first articulated the theoretical power of American "borderlands," comments on the nuances of this border contact, pointing toward its transformative realities in addition to its pain. Similar to Silko's portrayal of indigenous cultures that balance the past and future as well as incorporate change, Anzaldua's work accounts for the confluence of Anglo, Mexican, and indigenous identities and evokes hybridity as a source of strength.

Carving out her own sense of place, Anzaldua asserts, "I am a border woman" (8). For Anzaldua, the "tejas-Mexican border ... [is] not a comfortable territory to live in. ... Hatred, anger, and exploitation are the prominent features of this landscape" (8). However, living in this place is what spurs Anzaldua's creativity: "It is like a cactus needle embedded in the flesh.... When it begins to fester I have to do something to put an end to the aggravation and to figure out why I have it. ... That's what writing is for me, an endless cycle of making it worse, making it better, but always making meaning out of the experience" (73). Despite the discomfort of this creative process, Anzaldua concludes that affirming a border identity, which she names "la mestiza" (80), is the wave of the future, the source of a "new consciousness" (80). Asserting this new consciousness, then, is Anzaldua's way of asserting control, counteracting the dominant culture, which would render her identity to be one-dimensional rather than complex. Anzaldua's characterization of the borderlands reveals the way in which liberation can involve both acceptance of a European presence as well as rejection of the hegemony that that presence may represent. This reading illumines Silko's presentation of borderlands, which affirms multiplicity, including contact with Anglos, while privileging indigenous, decolonial worldviews against European control. 
Europeans' efforts to control American borderlands, literally as well as spiritually and intellectually, further reflect their occupation of "spaces" rather than "places" in Silko's text. While some indigenous characters actively resist this control, others are at risk of mirroring Anglos' dislocation from the earth. Lecha enthusiastically articulates resistance to territorial boundaries in a confrontation with the Border Patrol, explaining, “... Indians had nothing to do with elections.... the white man had always been trying to 'control' the border when no such thing existed to control except in the white man's mind" (592). Like Lecha, El Feo, who with his Mayan partner La Escapìa is organizing the people's revolution in Southern Mexico, also demonstrates the futility of European political control over indigenous lands: "El Feo did not believe in political parties, ideology, or rules. El Feo believed in the land. With the return of Indian land would come the return of justice, followed by peace" (513). El Feo's emphasis on the land has definite spiritual implications, which are the motivating force behind the people's revolution: "The masses of people in Asia and Africa, and the Americas too, no longer believed in so-called 'elected' leaders; they were listening to strange voices inside themselves. ... the voices they heard were voices out of the past, voices of their earliest memories, voices of nightmares and voices of sweet dreams, voices of the ancestors" (513). Importantly, while focusing on the borders surrounding Laguna as sites of resistance, Silko draws a broader connection, particularly a spiritual connection, between Lagunas, their Yaqui counterparts, and global masses.

This cross-cultural alliance of the masses has not always existed without conflict in the face of colonialism, however. Particularly because of the reach of Christian missionaries, many are disconnected from their ancestors. To El Feo, missionaries are "The Indians" worst enemies" (514). He continues, "missionaries ... sent Bibles instead of guns and . . preached 
blessed are the meek. Missionaries were stooges and spies for the government. Missionaries warned the village people against the evils of revolution and communism. They warned the people not to talk or to listen to spirit beings" (514). Missionaries, mirroring government relocation efforts, are behind Sterling's childhood experience at a boarding school, an experience common to many Natives. Because these schools, as well as the BIA, have drafted Indians to carry out their colonial missions, members of various Indian nations have turned against one another. As Sterling observes, "All the people from Southwestern tribes knew how mean Oklahoma Indians could be. The Bureau of Indian Affairs had used Oklahoma Indians to staff Southwestern reservation boarding schools, to keep the Pueblos and Navajos in line" (27). Such spiritual and intellectual colonialism is causing the world to seem altered to Sterling:

Something really had happened to the world. It wasn't just something his funny, wonderful, old aunts had made up. ... People now weren't the same. What had become of that world which had faded a little more each time one of his dear little aunts had passed? ... The short time he had been in Tucson, Sterling had begun to realize that people he had been used to calling 'Mexicans' were really remnants of different kinds of Indians. But what had remained of what was Indian was in appearance only - the skin and the hair and the eyes. . They had lost contact with their tribes and their ancestors' worlds. (89)

As cultures have edged against one another, therefore, boundaries have become blurred, which is both a source of strength for the future revolution as well as a challenge that must be overcome.

Uniting the masses is a goal that clearly calls to mind the work of Karl Marx, and global Marxism is thereby an appealing movement for La Escapìa and her fellow indigenous revolutionaries. La Escapìa has come to her work with Cuban Marxists, including her attendance at Marxist school, directly from missionaries, who knew her as "Angelita." She soon finds that, like the missionaries, the Marxists are uninterested in "what the old Indians 
thought about the passage of time or about history" (311); instead, they are most interested in manipulating her for sex. In particular, Bartolomeo, her blond instructor-turned-lover, threatens to report her for "harboring nationalistic, even tribal, tendencies" (310). La Escapia's encounters with Bartolomeo emphasize the ways in which the Marxists, despite their pretenses, display colonial tendencies of their own, especially appropriation of Native philosophies. As La Escapì describes when she is criticized by tribal leaders for being a communist, "Didn't they know where Karl Marx got his notions of egalitarian communism?" (311). She answers, "From here. . . Marx stole his ideas from us, the Native Americans" (311). While La Escapia recognizes this appropriation, she also finds that she is able to use the work of these revolutionaries for her own ends as well, dozing through the Cubans' lessons in exchange for arms, supplies, and knowledge of how to solicit the aid of sympathetic populations across the globe: "Whatever the rich outsiders wanted to believe was all right with the tribal people. They just wanted the means to take back their lands" (310).

Angelita La Escapì's collection of arms for a global revolution is understandable in light of the violence that has accompanied Europeans' efforts to control the borderlands. Yoeme's marriage to the rancher Guzman ${ }^{13}$ signifies this merging of disparate cultures, a union that brings about horrific consequences. A collection of cottonwood trees is the unifying image that exemplifies not only the violence of European conquest of various peoples, but also the impact of that conquest on the earth. According to Yoeme, the trees were the reason for her abandonment of her seven children, including Lecha's and Zeta's mother Amalia. At Guzman's insistence, African American slaves carried the cottonwood saplings to his ranch

\footnotetext{
${ }^{13}$ Dorothea Fischer-Hornung says that Silko is likely referring to Nuno de Guzman, a notorious lyncher of Indian slaves, as well as Abimael Guzman, a Maoist in Peru who exacted a "rule of terror" on the Indio population (212).
} 
in unbearable heat and with no water allowance, and once the trees were planted, were charged solely with delivering water to them. Eventually, the African American slaves were replaced with Indian laborers, and though Guzman had made an agreement with Yoeme's people to prevent the influx of more white settlers, he neglected to stand up to those infiltrators and did nothing as Yoeme's relatives were murdered.

Yoeme thus removed herself from association with her mixed-blood children, whom she believed took after Guzman. Seared in her memory is the image of the cottonwood, which normally "suckles like a baby ... on the mother water running under the ground ... [and] will talk to the mother water and tell her what human beings are doing" (117), being dug up and transplanted, used for a diabolical purpose. Reminiscent of Sethe's rememory of "boys hanging from the most beautiful sycamores in the world" (6) in Toni Morrison's Beloved, Yoeme recollects the lynching of her people, "who had all dried up like jerky" (118). Like Sethe's recognition of natural beauty that is obscured because of the trauma of enslavement, Yoeme is horrified by the grotesque "objects hanging in the beautiful green leaves and branches along the river" (117). Silko thus portrays historical amalgamation among African Americans, American Indians, and Euramericans, or borderlands, as marked by whites' violent destruction of both people and land.

The dubious relationship between Europeans and the earth, which is intimately connected to oppression of and violence against indigenous Americans and African Americans on the borderlands, leads Vietnam War veteran Clinton to call into question the efforts of white environmentalists. More specifically, Clinton criticizes deep ecologists:

Clinton did not trust the so-called "defenders of Planet Earth." Something about their choice of words had made Clinton uneasy. Clinton was suspicious whenever he heard the word pollution. Human beings had been exterminated strictly for "health" purposes by Europeans too often. Lately Clinton had seen ads purchased by so-called 
“deep ecologists." The ads blamed earth's pollution not on industrial wasteshydrocarbons and radiation - but on overpopulation. It was no coincidence the Green Party originated in Germany. "Too many people" meant too many brown-skinned people. Clinton could read between the lines. "Deep ecologists" invariably ended their magazine ads with "Stop immigration!" and "Close the borders!" Clinton had to chuckle. The Europeans had managed to dirty up the good land and good water in less than five hundred years. Now the despoilers wanted the last bits of living earth for themselves alone. (415)

In this passage, Clinton identifies the necessary convergence of ecological and human concerns, as he decries the lack of value placed on the lives of people of color. This disregard for life is apparent in the work of Trigg, who makes his living by harvesting and trading in human organs acquired from people killed in Mexico. As Brigham notes, this practice "literalizes the view that Mexico serves as the United States' labor reserve" (311). Trigg's trading in human products as if they were agricultural commodities is akin to Menardo's use of his crop-dusting plane to cover American Indian squatters on his coffee plantation with harmful chemicals, waging a kind of ecological warfare. These inhuman actions for agricultural aims confirm Kang's argument that "social justice and ecological justice cannot be discussed separately" (733).

In addition to portraying Clinton's suspicions, Silko further satirizes deep ecologists through characters called "Eco-Grizzly," "Eco-Coyote," and "Earth Avenger," who take the motto "Back to the Pleistocene." Like Clinton, the Korean eco-warrior Awa Gee muses on the ineffectual mission of these deep ecologists, a mission that seeks to recover a pristine era that will never return: "such a longing for the distant past was a symptom of what had become of the Europeans who had left their home continent to settle in strange lands. . . . Awa Gee could always return to Korea, but they could not get back to the Pleistocene" (689). In his book Confessions of an Eco-Warrior, environmentalist Dave Foreman, former leader of Earth First!, asserts just such a reversal of modernity, seeking in effect to atone for 
European transgressions in America. He states his mission as follows: "For us in America, bioregionalism means going back to that choice made by Cotton Mather and turning onto the other path. It means a second chance in the New World, another opportunity to meet that spiritual challenge" (44).

As Silko's novel suggests, Foreman's mission is not spurred by ecological sustainability for its own sake; instead, it seems to emerge out of a spiritual need, a recognition that somehow Europeans are not "in place" in the Americas. Indeed Foreman uses language referring to American Indians to elucidate the spiritual grounding he seeks, explaining, "The mystique and lore of 'night work' pervades our tribe, and with it a general acceptance that strategic monkeywrenching is a legitimate tool for defense of the wild" (34). Further, Foreman asserts, "Bioregionalists argue that human society—and therefore, politics and economics - should be based on natural ecosystems. They find affinity with Indian tribes and with Basque, Welsh, and Kurdish separatists, and have no sympathy with the modern nationstate, empire, or multinational corporation" (43). Yet while Foreman apparently aligns himself with Indians and other indigenous peoples for the sake of renouncing the spiritual vacuity of European values, he never names any specific ways in which his work benefits Native peoples or coincides with their beliefs, cultures, or needs, revealing complete absence of attention to environmental justice. Foreman offers a generic version of Indian spirituality that is akin to New Age representations of Indian religions that Womack criticizes for their lack of political concern. He states, "The New Agers will talk all day about medicine wheels and sweats, but who has ever heard them talk about Indian land claims? They have managed a perverse separation of the spiritual and political that leans toward the grotesque and is more 
influenced by traditional Western Christianity's spirit/flesh bifurcation than they realize" (53).

Further, Foreman seems all too willing to use the words "we" or "us in America" broadly, as if everyone, even those who are the targets of environmental racism, is equally guilty for transgressions against the earth. M. Jimmie Killingworth and Jacqueline S. Palmer rightly challenge this perspective, offering, "Obviously the 'we' who are responsible for environmental degradation is not as inclusive as well-intentioned environmentalists sometimes imagine" (197). Foreman's representation of Indianness for his own ends contrasts sharply with Silko's characters, who are motivated in large degree by practicalities of the living conditions of their peoples. Jodi Adamson Clarke highlights this contrast between self-representation and European appropriation: "the historical experiences of their peoples teach them that any program to protect indigenous peoples or to save nature must be based on social justice - an end to murder, rape, discrimination, illegal appropriation of lands, and unethical exploitation of the earth's natural resources" (158).

This contextualization of environmentalism within the discourse of borderlands applies to a specific Laguna place while also having relevance to populations across the globe. As Clarke explains, in 1991, the year of Almanac of the Dead's publication, the First National People of Color Environmental Leadership Summit convened in Washington, D.C., where participants discussed greater political representation as well as the effects of environmental racism (132). She explains further that in 1994, Zapatista rebellion occurred in Chiapas, Mexico, a movement that "called for land reform and redistribution," and was associated "with an indigenous fight for land that has been ongoing since the Spanish conquest of the Mayan empire" (129). Clarke joins these events to the activities within Silko's fiction: 
"When we place Angelita, Lecha, and Zeta into a context with the Zapatista rebels, ... we begin to see exactly why characters in the literature of environmental justice must do more than simply reflect on the postnatural landscape while dreaming of a pastoral homesite" (158).

Beyond the Americas, other populations in Silko's novel converge in borderland conflicts in which indigenous peoples struggle against European efforts to control their lands. From the Middle East, where Jews and Arabs are involved in "international killing" (26), to Africa, where Clinton believes that the U.S. government has engaged in biowarfare by developing and releasing AIDS in order to control the black population, the need for revolution appears to be widespread. In fact, Clinton views the Vietnam War as a conflict created in order to prevent the Civil Rights Movement in America: "Efficiently, the white men had sent sons and daughters to burn down Vietnam instead of Detroit, Miami, or Watts. Vietnam had been designed to stop the black man in America" (408). However, in Clinton's formulation, the reason for the U.S.'s loss of the war is the Viet Cong's use of "magic and spirits" summoned from the resources of the "jungle people" (411). Thus, Silko creates a global indigenous movement that Brigham describes as follows: "the tribal is expansive, foregrounding the multiple locations subjects occupy simultaneously" (318). Lecha observes that in addition to ranging across many geographies, this occupation of multiple locations can also occur within her individual person. Silko writes,

Years ago [Lecha] realized she had never seen any person, animal, place, or thing look the same twice. Some mornings Lecha has awakened to find a haggard, wrinkled face with Korean eyes watching her from the mirror. Other mornings, just waking up with a man in the bed beside her gives her a face in the mirror like the one she saw ... when she was nineteen. (167) 
Lecha's multiplicity touches on a theme that Aldama articulates as central to Silko's novelistic vision: "we can reclaim a vital heterogeneity that reconfirms our interconnectedness with all our relations" (33). Like Anzaldua, then, Lecha is a border woman individually as well as a participant in a global revolution.

This idea of expansive tribalism amid multiple borderlands provides thematic unity to the novel's wide-ranging settings and storylines. Yet, again, this expansive vision arises out of a specific Pueblo place. Calabazas articulates this balance of specificity and expansiveness in his philosophy of the future and his place in it: "Those who can't learn to appreciate the word's differences won't make it. They'll die" (203). Further, he connects this integrative view to the particular experiences of his people, explaining, "We don't believe in boundaries. Borders. Nothing like that. We are here thousands of years before the first whites....We know where we belong on this earth. We have always moved freely. North-south. East-west. We pay no attention to what isn't real" (216). Signifying his place within the Yaqui community, Calabazas has invented his name, which means "pumpkins." This name recalls the pumpkins that his brothers and cousins grew at San Rafael and the paper squash and pumpkin blossoms that his sister-in-law made for the feast of All Souls, a feast for which they traveled to the Mexican side of the U.S. Mexico border. Calabazas's description, according to Muthyala, reveals "the tension of affirming Yaqui identity and heritage on both sides of the boundary," which "engenders a Yaqui border subjectivity" (372). Interestingly, border subjectivity thus arises both within a particular tribe as well as within a broader global community. Muthyala further explains that Silko's vision is one in which "organic notions of ethnic and tribal identity, sangra pura, and national conceptions of time and history yield to the determining power of transborder processes and the unpredictable nature of local forces 
acting upon the international flow of people and cultural commerce in the Americas" (374). The almanac itself, Muthyala argues, signifies these transborder processes, as it survives migration and relocation; appears in Spanish, Latin, and English; and places Mayan codices alongside Yaqui prophecies (373).

In addition to uniting Mayan, Yaqui, and Laguna concerns in a simultaneously local and international vision, Silko also mingles African American with American Indian legacies in the Americas as part of the fulfillment of the almanac's prophecy. For example, Silko presents slavery as a hardship endured by both Indians and Africans. Not only do enslaved Indians and Africans both toil on Guzman's land in Yoeme's story of the cottonwood trees, but also, according to Clinton, both peoples were enslaved on American plantations. While "official" history attributes some responsibility for enslavement of Africans in America to African coastal tribes, Clinton is not convinced. He states, "To read the white man's version, Africans were responsible for the plantation slavery in the New World. But African slaves only replaced the Native American slaves, who died by the thousands. Before the European slave-buyers had arrived, African coastal tribes had practiced only local war-hostage slavery" (406). Clinton thereby suggests commonality among blacks and Natives and casts slavery as a system imposed upon varying cultures rather than as a mark of black-white polarity.

This African-Native alliance goes beyond shared hardship, however. As Clinton uncovers in his own family, American Indians and African Americans have amalgamated, especially in the South, and this cultural merging refutes static notions of race or ethnicity. Significantly, for Clinton, this amalgamation affirms African Americans' grounding on the American landscape: "Clinton had not agreed with Garvey and the others who wanted to go back to Africa. Clinton disagreed because blacks had been Americans for centuries now, and Clinton 
could feel the connection the people had, a connection so deep it ran in his blood" (414-5). Clinton's lineage, or in his words, "blood," contains a branch of Tennessee Cherokees. But while Clinton has lined out Europeans as in opposition to Africans and Natives, he recognizes that his Cherokee ancestors were wealthy slave-owners, representing their own form of border subjectivity. Clinton believes that this slave-ownership is evidence of a lapse in Cherokee culture, an aberration that is perhaps partly to blame for Cherokee removal. This example supports Fischer-Hornung's claim that Silko's Indians are not mere victims but are instead "agents in their own history" (217). He characterizes this phenomenon as follows:

Clinton had liked to imagine these Cherokee ancestors of his, puffed up with their wealth of mansions, expensive educations, and white and black slaves. Oh, how 'good' they thought they were! ... So pride had gone before their fall. That was why a people had to know their history, even the embarrassments when bad judgment had got them slaughtered by the millions. Lampshades made out of Native Americans by the conquistadors; lampshades made out of Jews. Watch out African-Americans! The next lampshades could be you! (415)

The intertwining of African and Native histories is both a source of power for Clinton, enabling him to view African Americans as indigenous to the Americas, as well as a cautionary warning against adopting colonial culture. In other words, black Indians like Clinton are border people, purveyors of a "new consciousness" that Anzaldua describes as defying European hegemony.

In addition to historical confluences, African Americans and American Indians also share spiritual commonalities, which in Clinton's view are the most important implications of their affiliation. Through radio broadcasts, Clinton's mission is to impart knowledge to African Americans about "all their history" (416) and "how deeply African blood had watered the soil of the Americas for five hundred years" (416). This all-encompassing history includes persistent spiritual beings that have traveled from Africa to America with the people, 
establishing a spiritual presence that signifies the deepest connection between the two hemispheres. According to Clinton, "certain of the African gods had located themselves in the Americas as well as Africa: the Giant Serpent, the Twin Brothers, the Maize Mother, to name a few.... great American and great African tribal cultures had come together to create a powerful consciousness within all people. All were welcome — everyone had been included" (416). This enduring, inclusive spirituality contrasts with European religion, which Silko portrays as having rung hollow in America, its god having neglected to relocate. Silko writes, "Now Clinton understood why European philosophers had told their people God was dead: the white man's God had died about the time the Europeans had started sailing around the world" (417). Susan Olmstead bases this Native-African alliance in "a shared ontological understanding of the world" (467) that reconfigures accepted history.

Reciprocally, American Indians also affirm spiritual alliance with African Americans. The Barefoot Hopi, who is organizing prisoners for revolution, works primarily in the realm of the spirits, talking with African inmates about African spirit beings and writing to the prisoners about the Hopi Corn Mother; Old Spider Woman, who, according to Allen, "weaves us together in a fabric of interconnection" (11); and the big snake. In the same way that El Feo looks for the revolution to arise out of the people's dreams, the Hopi conducts his work by entering others' subconscious minds: "Even redneck bikers ate up the Hopi's stories, but that was because the Hopi had already infiltrated their dreams with the help of the spirit world" (620). The Hopi publicly delivers his message at the holistic healers convention, where he discusses the spiritual alliance of tribal peoples in America and Africa as the source of military alliance during the coming revolution:

The Hopi said black Africans talked about the price they had paid in blood to take back the land; the spirits had been furious and had demanded blood in retribution for 
the sacrileges the people had allowed against the spirits. Their lands had been reconsecrated to Ogoun and Damballah with European as well as African blood. The Hopi had got promises from a dozen African nations; if the natives of the Americas rose up, the African nations would not remain neutral. The Hopi's plan depended upon the help of "foreign allies" in the Persian Gulf region also. (731-2)

To the Hopi, alliance with indigenous peoples across the globe is not simply a nicety; instead, it is an obligation in order to honor the spirit beings, who have also commingled.

Here again, Silko illustrates the coming prophecy as derived from an Indian sense of place, naming as inspiration Laguna beings such as Spider Woman and the big snake as well as the Hopi Corn Mother, at the same time that she makes that prophecy inclusive of African and Afro-Caribbean beings, namely the African snake god Damballah and the Haitian god Ogoun. Similar to the many peoples represented in Laguna culture and the border subjectivity that appears among Yaquis, Voudoun, the religion of free blacks and indigenous peoples in the mountains of Haiti, is itself a hybrid spirituality. According to FischerHornung, "Voudoun ... developed as a syncretistic religion of African, indigenous Carib, and Arawak, as well as European religious elements which to the present day expresses an exceedingly complex religious system of simultaneous integration and resistance" (215). Fischer-Hornung further delineates the spiritual dimensions of crossblood relations in Silko's text, emphasizing the author's use of doubling. Her examples are the Laguna snake Maah'shra-True-Ee and the south-of-the-border snake Quetzalcoatl, which are tied to Damballah in the Carribbean and West Africa; the Yaqui twins El Feo and Tacho, who are tied to Yaqui twins Zeta and Lecha; Clinton, the African American creator of Liberation Radio, and Rambo, the white organizer of the Army of the Homeless, who are tied to El Feo and Angelita of the Army of the Poor in Chiapas; and the Barefoot Hopi, who in his study of revolutionary activities in Africa is doubled with Clinton (218). This doubling thus forms, in 
Fischer-Hornung's words, a “binary-exploding spider's web of historical and contemporary geopolitical blood and spirit relations" (218). This web of spirit relations across varied and wide-ranging borders, which has an indigenous emphasis, is the source of strength in an anticolonial revolution.

As varied groups of peoples prepare for the fulfillment of the almanac's prophecy, each has methods of resistance that have spiritual, militaristic, and/or historical dimensions. For Clinton, vivid emblems of African-Native resistance to Europeans are black Indians at Mardi Gras. These individuals not only dress in feathers, animal skins, and grass aprons, wear headdresses that feature horns and antlers, and appear with cattle rings in their noses, but also they behave like rebellious, wild creatures, signifying the anger of spirit beings over European occupation. Clinton's notes about the phenomenon indicate that “'Wild creatures' have been enraged since time immemorial, over human behavior, but now especially, they reserve special fury for white people along the parade route" (420). The unification of blacks and Indians is vivid: "No outsider knows where Africa ends or America begins" (421).

This performative rebellion achieved through approximations of Indian regalia in Silko's text is based in actual traditions of Mardi Gras Indians in New Orleans. These groups began as street gangs and evolved into social clubs, which engage in musical showdowns with one another during Mardi Gras parades. Like the characters in Silko's novel, these groups find belonging - American belonging — through their "tribes." Smiley Ricks, a survivor of Hurricane Katrina, explains, "It was the music that took me from the streets, from doing things that were totally wrong to society. My cousin got me involved with his tribe, and when it started taking me a year to make my Indian suit, I liked that because I had to sew it right if I wanted it to be pretty" (Doerschuk 70). Rising to the rank of "chief" of the Comanche 
Hunters before having to relocate to Nashville after the hurricane, Ricks suggests that Mardi Gras Indians represent African American place in New Orleans: "I'll tell you this here, and I really mean it from my heart," he says. "That Indian culture was grounded there and it's going to be there again. If you listen to some of the Indian music, now you understand what they're talking about when they sing, 'We won't bow down, we don't know how.' When I hear that, I think things will come back there. It makes me want to go back right now" (70). The association of Indianness with fortitude also surfaces in the words of Geechie Johnson of the Wild Magnolias tribe: "if you were a true Indian, you evacuated with your costume" (Rawls 75).

The strength of black Indians at Mardi Gras comes in Silko's text from African spirit beings. A black Indian queen "darts her tongue out like a snake's, and her hips and stomach writhe like a snake's because black Indians still keep in touch with the serpent beings Damballah and Simbi" (422). These Americanized African spirits are distinguished by their temper, according to Clinton: "it was clear that in America, the African gods were shorttempered. What the African slaves had met face-to-face in this land was Death. Death roamed freely night and day in America" (423). Likewise, American Indian spirits are furious and seek to incur fear in the U.S.: "The Native Americans had died off deliberately to spite the Europeans. In death their spirits had been set free to roam at will and to help other powerful ancestor spirits already set loose on the slave masters" (424). These powerful, angry spirits create a sense of impending upheaval in people, both inspiring people of the Americas to rise up and preventing European overseers from continuing their occupation.

Clinton channels these spirits as he carries a knife that is endowed with the power of Ogou, the Voudoun god, which allows him to throw off his oppressors. Clinton erects a 
shrine for the knife and leaves apples for the ancestor spirits, metalworkers of Africa, whom the shrine honors. While in Vietnam, Clinton had kept the knife sharp, and it had protected him at all times. In his words, "The knife had a power all its own" (413). Clinton decides to use this power to inspire revolt, and he travels to Haiti to make a connection with Ogou's land, in effect, to honor an Afro-Caribbean "place" in order to achieve success. He explains, "Clinton just wanted to set his feet on the soil where the spirits of three continents had been manifested, where the first black Indians had been born and their descendents had triumphed against the French fleet" (747). Before he leaves for Haiti, Clinton visits black Indians in Manhatten who have been aiding Mohawk nations; in fact, he discovers, much as the Hopi called for, that African nations have also been sending financial aid. Clinton learns that "Now that black Africans had finally recovered their ancestral land the spirits would not allow the Africans to turn their backs on the tribes of the Americas as they fought to take back their land" (742). Indeed, the revolution has begun, and alliance across borders is the key to success: "Nothing could be black only or brown only or white only anymore. The ancient prophecies had foretold a time when the destruction by man had left the earth desolate, and the human race was itself endangered. This was the last chance the people had against the Destroyers, and they would never prevail if they did not work together as a common force" (747). Clinton thereby affirms the specificity of indigenous grounding, or place, as the source for his empowerment while also emphasizing the universal accessibility of that power.

As Clinton and various other characters prepare for the coming revolution, they come to possess and subvert various colonial machinations, especially those involving technology, in order to achieve their intended results. Clinton's plan is for his Army of the Homeless to reclaim democracy from corruption by seizing radio stations, a move that will be achieved 
when cities such as Tucson are abandoned due to lack of groundwater. Clinton will then broadcast his call to war, which will lead to ordinary Americans' reclamation of land: "Homeless U.S. citizens would occupy vacant dwellings and government land" (410). Likewise, Awa Gee, a computer hacker, plans to usurp global financial and security records, his so-called "big-tit cow" (680), and "strip 'the cow' of everything, milk her, then bleed her dry" (680), releasing computer viruses and time bombs that would crash computers all over the world. Awa Gee also specializes in creating new identities from the profiles of dead individuals buried in cemeteries. His statement, "The dead are my friends," suggests an affiliation with spirits even amid his technological work, and his "number project," which flashes "complex patterns of iridescent colors as if they were exotic blossoms or jungle birds" (683) will eventually bring down "the giants" (683) and transfer power to the dispossessed. And in a wonderfully subversive scene, an old Yupik woman, who realizes "the possibilities in the white man's gadgets" (155), rubs a television with a weasel pelt, harnessing electric energy from the atmosphere by "summoning spirit beings through recitations of the stories" (156). The old woman's activity brings down planes that are used to exploit the natural resources of the tundra, in effect "turn[ing] the destruction back on its senders" (156). All of these characters are motivated by a desire to reclaim the earth and its creatures, and they all achieve this end by manipulating technological phenomena. As Alex Hunt argues, "The novel is itself an indigenous appropriation of a colonial technology turned back on the dominant colonizing culture, enacting the same pattern of erasure that the characters of the novel achieve in profiting from the border even as a means of denying its legitimacy and materiality" (272).

The ultimate aim for Silko's revolutionaries is for the "lights to go out" (683). Once this 
result is realized, in Awa Gee's mind, the earth will be restored: "Earth that was bare and empty, earth that had been seized and torn open, would be allowed to heal and rest in the darkness" (683). Until that time, Awa Gee will tinker with war machines, preparing to make strikes against electrical power sources. The Barefoot Hopi, who has himself exercised his rebellion in shooting down a helicopter of Beverly Hills tourists who were hovering over a Snake Dance, also looks forward to the eco-warriors' hits on power sources, for then the inmates whom he has been recruiting will begin rioting. Fellow revolutionaries El Feo and La Escapía also see the disruption of electrical power as portentous, and they are particularly encouraged by the facility with which Native peoples will function without electricity:

The night the lights went out and didn't come back on, the tables would turn. The poorest, those living on the street or in the arroyo, they would laugh at the others because the homeless and poor lived every day without electricity or running water. ... the Lakota, Cheyenne, Crow, Hidatsa, as well as the Navajo and Apache - none of their people depended much on electricity. The same for the Eskimos. But they all had weapons and they all were ready to fight. Because if they didn't fight, they would be destroyed and Mother Earth with them. . . Now it was up to the poorest tribal people and survivors of European genocide to show the remaining humans how all could share and live together on earth, ravished as she was. . . The best was yet to come. (748-9)

As El Feo and La Escapía display, resistance occurs in Silko's text both as a wide cultural phenomenon, with common methods among many peoples, but the loci of this resistance, the ones who are most equipped to thrive as the prophecy is fulfilled, are American Indians.

In addition to enacting resistance by subverting technological conventions, Silko’s revolutionaries also contradict accepted, European notions of history that erase the power of indigenous communities. As Silko's characters prepare for revolution, uncovering more complete histories bolsters them. As La Escapìa explains, a complete history, revealed through stories, is the source of indigenous existence: "if the stories had somehow been lost, then the people were lost; the ancestors' spirits were summoned by the stories. . . The most 
complete history was the most powerful force" (316). To this end, La Escapìa publicly recounts a litany of historical occurrences, mostly Indian and African-Native slave revolts, that Marxists have overlooked. She asserts, "Indigenous American uprisings had been far more extensive than any Europeans had wanted to admit, not even the Marxists, who were jealous of African and Native American slave workers who had risen up successfully against colonial masters without the help of a white man" (527). Likewise, Clinton makes the subject of his second radio broadcast successful slave revolution in the Americas, focusing on the alliance of Natives and Africans, and he meticulously records in his notebook little-known instances both of colonial oppression as well as black and Indian resistance to that oppression. Additionally, Sterling affirms the presence of American Indians in outlaw culture, foregrounding resistance as a distinguishing feature of Native cultures: "Sterling thought he was probably one of the few Indians interested in famous Indian outlaws. He knew tribal leaders and so-called Indian experts preferred that Indians got left out of that part of American history too, since their only other appearances had been at so-called massacres of white settlers" (40).

In this way, Silko's characters resist oppression and assert agency both in practical ways, such as collecting arms and planning for technological warfare, as well as in intellectual and spiritual ways, affirming the stories of the ancestors and countering Europeans' incomplete renderings of their histories. As Daria Donnelly argues, the text "reconceives history as the struggle for domination between competing stories" and establishes that "individual explanations of reality become collective action" (245). Further, Marc Priewe characterizes these reconfigurations of history as follows: "certain tribal ideals ... have been exported from a local into a global arena, adapted to new localities, reconfigured and then returned via 
the global reach of European ideas in the wake of colonial and imperial expansions" (226). Thus, these historical revisions emphasize both specific indigenous histories as well as the confluence of those histories with global decolonial struggles.

Uniting all of these activities, both practical and philosophical, is the almanac, which itself contains gaps that humans must fulfill. Yoeme, the almanac's keeper, acknowledges that a section was lost before she acquired the text, a section that was in code and therefore difficult to comprehend. Yoeme's charge is to replace that section carefully, avoiding the addition of material that was not already present and inscribing the section with a suitable code. After careful thought, Yoeme understands that her contemplation of Geronimo, which arises from the image of cottonwoods on Guzman's ranch, is the most appropriate contribution that she can make. She recounts that the purpose of the widespread killing of Indians near the mountains was pursuit of Geronimo and the Apaches that ran with him. However, as Calabazas reveals, there were "at least four Apache raiders who were called by the name Geronimo" (224), all of whom cleverly evoked a mythological individual, coyote-style, in order to advance their anti-colonial activities. Yoeme recalls, in a beautiful memory, one instance when she saw the actual Apache warrior. Having been brought down from the mountains so that he could attend to his work, he watched the gulls ride the waves as the sun was setting. Yoeme remembers, "I never moved my eyes from the man at the edge of the water. But in an instant he was gone" (130). This recollection emphasizes that individuals in the present, such as Yoeme, must take up the work of Geronimo and continue to tell his story so that the almanac's prophecy can be fulfilled. This history — Indian history-counters European versions of Geronimo's legacy, and its revelation is itself an act of resistance. As Clarke states, "Silko's keepers are creating a text that insists that indigenous peoples and 
their environments are not the ground and matrix of Euro-American action, but alive, responsive, resistant, and capable of articulating their own perspectives about the world and their place in it" (144).

As Yoeme explains to Zeta, the smallest collection of pages, which contains colorful drawings of snakes, is actually the key to the rest of the almanac, and it is in these pages that Silko most explicitly outlines the unifying prophecy of her novel. These pages describe Maah' shra-True'-Ee, the Laguna snake being, and outline his inhabitation of Lake Ka-waik as well as his disappearance with the coming of the uranium mine, which drained the lake of all its water. The spirit snake's message is clear:

I have been talking to you people from the beginning I have told you the names and identities of the Days and Years. I have told you the stories on each day and year so you could be prepared and protect yourselves. What I have told you now is that this world is about to end. (135)

When Sterling reveals to Lecha and Zeta that the stone serpent has reappeared, they are aware of the immediacy of the world's end, and they know that they have "important work" (703) to do. Ultimately, it is Sterling who is able to return to the sacred serpent and be transformed, living out his end in the same Laguna place where he began. Thus, the prophecy is fulfilled, as Kang argues: "there is a hint that the fertile Great Plains where all members of the ecosystem coexist is actually possible. ... the realization of ecological justice ... [is] reinforced by the contrast between farms, ranches, and towns, . . . and the recovered ecosystem symbolized by the reappearance of the buffalo" (749-50).

Though Silko has outlined the almanac's prophecy as distinctly Laguna, this prophecy is nonetheless inclusive, expansive while specific. The notebooks themselves contain a multi- 
layered definition for the word "almanac," naming Arabic, English, and Spanish origins, and referencing codices from Madrid, Paris, and Dresden (136). As twins Wacah and El Feo lead the people north at the end of the novel, Wacah asserts that the journey is for everyone: "All were welcome.... One must be able to let go of a great many comforts and all things European; but the reward would be peace and harmony with all living things. All they had to do was return to Mother Earth. No more blasting, digging, or burning" (710). Weasel Tail also cites the expansive nature of the prophecy by describing an inclusive Ghost Dance: "The Ghost Dance has never ended, it has continued, and the people have never stopped dancing; they may call it by other names, but when they dance, their hearts are reunited with the spirits of the beloved ancestors.... Throughout the Americas, from Chile to Canada, the people have never stopped dancing" (724). These instances privilege indigenous cultures as inspiration for change but do not necessarily deny the inclusion of Europeans in this change; Europeans must renounce the negative implications of their colonial culture, however, particularly the environmentally destructive implications, to participate. Finally, characters such as Seese, who learns from her relationship with Sterling and her translation of the almanac for Yoeme, as well as Root, who learns from his relationship with Calabazas, are able to see the prophecy revealed. Silko's text thereby can be described as "glocal" according to Priewe, an "interdependence between the global and the local, or, the mutual implication of the universal and the particular" (223).

Leslie Marmon Silko's Almanac of the Dead achieves a delicate, though shocking, balance of Laguna "place" with global movements along transcultural borders. The form of her text, an almanac, supports this expansive vision, allowing her, as Donnelly argues, to achieve new heights, or "Laguna expansiveness" (253) as a storyteller, which represents a departure from 
her novel Ceremony. All of this is inextricately bound, however, to the land. Reporting the conversation between spirit beings and revolutionaries, uncovering the connection between human justice and ecological responsibilities, and integrating stories of resistance and renewal, Almanac of the Dead's radical prophecy is quite simple: The earth remains. 


\section{WORKS CITED}

Ahokas, Pirijo. "Constructing Hybrid Ethnic Female Identities: Alice Walker's Meridian and Louise Erdrich's Love Medicine." Literature on the Move: Comparing Diasporic Ethnicities in Europe and the Americas. Ed. Dominique Marcais, Mark Niemeyer, Bernard Vincent, and Cathy Waegner. Heidelberg, Germany: Carl Winter Universitatsverlag, 2002. 199-207.

---. "Hybridized Black Female Identity in Alice Walker's Meridian." America Today: Highways And Labyrinths. Ed. Gigliolla Necora. Siracusa, Italy: Grafia, 2003. 481-8.

Aldama, Arturo. Disrupting Savagism: Intersecting Chicana/o, Mexicana/o and Native American Struggles for Representation. Durham, NC: Duke UP, 2001.

Allen, Paula Gunn. The Sacred Hoop: Recovering the Feminine in American Indian Traditions. Boston: Beacon, 1980.

Anzaldua, Gloria. Borderlands / La Frontera: The New Mestiza. San Francisco: Aunt Lute, 1987.

Baker, Lindsay T. and Julie P. Baker, Eds. The WPA Oklahoma Slave Narratives. Norman, OK: U of Oklahoma P, 1996.

Balzac, Honoré de. "Lettres sur la literature." Leatherstocking and the Critics. Ed. Warren S. Walker. Chicago: Scott, Foresman and Company, 1965.

Barnes, Kim. "A Leslie Marmon Silko Interview." The Journal of Ethnic Studies 9:1 (Winter 1986): 83-105.

Barnett, Louise K. and James L. Thorson. Leslie Marmon Silko: A Collection of Critical Essays. Albuquerque: U of New Mexico P, 1999.

Barnhill, David Landis. "Introduction." Becoming Native to Our Place: A Multicultural Anthology. Ed. David Landis Barnhill. Berkeley: U of California P, 1999. 1-13.

Baym, Nina. "How Men and Women Wrote Indian Stories." New Essays on The Last of the Mohicans. Ed. Daniel H. Peck. Cambridge: Cambridge UP, 1992. 67-86.

Becker-Theye, Betty. "Cooper and Chateaubriand: The American Wilderness as Simpler/More Complex World." Platte Valley Review 19.2 (1991): 45-53.

Berry, Wes. “Toni Morrison's Revisionary 'Nature Writing': Song of Solomon and the Blasted Pastoral." South to a New Place: Region, Literature, Culture. Ed. Suzanne W. Jones and Sharon Monteith. Baton Rouge, LA: Louisiana State UP, 2002. 148-64.

Bhabha, Homi. The Location of Culture. Routledge: London, 2004. 
Blotner, Joseph. Faulkner: A Biography. 2 vols. New York: Random House, 1974.

Brennan, Jonathan. "Introduction." When Brer Rabbit Meets Coyote: African-Native Literature. Ed. Jonathan Brennan. Champagne, IL: U of Illinois P, 2003. 1-97.

Brigham, Ann: "Productions of Geographic Scale and Capitalist-Colonialist Enterprise in Leslie Marmon Silko's Almanac of the Dead." Modern Fiction Studies 50:2 (2004): 30331.

Brogan, Kathleen. "American Stories of Cultural Haunting: Tales of Heirs and Ethnographers." College English 57:2 (1995): 149-65.

Brown, Joseph. “'All Saints Should Walk Away': The Mystical Pilgrimage of Meridian.” Callaloo 39 (1989): 310-20.

Buell, Lawrence. The Environmental Imagination: Thoreau, Nature Writing, and the Formation of American Culture. Cambridge, MA: Belknap Press, Harvard UP, 1995.

---. "Faulkner and the Claims of the Natural World. Faulkner and the Natural World: Faulkner and Yoknapatawpha, 1996. Ed. Donald Kartiganer and Ann Abadie. Jackson, MS: UP of Mississippi, 1999. 1-18.

---. The Future of Environmental Criticism: Environmental Crisis and Literary Imagination. Malden, MA: Blackwell, 2005.

Christian, Barbara. "Community and Nature: The Novels of Toni Morrison." The Journal of Ethnic Studies 7.4 (1980): 65-78.

Claridge, Laura P. “Isaac McCaslin's Failed Bid for Adulthood.” American Literature 55.2 (1983): 241-51.

Clarke, Joni Adamson. American Indian Literature, Environmental Justice, and Ecocriticism: The Middle Place. Tucson, AZ: U of Arizona P, 2001.

Comer, Krista. "Sidestepping Environmental Justice: 'Natural' Landscapes and the Wilderness Plot." Breaking Boundaries: New Perspectives on Women's Regional Writing. Ed. Sherrie Inness and Diana Royer. Iowa City, IA: U of Iowa P, 1997. 216-36.

Cooper, James Fenimore. The Last of the Mohicans. New York: Penguin, 1980.

Cro, Stelio. "Classical Antiquity, America, and the Myth of the Noble Savage." The Classical Tradition and The Americas. Ed. Wolfgang Haase and Meyer Reinhold. Vol. I. Berlin: Walter de Gruyter, 1993. 379-418. 2 vols.

Dabney, Lewis M. The Indians of Yoknapatawpha: A Study in Literature and History. Baton 
Rouge: Louisiana State UP, 1974.

Dalsgard, Katrine. "The One All-Black Town Worth the Pain: (African) American Exceptionalism, Historical Narration, and the Critique of Nationhood in Toni Morrison's Paradise." African American Review 35.2 (2001): 233-48.

Davis, Thadious. Games of Property: Law, Race, Gender, and Faulkner's Go Down, Moses. Durham, NC: Duke UP, 2003.

---. Faulkner's "Negro": Art and the Southern Context. Baton Rouge: Louisiana State UP, 1983.

Debo, Angie. The Rise and Fall of the Choctaw Republic. Norman, OK: U of Oklahoma P, 1934.

---. And Still the Waters Run. Princeton, NJ: Princeton UP, 1973.

Deloria, Philip. Indians in Unexpected Places. Lawrence, KS: UP of Kansas, 2004.

---. Playing Indian. New Haven: Yale UP, 1998.

Doerschuk, Robert L. “Glitter and Glue.” No Depression November-December 2005: 68-74.

Donnelly, Daria. "Old and New Notebooks: Almanac of the Dead as Revolutionary Entertainment." Leslie Marmon Silko: A Collection of Critical Essays. Ed. Robert Franklin Gish, Louise K. Barnett, and James L. Thorson. Albuquerque, NM: U of New Mexico P, 1999. 245-49.

Downey, Anne. ““A Broken and Bloody Hoop': The Intertextuality of Black Elk Speaks and Alice Walker's Meridian.” MELUS 19.3 (1994): 37-45.

Doyle, Don H. "The Mississippi Frontier in Faulkner's Fiction and in Fact." The Southern Quarterly 29.4 (1991): 145-60.

Dreese, Donelle N. Ecocriticism: Creating Self and Place in Environmental and American Indian Literatures. New York: Peter Lang, 2002.

Ellison, Mary. "Black Perceptions and Red Images: Indian and Black Literary Links." Phylon 44.1 (1983): 44-55.

Faris, Wendy B. "Devastation and Replenishment: New World Narratives of Love and Nature." Studies in the Humanities 19.2 (1992): 171-82.

Faulkner, William. "Appendix: The Compsons." The Portable Faulkner. Ed. Malcolm Cowley. New York: Viking Press, 1967. 704-721. 
---. “A Courtship.” The Sewanee Review 56 (1948): 634-53.

---. Go Down, Moses. New York: Random House, 1973.

---. “A Justice.” These Thirteen: Stories. New York: J. Cape and H. Smith, 1931. 183-207.

---. "Lo!" Story 5.11 (1934): 5-21.

---. “A Mountain Victory.” The Saturday Evening Post 3 December 1932: 6+.

---. "Red Leaves." The Saturday Evening Post 25 October 1930: 6+.

---. Requiem for a Nun. New York: Random House, 1975.

Fiedler, Leslie. Love and Death in the American Novel. New York: Anchor Books, 1992.

Fischer-Hornung, Dorothea. "Economies of Memory: Trafficking in Blood, Body Parts, and Crossblood Ancestors." Amerikastudien/American Studies 47.2 (2002): 199-221.

Folsom, Israel. "Lo! The Poor Indian's Hope." Native American Writing in the Southeast: An Anthology, 1875-1935. Ed. Daniel Littlefield, Jr. and James W. Parins. Jackson: UP of Mississippi, 1995. 4.

Forbes, Jack D. Africans and Native Americans: The Language of Race and the Evolution of Red-Black Peoples. Urbana IL: U of Illinois P, 1993.

Foreman, Dave. Confessions of an Eco-Warrior. New York: Plume, 1994.

Gaard, Greta. "Strategies for a Cross-Cultural Ecofeminist Ethics: Interrogating Tradition, Preserving Nature." Bucknell Review 44.1 (2000): 82-101.

Galloway, Patricia. “The Construction of Faulkner's Indians.” The Faulkner Journal 18.1-2 (2002-03): 9-31.

Gerhardt, Christine. "The Greening of African-American Landscapes: Where Ecocriticism Meets Post-Colonial Theory.” The Mississippi Quarterly 55.4 (2002): 515-33.

Gibson, Arrell. The Chickasaws. Norman, OK: U of Oklahoma P, 1971.

Gwynn, Frederick L. and Joseph Blotner. Eds. Faulkner in the University: Class Conferences at the University of Virginia 1957-1958. Charlottesville, VA: U of Virginia P, 1959.

Halliburton, R., Jr. "Chief Greenwood LeFlore and his Malmaison Plantation." After Removal: The Choctaw in Mississippi. Ed. Samuel J. Wells and Roseanna Tubby. Jackson: UP of Mississippi, 1986. 56-63. 
Hallowell, A. Irving. "Papers in Honor of Melville J. Herskovits: American Indians, White and Black: The Phenomenon of Transculturalization." Current Anthropology 4.5 (1963): 519-31.

Harris, Trudier. Fiction and Folklore: The Novels of Toni Morrison. Knoxville: U of Tennessee P, 1991.

Holland, Sharon and Tiya Miles, Eds. Crossing Borders, Crossing Paths. Durham, NC: Duke UP. Forthcoming 2004.

Holland, Sharon. "“If You Know I Have a History, You Will Respect Me': A Perspective on Afro-Native Literature.” Callaloo 17.1 (1994): 334-50.

hooks, bell. Black Looks: Race and Representation. Boston: South End Press, 1992.

---. "Touching the Earth." At Home on the Earth: Becoming Native to Our Place: A Multicultural Anthology. Ed. David Landis Barnhill. Berkeley, CA: U of California P, 1999. 51-56.

Howell, Elmo. "President Jackson and William Faulkner's Choctaws." Chronicles of Oklahoma 45.3 (1967): 252-57.

Huhndorf, Shari M. Going Native: Indians in the American Cultural Imagination. Ithaca: Cornell UP, 2001.

Hunt, Alex: "The Radical Geography of Silko's Almanac of the Dead." Western American Literature 39:3 (2004): 256-78.

Irr, Caren. "The Timeliness of Almanac of the Dead: Or, A Postmodern Rewriting of Radical Fiction." Leslie Marmon Silko: A Collection of Critical Essays. Ed. Robert Franklin Gish, Louise K. Barnett, and James L. Thorson. Albuquerque, NM: U of New Mexico P, 1999. 223-44.

Jablon, Madelyn. "Rememory, Dream Memory, and Revision in Toni Morrison's Beloved and Alice Walker's The Temple of My Familiar." College Language Association Journal 37.2 (1993): 136-44.

Johnson, Bruce G. "Indigenous Doom: Colonial Mimicry in Faulkner's Indian Tales.” The Faulkner Journal 18.1-2 (2002-03): 101-27.

Kakutani, Michiko. "If the River is Dry, Can You Be All Wet?" Rev. of Now is the Time to Open Your Heart, by Alice Walker. New York Times 20 April 2004. Accessed 26 April 2004. <http://query.nytimes.com/gst/fullpage.html?res=950CEEDA113BF933A15757C0 A9629C8B63>

Kang, Ja-mo. "An Ecological Reading of Leslie Marmon Silko's Almanac of the Dead." 
Journal of English Language and Literature/Yongo Yongmunhak 49:4 (2003):731-54.

Kaplan, Amy. "Left Alone with America: The Absence of Empire in the Study of American Culture." Cultures of United States Imperialism. Ed. Amy Kaplan and Donald Pease. Durham: Duke UP, 1993. 3-21.

Katz, William Loren. Black Indians: A Hidden Heritage. New York: Atheneum, 1986.

Kaup, Monika and Debra J. Rosenthal. "Introduction.” Mixing Race, Mixing Culture: Inter-American Literary Dialogues. Ed. Monika Kaup and Debra J. Rosenthal. Austin: $\mathrm{U}$ of Texas P, 2002. xi-xxix.

Killingsworth, Jimmie and Jacqueline Palmer. "Ecopolitics and the Literature of the Borderlands: The Frontiers of Environmental Justice in Latina and Native American Writing." Writing the Environment: Ecocriticism and Literature. Ed. Richard Kerridge and Neil Sammells. London: Zed, 1998. 196-207.

Kinney, Arthur F. "Introduction." Critical Essays on William Faulkner: The McCaslin Family. Ed. Arthur Kinney. Boston: G.K. Hall \& Co., 1990. 1-57.

---. "Faulkner's Other Others." Faulkner at 100: Retrospect and Prospect. Ed. Donald M. Kartiganer and Ann J. Abadie. Jackson: UP of Mississippi, 2000. 195-203.

Krupat, Arnold. The Voice in the Margin: Native American Literature and the Canon. Berkeley: U of California P, 1989.

Langford, Beverly Young. "History and Legend in William Faulkner's 'Red Leaves." Notes on Mississippi Writers 6.1 (1972): 19-24.

Legler, Gretchen. "Body Politics in American Nature Writing. 'Who May Contest for What the Body of Nature Will Be?" Writing the Environment: Ecocriticism and Literature. Ed. Richard Kerridge and Neil Sammells. London: Zed, 1998.

Littlefield, Daniel. The Chickasaw Freedmen: People Without a Country. Lanham: Greenwood, 1980.

Littlefield, Daniel, and James W. Parins. Eds. Native American Writing in the Southeast: An Anthology, 1875-1935. Jackson, MS: UP of Mississippi, 1995.

Mann, Barbara A. "Whipped Like a Dog: Crossed Blood in The Last of the Mohicans." James Fenimore Cooper: His Country and His Art: Papers from the 1995 Cooper Seminar. Ed.Hugh C. MacDougall. Oneonta, NY: The State University of New York College at Oneonta, 1995. 48-61.

Mazel, David. “American Literary Environmentalism as Domestic Orientalism.” ISLE 3.2 (1996): 37-55. 
-. "Performing 'Wilderness' in The Last of the Mohicans." Reading Under the Sign of Nature: New Essays on Ecocriticism. Ed. John Tallmadge and Henry Harrington. Salt Lake City: U of Utah P, 2000. 101-114.

McGregor, Gaile. The Noble Savage in the New World Garden: Notes Toward a Syntactics of Place. Bowling Green: Bowling Green State University Popular Press, 1988.

McWillams, John. The Last of the Mohicans: Civil Savagery and Savage Civility. New York: Twayne, 1995.

Milder, Robert. "The Last of the Mohicans and the New World Fall." American Literature 52.3 (1980): 407-429.

Miles, Tiya. Ties That Bind: The Story of an Afro-Cherokee Family in Slavery and Freedom. Berkeley: U of California P, 2005.

---. "Uncle Tom Was an Indian: Tracing the Red in Black Slavery." Confounding the Color Line: The Indian-Black Experience in North America. Lincoln: U of Nebraska P, 2002.137-60.

Moore, Gene M. "'European Finery' and Cultural Survival in Faulkner's 'Red Leaves."” William Faulkner's Short Fiction: An International Symposium. Ed. Hans H. Skei. Oslo: Solum, 1997. 263-8.

---. "Chronological Problems in Faulkner's 'Wilderness' Stories.” The Faulkner Journal 18.1-2 (2002-03): 51-67.

---. “Faulkner's Incorrect ‘Indians'?” Introduction. The Faulkner Journal 18.1-2 (2002-03): 3-7.

Morrison, Toni. Beloved. New York: Penguin, 1987.

---. "Black Matters." Grand Street 10.4.40 (1991): 205-25.

---. Paradise. New York: Alfred A. Knopf, 1998.

---. Playing in the Dark: Whiteness and the Literary Imagination. Cambridge: Harvard UP, 1992.

---. Song of Solomon. New York: Penguin, 1977.

Murphy, Patrick. "Anotherness and Inhabitation in Recent Multicultural American Literature." Writing the Environment: Ecocriticism and Literature. Ed. Richard Kerridge and Neil Sammells. London: Zed, 1998. 20-52. 
Muthyala, John: "Almanac of the Dead: The Dream of the Fifth World in the Borderlands." Literature Interpretation Theory 14:4 (2003): 357-85.

Nelson, Robert. Place and Vision: The Function of Landscape in Native American Fiction. New York: Peter Lang, 1995.

Owens, Louis. Other Destinies: Understanding the American Indian Novel. Norman and London: U of Oklahoma P, 1992.

Parker, Robert Dale. "Red Slippers and Cottomouth Moccasins: White Anxieties in Faulkner's Indian Stories.” The Faulkner Journal 18.1-2 (2002-03): 81-99.

Pasqueretta, Paul. "African-Native Subjectivity and the Blues Voice in the Writings of Toni Morrison and Sherman Alexie." When Brer Rabbit Meets Coyote: African-Native Literature. Ed. Jonathan Brennan. Champagne, IL: U of Illinois P, 2003.

Peck, H. Daniel. "Introduction." New Essays on The Last of the Mohicans. Ed. Daniel H. Peck. Cambridge: Cambridge UP, 1992. 1-23.

Polk, Noel. Faulkner's Requiem for a Nun: A Critical Study. Bloomington, IN: Indiana UP, 1981.

---. Rev. of The Indians of Yoknapatawpha, by Lewis M. Dabney, and "Faulkner's Indians," by Marc A. Nigliazzo. Mississippi Quarterly 28.3 (1975): 387-92.

Powell, Timothy B. Ruthless Democracy: A Multicultural Interpretation of the American Renaissance. Princeton, NJ: Princeton UP, 2000.

Priewe, Marc. "Negotiating the Global and the Local: Leslie Marmon Silko's Almanac of the Dead as "Glocal Fiction." Amerikastudien/American Studies 47.2 (2002): 223-35.

Pullin, Faith. Landscapes of Reality: the Fiction of Contemporary Afro-American Women. Black Fiction: New Studies in the Afro-American Novel since 1945. Ed. Robert E. Lee. New York: Barnes and Noble, 1980. 173-203.

Rans, Geoffrey. Cooper's Leatherstocking Novels: A Secular Reading. Chapel Hill: U of North Carolina P, 1991.

Rawls, Alex. "The Battle of New Orleans.” No Depression November-December 2005: 7481.

Ridley, Chauncey. “Animism and Testimony in Alice Walker's The Color Purple." MAWA Review 4.2 (1989): 32-6.

Riley, Patricia. "Wrapped in the Serpent's Tail: Alice Walker's African-Native American 
Subjectivity." When Brer Rabbit Meets Coyote: African-Native American Literature. Ed. Jonathan Brennan. Champagne, IL: U of Illinois P, 2003. 241-56.

Rinne, Craig. "White Romance and American Indian Action in Hollywood's The Last of The Mohicans." SAIL 13.1 (2001): 3-22.

Rosenthal, Debra J. "Race Mixture and the Representation of Indians in the U.S. and the Andes." Mixing Race, Mixing Culture: Inter-American Literary Dialogues. Ed. Monika Kaup and Debra J. Rosenthal. Austin: U of Texas P, 2002. 122-139.

Rousseau, Jean-Jacques. "Discourse on the Origin and Foundations of Inequality Among Men."Rousseau's Political Writings. Ed. Alan Ritter and Julia Conaway Bondanella. New York: Norton, 1988. 3-57.

Said, Edward. Orientalism. New York: Random House, 1978.

Samuels, Shirley. "Generation through Violence: Cooper and the Making of Americans." New Essays on The Last of the Mohicans. Ed. Daniel H. Peck. Cambridge: Cambridge UP, 1992. 87-114.

Sayre, Robert Woods. “Faulkner's Indians and the Romantic Vision.” The Faulkner Journal 18.1-2 (2002-03): 33-49.

Shorty, Lawrence. "The Practical Use of Culture, Context, and History to Create Action within American Indian Tobacco Control Practice." Proceedings of the New Directions in American Indian Research Conference. Chapel Hill, NC: The Graduate School, 2004.18 Sept. 2005. <http://gradschool.unc.edu/natam/panels/shorty.html $>$.

Silko, Leslie Marmon. Almanac of the Dead. New York: Penguin, 1991.

---. Ceremony. New York: Penguin, 1977.

--- "Fifth World: The Return of Ma ah shra true ee, the Giant Serpent." At Home on this Earth: Two Centuries of Women's Nature Writing. Ed. Lorraine Anderson and Thomas S. Edwards.Hanover, NH: UP of New England, 2002. 334-40.

---.. "Interior and Exterior Landscapes: The Pueblo Migration Stories." Landscape in America. Ed. George F. Thompson and Charles E. Little. Austin: U of Texas P, 1995. $155-69$.

---. "Through the Stories We Hear Who We Are." Short Fiction: Classic and Contemporary. $5^{\text {th }}$ Ed. Charles Bohner and Lyman Grant. Upper Saddle River, NJ: Prentice Hall, 2002. 1303-1305.

Smith, Patricia and Paula Gunn Allen. "Earthly Relations, Carnal Knowledge: Southwestern American Indian Women Writers and Landscape." The Desert is No Lady: Southwestern 
Landscapes in Women's Writing and Art. Ed. Vera Norwood and Janice Monk. New Haven: Yale UP, 1987. 174-196.

Stanford, Ann Folwell. “'Human Debris': Border Politics, Body Parts, and the Reclamation of The Americas in Leslie Marmon Silko's Almanac of the Dead." Literature and Medicine 16.1 (1997): 23-42.

Stein, Karen. "Meridian: Alice Walker's Critique of Revolution.” Black American Literature Forum 20.1/2 (1986): 129-41.

Tompkins, Jane. "No Apologies for the Iroquois: A New Way to Read the Leatherstocking Novels." Criticism 23.1 (1981): 24-41.

Ulman, H. Lewis. "Seeing, believing, Being, and Acting." Reading the Earth: New Directions In the Study of Literature and the Environment. Ed. Michael P. Branch, Rochelle Johnson, Daniel Patterson, and Scott Slovic. Moscow, ID: U of Idaho P, 1998. 225-33.

Usner, Daniel H. Jr. "American Indians on the Cotton Frontier: Changing Economic Relations With Citizens and Slaves in the Mississippi Territory." The Journal of American History 72.2 (1985): 297-317.

Waldron, Karen. "The Land as Consciousness: Ecological Being and the Movement of Words in The Works of Leslie Marmon Silko." Such Nesw of the Land: U.S. Women Nature Writers. Ed. Thomas S. Edwards and Elizabeth A. DeWolfe. Hanover, NH: UP of New England, 2001. 178-203.

Walker, Alice. The Color Purple. New York: Washington Square Press, 1982.

---. Living by the Word: Selected Writings 1973-1987. San Diego: Harcourt Brace Jovanovich, 1988.

---. Meridian. New York: Simon and Schuster, 1976.

---. Now is the Time to Open Your Heart. New York: Random House, 2004.

---. The Temple of My Familiar. Diego: Harcourt Brace Jovanovich, 1989.

Walker, Charlotte Zoe. "A Saintly Reading of Nature's Text: Alice Walker's Meridian." Bucknell Review 44.1 (2000): 43-55.

Wallace, Kathleen and Karla Armbruster. "The Novels of Toni Morrison: 'Wild Wilderness Where There Was None." Beyond Nature Writings: Expanding the Boundaries of Ecocriticism. Ed. Kathleen Wallace and Karla Armbruster. Charlottesville, VA: UP of Virginia, 2001. 211-30. 
Weinstein, Philip. What Else But Love? The Ordeal of Race in Faulkner and Morrison. New York: Columbia UP, 1996.

Welling, Bart. "A Meeting with Old Ben: Seeing and Writing Nature in Faulkner's Go Down, Moses." Mississippi Quarterly 55.4 (2002): 461-96.

Wheeler, Otis B. “Faulkner’s Wilderness.” American Literature 31.2 (1959): 127-36.

Wittenburg, Judith Bryant. "Go Down, Moses and the Discourse of Environmentalism." New Essays on Go, Down Moses. Ed. Linda Wagner-Martin. Cambridge: Cambridge UP, 1996. 49-71.

Womack, Craig. Red on Red: Native American Literary Separatism. Minneapolis, MN: University of Minnesota Press, 1999. 